\title{
COMPARISON OF MINDFUL AND SLOW EATING STRATEGIES ON ACUTE ENERGY INTAKE
}

by

\section{Anna Peluso}

B.S., University of Pittsburgh, 2005

M.S., University of Pittsburgh, 2013

Submitted to the Graduate Faculty of

The School of Education in partial fulfillment

of the requirements for the degree of

Doctor of Philosophy

University of Pittsburgh 


\section{UNIVERSITY OF PITTSBURGH SCHOOL OF EDUCATION}

This dissertation was presented

by

Anna Peluso

It was defended on

July $28^{\text {th }}, 2016$

and approved by

Dr. Bethany Barone Gibbs, Assistant Professor, Health and Physical Activity

Dr. Elizabeth Venditti, Assistant Professor, Psychiatry and Epidemiology

Dissertation Co-Advisor: Dr. John Jakicic, Full Professor, Health and Physical Activity

Dissertation Co-Advisor: Dr. Kelliann Davis, Assistant Professor, Health and Physical

Activity 
Copyright (C) by Anna Peluso

2016 


\title{
COMPARISON OF MINDFUL AND SLOW EATING STRATEGIES ON ACUTE ENERGY INTAKE
}

\author{
Anna Peluso, Ph.D. \\ University of Pittsburgh, 2016
}

Introduction: Mindfulness and slow eating techniques are commonly recommended to aid in weight loss within behavioral weight management programs; yet, the role of these eating strategies on acute energy intake (EI) and satiety are not clear. Purpose: The purpose of this study was to investigate the effects of mindful and slow eating strategies on acute EI and satiety. Methods: 24 subjects (median BMI: 29.1 (24.3 - 36.7), median age: $24.0(21.0$ - 31.8)) were randomized to one of three eating conditions (EAT, SLOW, or MIND). For the EAT condition, subjects were instructed to eat as they normally would for both test meal sessions. For the SLOW condition, subjects were instructed to eat as they normally would for their first test meal session and to slow their eating for their second test meal session. For the MIND condition, subjects were instructed to eat as they normally would during their first test meal session and were given brief instructions on mindful eating for their second test meal session. For each condition, subjects were provided ad-libitum access to a test meal and EI was calculated based upon food consumed during this period. Subjects rated their level of satiety following each meal. Results: There were no significant differences in EI between eating strategy conditions (EAT: 848 (704-1071) kcals, MIND: 673 (485- 846) kcals, SLOW: $756(611-1076)$ kcals $)(p=0.786)$. There was a trend toward 
a decrease in energy intake in the MIND condition (mean change in energy intake: $-64.4 \pm 178.4$ kcals) compared with the EAT (mean change in energy intake: $98.3 \pm 169.6$ kcals) condition and a prevention of increased intake in the SLOW (mean change in energy intake: $2.6 \pm 107.9$ kcals) condition $(\mathrm{p}=0.133)$. There were no significant differences in ratings of satiety between conditions. Conclusion: Neither mindful nor slow eating strategies significantly decreased acute EI or satiety, although a decrease in EI achieved through a brief mindfulness practice and prevention of increased intake through slow eating may be clinically meaningful for weight management. Future studies should aim to investigate the potential benefits of slow eating and mindfulness for weight management. 


\section{TABLE OF CONTENTS}

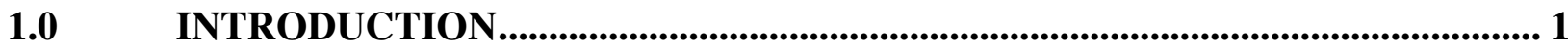

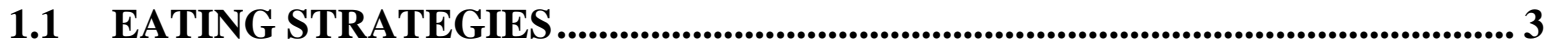

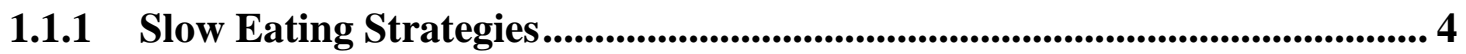

1.1.2 Mindfulness Strategies .................................................................................... 5

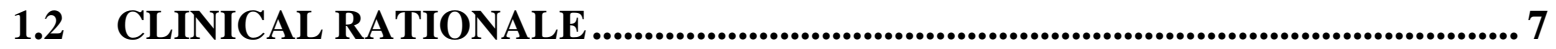

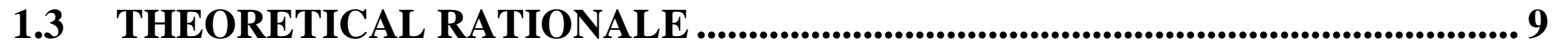

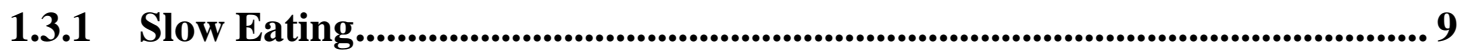

1.3.2 Mindfulness ................................................................................................... 10

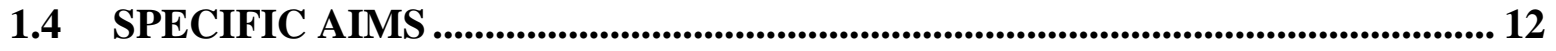

1.5 EXPLORATORY/SECONDARY AIMS .............................................................. 13

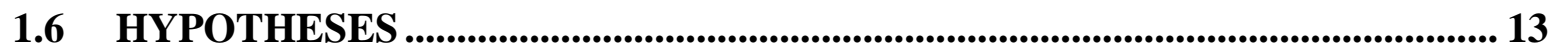

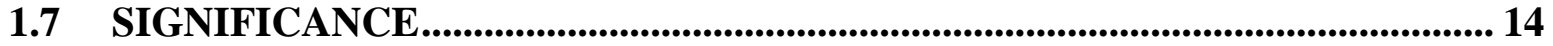

2.0 REVIEW OF THE LITERATURE.................................................................. 15

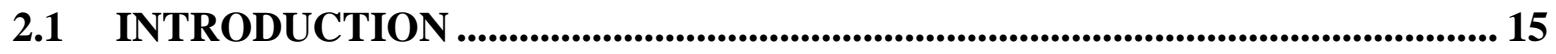

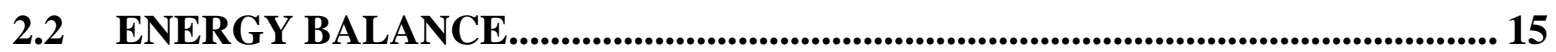

2.2.1 Energy Expenditure ...................................................................................... 16

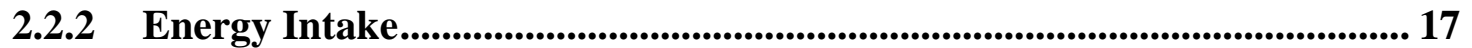

2.3 RECOMMENDATIONS FOR WEIGHT MANAGEMENT ............................. 19

2.4 BEHAVIORAL WEIGHT MANAGEMENT PROGRAMS ........................... 20 
2.4.1 Short Term Success Rates....................................................................................... 20

2.4.2 Long Term Success Rates _............................................................................ 21

2.4.3 Challenges and Implications for Practice.............................................................. 22

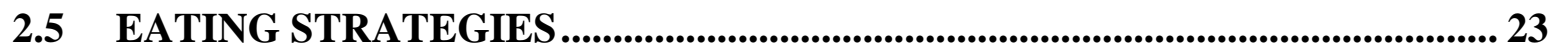

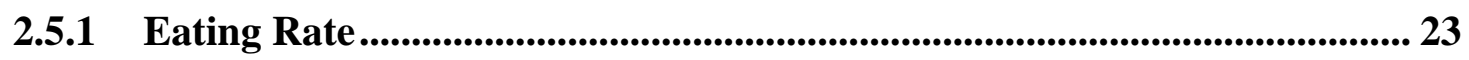

2.5.2 Mindfulness .............................................................................................................. 25

2.6 EFFECT OF BEHAVIORAL EATING STRATEGIES ON ENERGY INTAKE

2.6.1 Eating Rate .................................................................................................................... 29

2.6.2 Mindfulness ............................................................................................... 31

2.7 PATHWAYS BY WHICH STRATEGIES EFFECT ENERGY INTAKE AND

SATIETY............................................................................................................................................. 36

2.7.1 Eating Rate ................................................................................................................. 36

2.7.2 Mindfulness ............................................................................................................... 37

2.8 SUBJECT CHARACTERISTICS AFFECTING ENERGY INTAKE AND

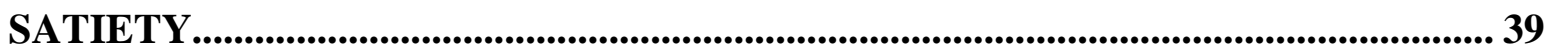

2.8.1 Weight Status of Subjects .......................................................................................... 40

2.8.2 Gender of Subjects................................................................................................ 40

2.8.3 Dietary Restraint ...................................................................................................... 41

2.9 EFFECT OF BEHAVIORAL EATING STRATEGIES ON SUBJECTIVE FEELINGS OF SATIETY ........................................................................................................... 42

2.9.1 Eating Rate ....................................................................................................................... 42

2.9.2 Mindfulness .............................................................................................................. 43 
2.10 CONCLUSION …................................................................................................................ 44

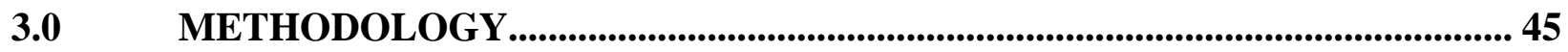

3.1 SUBJECTS ....................................................................................................................... 45

3.2 RECRUITMENT AND SCREENING PROCEDURES....................................... 46

$3.3 \quad$ EXPERIMENTAL DESIGN _............................................................................... 47

3.3.1 Baseline Assessment Visit ....................................................................................... 47

3.3.2 Test Meal Sessions ............................................................................................. 49

3.3.2.1 Control Eating Strategy Condition (EAT) .............................................50

3.3.2.2 Slow Eating Strategy Condition (SLOW) .............................................. 51

3.3.2.3 Mindful Eating Test Meal Session (MIND) ............................................. 52

3.3.2.4 Post-Test Meal Session Questionnaires..................................................... 52

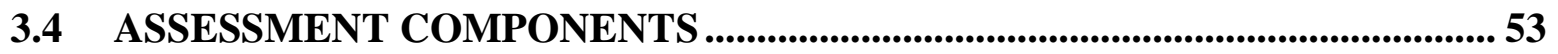

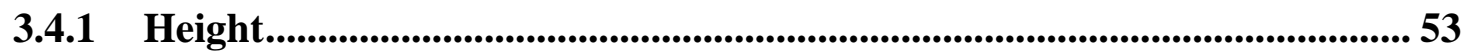

3.4.2 Body Weight..................................................................................................................... 54

3.4.3 Dietary Restraint ...................................................................................................... 54

3.4.4 Positive and Negative Affect .................................................................................. 54

3.4.5 Measurement of Energy Intake......................................................................... 55

3.4.6 Satiety Questionnaire ............................................................................................. 55

3.4.7 Meal Satisfaction/Enjoyment Questionnaire ..................................................... 56

3.4.8 Mindful Eating Adherence .............................................................................. 56

3.4.9 Slow Eating Adherence ............................................................................................... 57

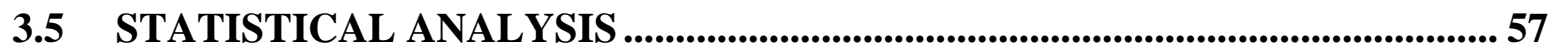

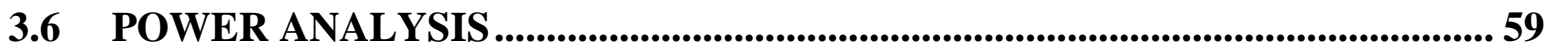




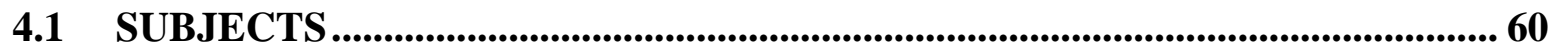

4.2 ANALYSIS OF DATA BY SPECIFIC AIM.......................................................62

4.2.1 Specific Aim 1: Comparison of Energy Intake in Three Eating Strategy

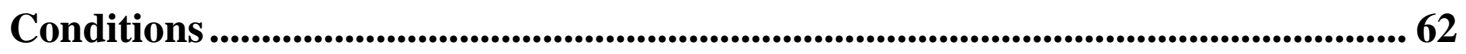

4.2.1.1 Energy Served.................................................................................6 63

4.2.1.2 Process Measures.......................................................................... 63

4.2.1.3 Meal Duration.......................................................................... 64

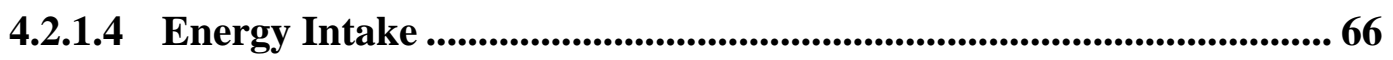

4.2.2 Specific Aim 2: Comparison of Satiety in Three Eating Strategy Conditions 69

4.2.3 Correlations between Primary Endpoints and Descriptive Variables ..... 71

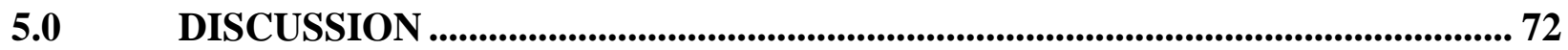

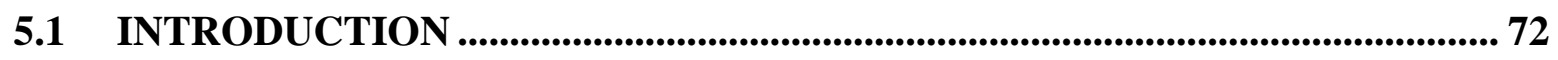

5.2 SUMMARY OF MAJOR FINDINGS ............................................................... 73

5.2.1 Comparison of a slow eating strategy with a no-strategy control............. 73

5.2.2 Comparison of a mindful eating strategy with a no-strategy control....... 76

5.2.3 Comparison of a slow eating strategy with a mindful eating strategy ...... 80

5.3 LIMITATIONS AND RECOMMENDATIONS FOR FUTURE RESEARCH. 80

5.4 IMPLICATIONS FOR WEIGHT MANAGEMENT .................................... 83

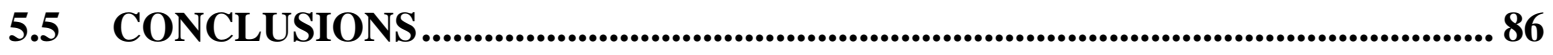

APPENDIX A: INFORMED CONSENT DOCUMENTS ........................................................... 88

APPENDIX B: TELEPHONE SCREENING FORM ........................................................ 98 
APPENDIX C: BASELINE ASSESSMENT DATA COLLECTION FORM . 104

APPENDIX D: BASELINE QUESTIONNAIRES 107

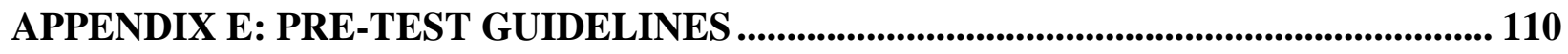
APPENDIX F: CONTROL EATING STRATEGY CONDITION DATA COLLECTION

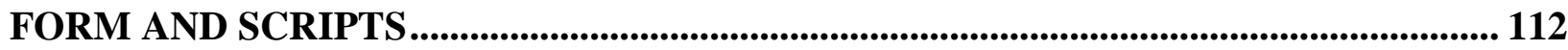
APPENDIX G: SLOW EATING STRATEGY CONDITION DATA COLLECTION FORM AND SCRIPT 119 APPENDIX H: MINDFUL EATING STRATEGY CONDITION DATA COLLECTION FORM AND SCRIPT 125 APPENDIX I: POST-TEST QUESTIONNAIRES........................................................ 131 BIBLIOGRAPHY 138 


\section{LIST OF TABLES}

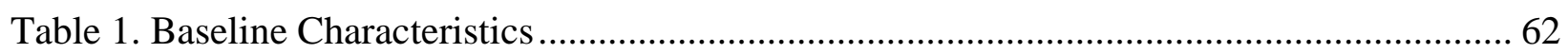

Table 2. Condition differences in energy served, meal duration, and energy intake between test

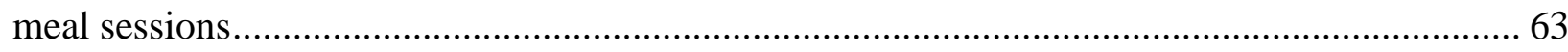

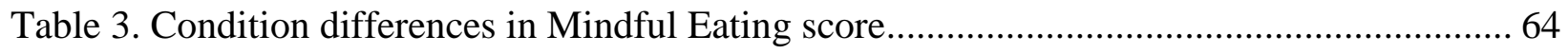
Table 4. Condition differences in change in alertness and change in attentiveness between test meal

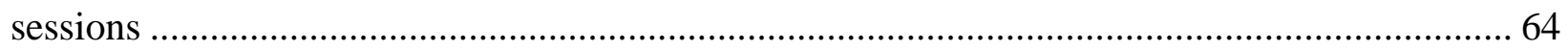

Table 5. BMI Classification differences in energy intake between test meal sessions.................. 68

Table 6. Gender differences in energy intake between test meal sessions ................................... 68

Table 7. Condition differences in hunger and satiety between test meal sessions ....................... 70

Table 8. Correlational matrix for energy intake, satiety, and descriptive variables ...................... 71 


\section{LIST OF FIGURES}

Figure 1. Theoretical pathways by which eating rate may influence acute energy intake and body

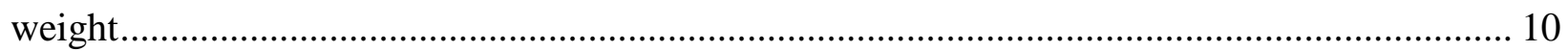

Figure 2. Theoretical pathways by which mindfulness may influence acute energy intake and body

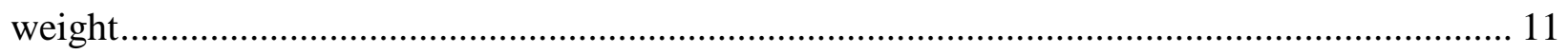

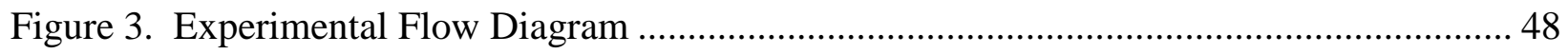

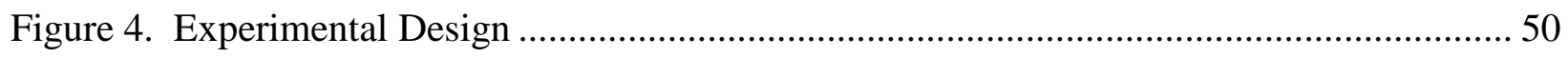

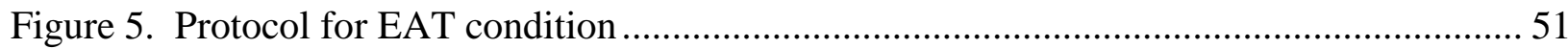

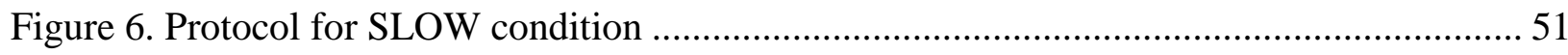

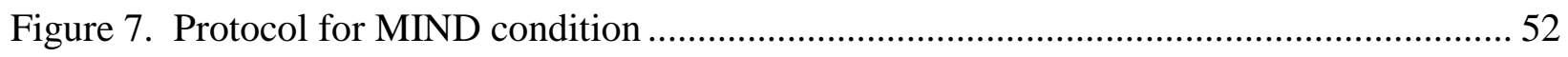

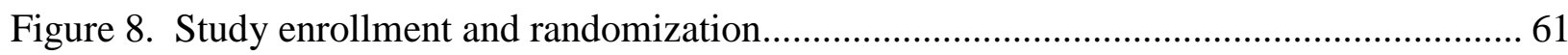

Figure 9. Condition differences in meal duration between test meal sessions ............................ 65

Figure 10. Condition differences in energy intake between test meal sessions........................... 67

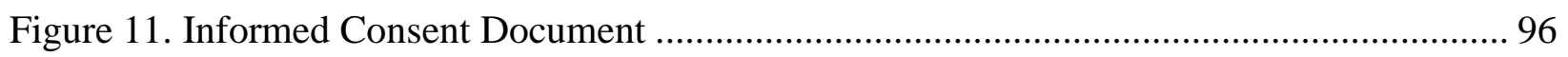

Figure 12. Verification of Ability to Provide Informed Consent.................................................... 97

Figure 13. Recruitment and Telephone Screening Form ........................................................... 103

Figure 14. Baseline Assessment Data Collection Form.................................................................. 106

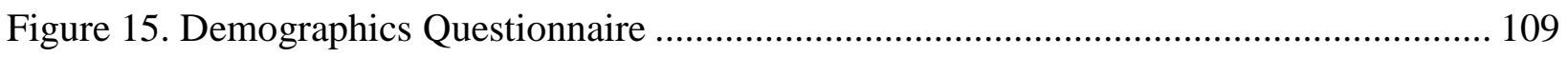

Figure 16. Pre-Test Guidelines ..................................................................................... 111 
Figure 17. Control Test Meal Session Data Collection Form.................................................... 115

Figure 18. Control Test Meal Session 1 Script …………........................................................... 117

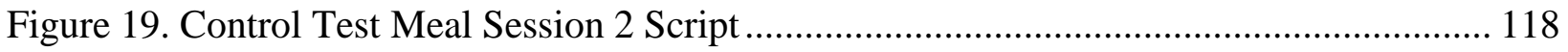

Figure 20. Slow Test Meal Session Data Collection Form....................................................... 122

Figure 21. Slow Test Meal Session Script ............................................................................ 124

Figure 22. Mindful Test Meal Session Data Collection Form.................................................. 128

Figure 23. Mindful Test Meal Session Script ................................................................... 130

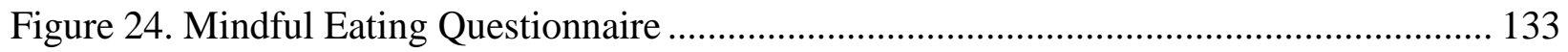

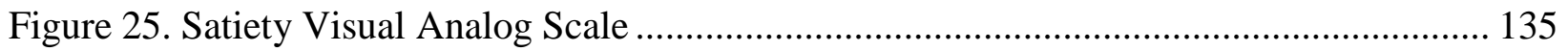

Figure 26. Meal Satisfaction Visual Analog Scale ………...................................................... 137 


\subsection{INTRODUCTION}

Obesity is a major health epidemic in the United States. Classified by body mass index (BMI), $68.5 \%$ of US adults aged 20 and older are considered to be overweight (BMI $\geq 25.0-29.9 \mathrm{~kg} / \mathrm{m}^{2}$ ) and $34.9 \%$ are obese (BMI $\left.\geq 30.0 \mathrm{~kg} / \mathrm{m}^{2}\right)(1)$. Increased body weight is associated with greater risk of comorbidities such as diabetes, hypertension, cardiovascular disease (CVD), and some cancers, along with increased risk of all-cause and CVD mortality (2). Despite additional health risks associated with excess body weight, the prevalence of obesity has remained virtually unchanged since 2003-2004 (1). The increased risk for comorbidities combined with the high, unabaiting prevalence of obesity supports the need for further research examining the factors that impact body weight.

One of the primary treatments for obesity and related comorbidities are standard behavioral weight loss interventions. These interventions typically result in weight loss of 5-10\% of initial body weight in 6 months and up to 10-12 kg at one year (2-4). However, despite the existence of standard behavioral weight management programs to reduce body weight, efficacy of these interventions is somewhat limited. Programs and interventions can also vary widely in intensity with some interventions focusing on minimizing in-person contact time to mitigate costs (4-6), which can be anywhere from $\$ 739$ to $\$ 1442$ per participant (3). Additionally, the long-term maintenance of these weight losses remains a challenge with average gradual regains of 1 to $2 \mathrm{kgs}$ per year from the weight loss achieved by 6 months $(2,7,8)$. Because of limited long-term success 
of current programs and interventions, even those conducted by clinical experts, improvements are needed in order to increase effectiveness of these programs.

Standard behavioral weight loss programs aim to assist participants in reducing body weight by implementing recommendations for caloric restriction and physical activity. Exercise is prescribed in a dose that is recommended for weight loss, typically 60 to 90 minutes of moderate to vigorous intensity cardiovascular activity on most days of the week, totaling 250 to 300 minutes per week $(3,9)$. Interventionists also strive to help participants modify behaviors and implement strategies to adopt a healthy diet. Commonly utilized strategies include, but are not limited to, barrier identification $(3,10)$, goal setting $(10)$, problem solving $(3,10)$, and self-monitoring of weight, caloric intake, and physical activity $(3,5,10-12)$. Through the employment of these strategies, behavioral weight management programs endeavor to aid participants in creating a negative energy balance that will result in a reduction in body weight.

While there are numerous behavioral and physiological drivers, body weight is determined by two primary factors: energy intake (EI) and energy expenditure (EE). Current treatment recommendations for reducing body weight include both a decrease in energy intake through caloric restriction and an increase in energy expenditure through physical activity $(9,13)$. Energy intake can be defined as the amount of calories a person consumes, either acutely or over time, and is typically reported as kcals per day. Energy expenditure is the amount of calories burned or expended in one day or one exercise bout. Energy expenditure is comprised of four components: 1) resting metabolic rate, or the amount of energy expended to perform vital functions; 2) thermic effect of food, or the amount of energy used to metabolize food that has been consumed; 3) nonexercise activity thermogenesis (NEAT) or the amount of energy used to perform daily tasks such as walking; and 4) exercise, or the amount of energy expended doing activity for the purpose of 
health benefits and physiological change (14). If energy intake and energy expenditure are balanced, a person will be weight stable. Deviations in either element of energy balance will cause weight change. It has been established that obesity results from a chronic positive energy balance, with energy intake routinely surpassing energy expenditure. Conversely, if energy intake is less than energy expenditure creating a negative energy balance, weight loss will ensue. While both components of energy balance are extremely important for weight management, this investigation focused on the energy intake component of energy balance.

\subsection{EATING STRATEGIES}

Successful weight management focuses on lifestyle modifications that result in an increase in energy expenditure through physical activity and a corresponding decrease in energy consumption through different eating strategies that create a caloric deficit $(3,15,16)$. The most common behavioral eating techniques recommended for caloric restriction fit into five main categories: mindfulness, meal frequency (including breakfast eating and snacking), volumetrics

(including fruit and vegetable consumption and water intake), stimulus control, and portion control (including plate size, bite/utensil size, and eating rate) $(3,5,10,13,16-21)$. While these strategies are commonly recommended, research has not fully examined the effectiveness of some of these strategies on acute energy intake. For the purpose of this investigation, slow eating and mindfulness strategies were examined. 


\subsubsection{Slow Eating Strategies}

It has been postulated that increased ingestion rate is positively associated with body weight (22, 23); however, one prospective trial showed that faster eating or a change in eating speed was not associated with increased risk for obesity at 3 years (24). Therefore, this association is still undefined. Many acute behavioral strategies that aim to reduce ingestion rate include decreasing bite size $(23,25-28)$, utilizing smaller utensils (25), increasing chewing frequency (25), or creating with-in meal pauses by taking sips of water or putting utensils down between bites $(23,25,28)$. However, it is not clear whether these strategies significantly decrease eating rate. Evidence regarding eating rate is varied in that some studies suggest that a decrease in caloric intake is associated with a decrease in rate $(25,28)$ while others show either no effect $(26,27,29,30)$ or an increase in intake (31).

An additional consideration is that biological and behavioral confounders may influence the relationship between mindful and slow eating strategies, energy intake and satiety. BMI, gender, and age have been suggested as biological confounders in the relationship between eating strategies and energy intake and satiety (32). For example, previous research has demonstrated that males have a higher eating rate than females (33); however, the effect of gender and eating rate on energy intake is still unclear. Eating slowly has been shown to reduce intake in normal weight, healthy women (25), while another study suggests that slower rates reduce intake in overweight/obese men but not overweight/obese women (30). Results from a study by Park et al. suggest that in normal weight males, within meal pauses actually increased energy intake (33). Behavioral confounders such as dietary and physical activity habits, dietary restraint, prior beliefs about test foods, and the presence of other people have been shown to affect energy intake and satiety (32). For example, research suggests that a decreased eating rate does not affect energy 
intake in participants who exhibit high dietary restraint (26). Women who ate in the company of a friend consumed more pasta (34) and young women also consumed more when their eating companion ate more (35); yet, other studies suggest that awareness of eating under observation reduces energy intake in a laboratory situation (36)

A variety of strategies to reduce ingestion rate have been examined for their potential effects on energy intake. Despite many investigations, the association between these strategies, acute energy intake, and satiety remains unclear. Modifiers such as gender, BMI, and dietary restraint have been shown to impact this association, making recommendations of slow eating strategies more complicated. Because of the effect of these modifiers on the relationship between eating rate and acute energy intake, future studies are needed to clarify this association.

\subsubsection{Mindfulness Strategies}

Mindfulness, or the conscious, moment-to-moment recognition of thought without judgment (3739), is a concept that is being implemented in behavioral interventions across disciplines. Mindfulness research has been primarily conducted in the areas of binge eating disorder, stress and alcohol dependency (40-42) but more recently the scope of mindfulness-based interventions has broadened to encompass weight loss and negative or other unhealthy eating behaviors $(43,44)$. Mindful eating has been defined as "the nonjudgmental awareness of physical and emotional sensations while eating or in a food-related environment" (39). Mindfulness-based eating interventions employ the basic principles which "involve listening to internal cues (i.e., hunger and satiety) to avoid overconsumption and utilizing external cues (reducing portion sizes and distractions while eating, and eating slowly) to assist in achieving awareness" (39). Satiety and satiation are part of the body's physiological control system to regulate appetite. Satiation is the 
process that causes meal termination; whereas, satiety is a feeling of fullness that remains after eating and affects subsequent consumption (32). Mindful eating practices employ techniques to make a person more aware of sensations of hunger and fullness in hopes of affecting satiation and satiety.

Mindfulness-based interventions have been shown to reduce energy intake. A study conducted by Timmerman and Brown examined the effects of a mindfulness-based restaurant eating intervention in perimenopausal women and found that women in the mindfulness group ate less (45). Reviewers of 21 mindfulness-based interventions found that $86 \%$ of studies supported the notion that these interventions are efficacious in positively changing obesity-related eating behaviors (46). Along with a potential impact on acute energy intake, it is suggested that mindfulness-based strategies may also affect satiety and eating behaviors. However, one study indicated that subjects utilizing mindfulness exercises did not rate satiety as more influential than the amount of food available (47).

Research shows that mindfulness based practice may have a positive effect not only on energy intake, but also on stress (48-50), negative affect (48), depression (40, 48), body image (51), binge eating $(40,46,48,52,53)$, food cravings (51), and overall healthier eating behaviors (46, 48-51, 54-56). For example, mindfulness-based interventions to reduce stress eating (also known as emotional eating), or eating in response to emotional cues - positive or negative (5759), resulted in improvement in mindfulness, anxiety, cortisol awakening response (CAR), and external-based eating as well as maintenance of body weight (49).

Conversely, some research suggests that mindfulness interventions may not affect excess intake in the presence of larger portion sizes $(47,55)$ or that the benefits may not extend to weight control (52). The majority of the obesity-related research in mindfulness is focused on overweight 
or obese populations or those with emotional eating symptoms. Results from other studies indicate that mindfulness behaviors did not reduce portion sizes $(47,55)$. Based upon the mixed evidence, further investigation into the effectiveness of mindfulness-based eating strategies on decreasing acute energy intake is warranted.

In summary, mindfulness based eating interventions have shown promise in implementing strategies that ultimately decrease acute energy intake or increase satiety ratings. Whether through improvements in stress response, emotional eating, or anxiety, mindful eating strategies may be beneficial to reduce intake and produce subsequent weight loss. However, evidence remains unclear regarding the actual effect of these strategies on intake and the mechanism through which they may influence consumption. Because of this uncertainty, research investigating the effects of mindful eating strategies on acute energy intake is warranted.

\subsection{CLINICAL RATIONALE}

Behavioral recommendations for weight loss include increased physical activity coupled with caloric restriction $(9,13)$. In behavioral weight management settings, eating strategies such as chewing a certain number of times, putting utensils down between bites, and using smaller plates and utensils are commonly suggested to decrease energy intake, thereby inducing weight loss [4, 5, 7-14]. However, evidence regarding these strategies is mixed; some results suggest a decrease in energy intake $(34,60-63)$ while others suggest no effect (64)or an increase in intake (31). In addition, it is not understood if differences in the impact of strategies exist. Strategies are recommended and implemented generally across all populations and BMI categories. It is possible that one strategy may reduce intake to a greater extent compared with another and that the effect 
of a strategy may differ between participant or population types. This study compared 2 of these strategies: a mindfulness-based and a slow-eating strategy, in order to determine their effect on acute energy intake and to investigate the existence of potential differences in their effectiveness.

While this investigation focused on eating strategies to decrease acute energy intake, ultimately the clinical implication is that over time, chronic reduction in consumption would lead to body weight reduction or maintenance. Mindful eating has been shown to decrease weight (48) and improvements in mindfulness, stress, and the stress response have been associated with reductions in abdominal fat (49). Eating quickly has been associated with excess body weight (22) and increased meal duration or slower rate of eating has been associated with greater weight loss (23). However, few studies have attempted to examine the effect of these techniques on acute energy intake. While it may seem that mindfulness and slow eating strategies would have a positive effect on satiation and satiety, current evidence is unclear. Without knowledge on the immediate effects of these strategies, the long-term effects on weight loss and the mechanisms by which they work will remain unclear.

As previously described, eating strategies are implemented in standard behavioral weight management programs. However, the success rates and efficacy of these programs are limited long-term. Recommendations for improving clinical programs include the adoption of a more individualized approach to weight loss by triaging participants via weight and lifestyle histories (2) or obesity phenotypes (8). By further categorizing participants by BMI category, gender, and dietary restraint, this investigation will explore the potential for two strategies to reduce energy intake in different "phenotypes" or categories of participants. This classification may allow for more tailored strategy recommendations for use in behavioral weight management programs. 


\subsection{THEORETICAL RATIONALE}

Despite evidence of the significant role that both mindfulness and ingestion rate might play in control of energy intake, the mechanisms through which these strategies exert their effect on consumption are currently unknown. Figure 1 illustrates potential theoretical pathways through which eating rate may influence acute energy intake. Figure 2 illustrates potential pathways by which mindfulness may influence acute energy intake.

\subsubsection{Slow Eating}

Slow-eating strategies are thought to impact energy intake through two main pathways, both of which result in enhanced satiety and satiation signaling from the gut hormones cholecystokinin (CCK) and glucagon-like peptide 1 (GLP-1). CCK and GLP-1 have been shown to delay gastric emptying resulting in decreased hunger ratings and subsequent decreased energy intake $(65,66)$.

Digestion of food from a meal including fat and carbohydrate begins in the mouth. A review of studies suggests that an increase in satiety-related hormone response is associated with an increase in oral processing time, or the amount of time that food spends in the oral cavity (67). Increased oral processing time is also suggested to accelerate satiation (68). It is likely, though not guaranteed, that a decreased eating rate would cause and increase in oro-sensory processing time. With a decreased time to meal termination and increased satiety hormone response, the potential for decreased energy intake due to increased oro-sensory exposure from a slower eating rate is great.

It is also well known that there is a delay of approximately 20 minutes from the time food enters the mouth until the brain receives these satiety signals (69-72). A slower rate of ingestion 
decreases the likelihood that excess calories would be consumed during the delay period and prior to satiation. Decreased ingestion rates and resultant increased meal duration allow for more time for the chemical and physical processes of oral processing and satiety recognition to take place; thus an increase in time course would suggest a reduction in energy intake.

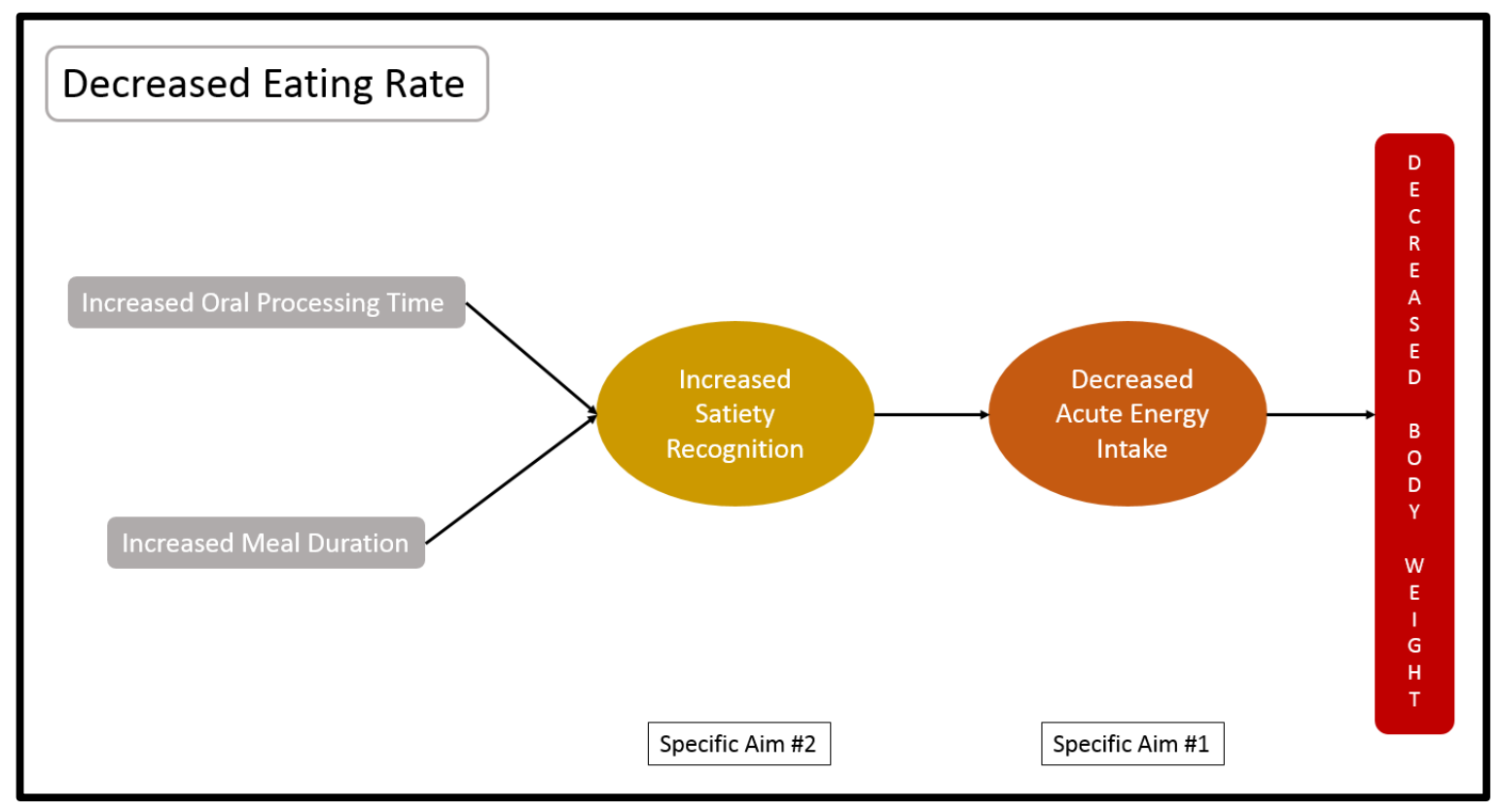

Figure 1. Theoretical pathways by which eating rate may influence acute energy intake and body weight

\subsubsection{Mindfulness}

The first pathway through which mindfulness may impact energy intake is related to the stress response. Mindful eating has been associated with decreased perceived stress $(48,50)$ and emotional or stress eating $(57,58)$. Emotional eating has been shown to increase consumption of fat and sugar (73-77). Increasing fat and sugar intake would result in increased energy intake both acutely and chronically, depending upon the duration of the stressor. Ultimately, increased energy intake over time would lead to increased body weight. Therefore, if mindfulness can 
decrease the likelihood of emotional eating, it may also reduce energy intake and subsequently decrease body weight.

Second, mindfulness-based dietary approaches may impact energy intake by increasing awareness of internal states and decreasing reliance on external cues. Increased internal awareness allows a person to rely on their cognitive control of intake rather than eating as an impulsive reaction to emotional or external stimuli (78-81). Mindfulness-based interventions have been shown to improve self-efficacy (45), coping skills, and the ability to deal with food cravings (51, 56). Without internal or external cues driving intake, the physiological need for energy and cognitive choice would be the primary drivers of energy intake; thus, possibly reducing overall intake in those actively seeking weight loss.

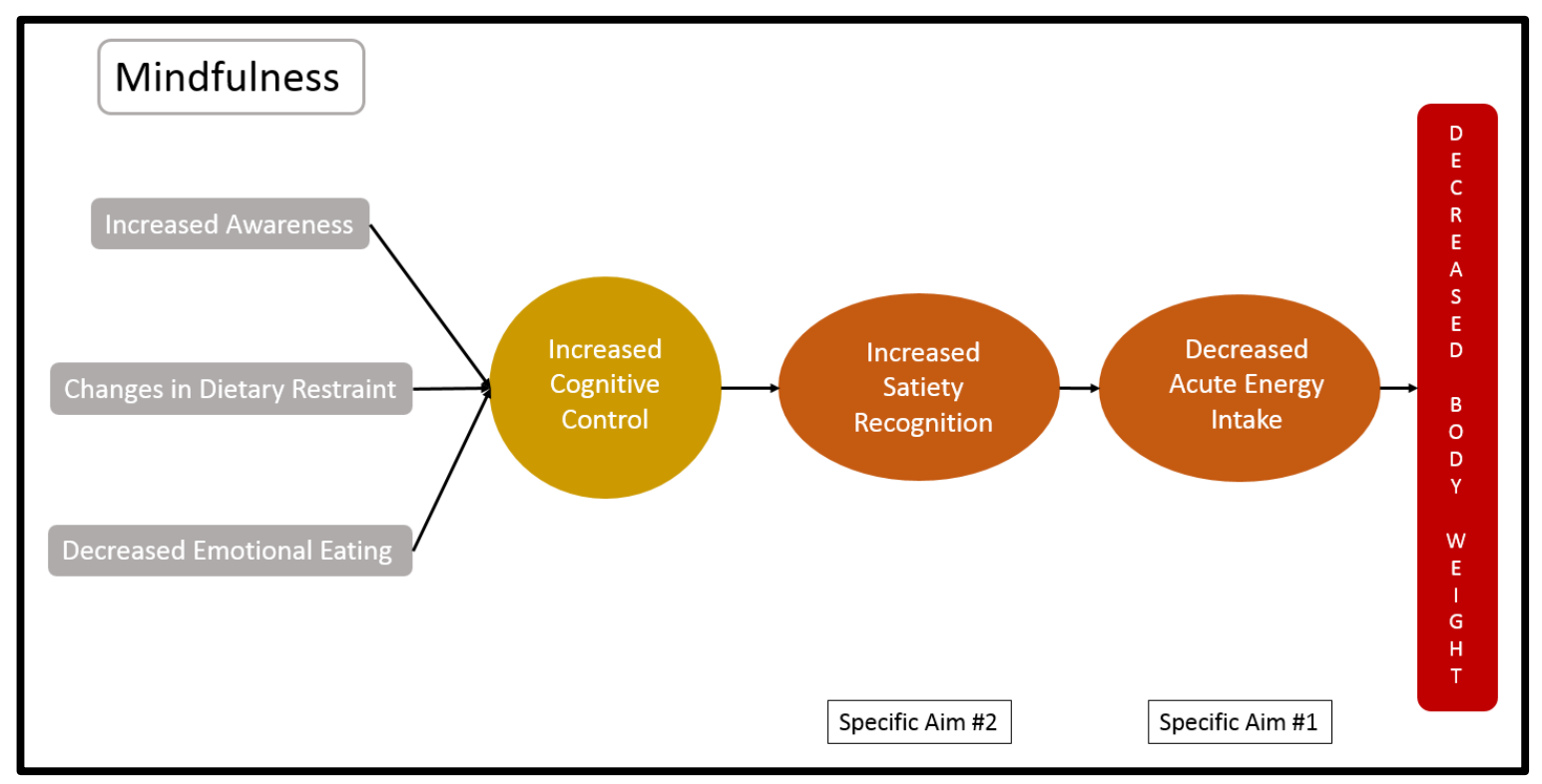

Figure 2. Theoretical pathways by which mindfulness may influence acute energy intake and body weight

For both mindful and slow eating strategies, physiological mechanisms exist which could explain an effect of these eating strategies on acute energy intake, satiation, and satiety. Increased cognitive control and reductions in stress response and emotional eating could be pathways 
through which mindful eating reduces acute energy intake and improves satiety and satiation. Increased oral processing time and increased meal duration causing increased sensitivity to satiety hormones such as CCK and GLP-1 may be possible explanations for a resultant decrease in energy intake and increase in satiety with utilization of slow eating strategies. Moreover, it is unclear if the mechanism by which mindfulness-based strategies influences eating behavior is also through slowing the rate of eating or if other factors exist that can influence one's sense of fullness and satiation. Because of these potential pathways and theoretical mechanisms, an investigation of the impact of mindful and slow eating strategies on energy intake and satiety is justified.

\subsection{SPECIFIC AIMS}

In order to examine the effects of behavioral eating strategies on acute energy intake, this study randomized subjects to one of three eating conditions (EAT, MIND, and SLOW). The first eating condition (EAT) acted as a control condition and subjects participated in the control test meal session on two separate occasions. The second condition (MIND) instructed subjects to use mindful eating strategies such as rating their hunger and savoring the taste and texture of their food. Subjects in the MIND condition took part in the control test meal session during their second visit and the mindful eating test meal session on their third visit. The third condition (SLOW) aimed to decrease ingestion rate by requiring participants to put their fork down in between each bite. Subjects in the SLOW condition participated in the control test meal session during their second visit and the slow eating test meal session on their third visit. 
The specific aims of this study include:

1) To compare acute energy intake in 3 eating strategy conditions. A-priori comparisons will include EAT vs. SLOW, EAT vs. MIND, SLOW vs. MIND.

2) To compare satiety in response to 3 eating strategy conditions. A-priori comparisons will include EAT vs. SLOW, EAT vs. MIND, SLOW vs. MIND.

\subsection{EXPLORATORY/SECONDARY AIMS}

1) To compare acute energy intake in 2 eating strategy conditions across BMI categories. Comparison will include MIND vs. SLOW.

2) To compare acute energy intake in 2 eating strategy conditions across genders. Comparison will include MIND vs. SLOW.

3) To compare acute energy intake in 2 eating strategy conditions across levels of dietary restraint. Comparison will include MIND vs. SLOW.

\subsection{HYPOTHESES}

1) Calorie intake will differ between the eating strategy conditions. Specifically:

a. Calorie intake will be less in SLOW vs. EAT.

b. Calorie intake will be less in MIND vs. EAT.

c. Calorie intake will be less in MIND vs. SLOW.

2) Satiety will differ between the eating strategy conditions. Specifically: 

a. Satiety will be greater in SLOW vs. EAT.
b. Satiety will be greater in MIND vs. EAT.
c. Satiety will be greater in MIND vs. SLOW.

\subsection{SIGNIFICANCE}

Overweight and obesity are a public health epidemic in the United States. Current recommendations for weight loss include caloric restriction and increasing physical activity. It is assumed that recommended behavioral eating strategies would decrease energy intake both in an acute setting and chronically. However, some evidence suggests that behavioral strategies such as mindfulness practice and decreased eating speed may decrease energy intake, yet the effectiveness of these strategies on acute energy intake and a comparison between them has not been thoroughly examined.

This study proposed to address gaps in the literature regarding whether behavioral eating strategies acutely affect energy intake in lean, overweight, and obese adults. We hypothesized that implementation of behavioral eating strategies would result in an acute reduction in energy intake, ultimately inducing weight loss or weight maintenance over time. However, it is possible that these eating strategies affect subjective satiety ratings and not energy intake, which may have no effect on weight loss. These strategies and questions have not been fully investigated. Moreover, if an effect of or differences between eating strategies are detected, this would influence the recommendations for reducing energy intake in behavioral weight management programs. 


\subsection{REVIEW OF THE LITERATURE}

\section{$2.1 \quad$ INTRODUCTION}

Obesity is a major health concern for millions of Americans (1). Individuals with obesity are characterized by a body mass index (BMI) of $\geq 30 \mathrm{~kg} / \mathrm{m}^{2}$ and excess body fat. Excess body fat is associated with several comorbid conditions and chronic diseases including hypertension, hypercholesterolemia, certain types of cancer, and type 2 diabetes (82). For example, data from the Framingham Heart Study has shown that excess body weight, independent of age, cholesterol, systolic blood pressure, smoking history, left ventricular hypertrophy and glucose intolerance, predicted 26-year incidence of cardiovascular disease. (83). Additionally, annual health care costs for obesity are estimated at $\$ 147$ billion (84) with a $\$ 2741$ increase in costs per person per year (85). Thus, it is imperative to combat the American obesity epidemic through the development of effective and appropriate intervention strategies for weight management.

\subsection{ENERGY BALANCE}

The maintenance of a healthy body weight results from a balance of energy in the body. A person would be described as being in energy balance when the number of calories consumed (energy intake) is equal to the amount of calories expended (energy expenditure), resulting in a relatively 
stable body weight. Obesity is typically the result of chronic energy imbalance where calories in are greater than calories out consistently over time. Recommendations for body weight loss include strategies that affect both energy consumed and energy expended with the goal of producing a negative energy balance. Typical weight management programs achieve negative energy balance through two primary avenues: control of energy intake through caloric restriction and control of energy expenditure through increased physical activity. It should be noted that while regulation of energy balance has been simplified here, there are numerous factors that impact both the intake and expenditure sides of the equation that are beyond the scope of this project.

\subsubsection{Energy Expenditure}

A primary recommendation for weight loss is an increase in energy expenditure through physical activity. Four main components comprise energy expenditure. The first component is basal or resting metabolic rate. Basal metabolic rate is the amount of energy expended by the body to carry out vital functions such as breathing and oxygen transport.

The second component of energy expenditure that remains relatively unchanged is the thermic effect of food (TEF). TEF is the smallest contributor, representing $10 \%$ of total energy expenditure $(86,87)$. Energy expended by the body for the hydrolysis of ATP during nutrient absorption, preliminary metabolic processes and storage of nutrients comprises the TEF (87).

Non-exercise activity thermogenesis (NEAT) is the third component of energy expenditure and one of the components driving total activity thermogenesis. NEAT is the energy expenditure derived from activities other than purposeful exercise. Non-exercise activities include but are not limited to walking, dancing, working, playing, etc. Because activity levels can vary greatly 
between individuals, NEAT fluctuates drastically among the population (up to 2000 kcals per day) (88).

Physical activity from purposeful exercise is the fourth and final component of energy expenditure. Similar to NEAT, energy expenditure from physical activity can vary widely among individuals; ranging from sedentary to highly active.

While there are four components of energy expenditure, only NEAT and physical activity are reasonably modifiable for weight control. It is for this reason that weight management recommendations suggest increasing physical activity. Despite the contribution of energy expenditure to weight control, behavior modifications to increase expenditure can only contribute so much. In theory, an individual could exercise and move enough to lose weight solely through physical activity and increasing energy expenditure. However, this level of activity would be so great that it may not be considered reasonable and attainable for most individuals, particularly those whose activity and mobility may already be limited due to the consequences of current obesity. Because of this, physical activity recommendations for weight loss are typically paired with the additional recommendation of caloric restriction, as will be described below.

\subsubsection{Energy Intake}

In conjunction with recommendations to increase energy expenditure, decreasing energy intake is also prescribed due to its integral role in weight management. Energy intake can be defined as the amount of energy in kilocalories consumed in a specified time period, typically during a meal or throughout the course of a day. Data from the 2007-2010 National Health and Nutrition Examination Survey (NHANES) suggests that adult men consume a mean of $1967 \pm 22 \mathrm{kcal}$ during meals and a mean of $634 \pm 13 \mathrm{kcal}$ from snacks while adult women consume less energy overall 
with a mean of $1358 \pm 15 \mathrm{kcal}$ from meals and $438 \pm 8 \mathrm{kcal}$ from snacks (89). Results from this survey demonstrate that approximately $16 \%$ of daily energy intake is consumed at breakfast (314 $\mathrm{kcal}$ for men and $217 \mathrm{kcal}$ for women), 23\%-24\% at lunch (472 kcal for men and $312 \mathrm{kcal}$ for women), 36\% at dinner (708 kcal for men and $489 \mathrm{kcal}$ for women), and the remaining $24 \%$ from snacks consumed throughout the day (89).

In free-living environments, energy intake can be measured through self-report methods such as the surveys utilized in the NHANES study described above, as well as other methods such as visual analogue scales, self-monitoring tools, and food frequency questionnaires (32). As with all self-report measures, uncontrolled environments and misreporting can influence results. Laboratory based measures, such as food scales (both apparent and hidden), nutrient analysis software, and direct observation, provide more accurate estimates of energy intake; however, these measures may not be generalizable to a free-living environment (32). Along with observation (32, 36), emotional stress, palatability of available foods, boredom (32), and changes in psychological, environmental and social factors $(32,34,35)$ can all influence energy intake.

Decreased energy intake achieved through caloric restriction contributes to the creation of a negative energy balance that is needed for weight loss. Typical recommendations for safe and sustainable weight loss range from 1-2 pounds per week, which is generally equivalent to a caloric restriction of 500-750 calories per day. Calorie targets for weight loss usually range from 1200 to 1500 calories per day for women and 1500 to 1800 calories per day for men (2). Behavioral modification strategies are often utilized to achieve this caloric restriction. For example, those attempting to lose weight are directed to reduce calorie intake by decreasing portion sizes of energy dense food (2), reducing food cues in the environment, or recognizing high risk situations for 
overeating. These types of strategies to reduce energy intake are commonly recommended in lifestyle interventions and behavioral weight management programs.

\subsection{RECOMMENDATIONS FOR WEIGHT MANAGEMENT}

Increasing energy expenditure through increased physical activity comprises one of the two main recommendations for weight management. The American College of Sports Medicine recommends a progressive increase to 150 minutes per week of moderate intensity physical activity to realize positive changes in health and fitness. An additional recommendation exists to progress to greater amounts of physical activity of 250 minutes of moderate intensity activity per week or more to promote long-term control of weight (90). According to the 2013 AHA/ACC/TOS Guidelines for the Management of Overweight and Obesity in Adults, strong evidence exists for prescriptions of aerobic physical activity greater than 150 minutes per week for weight loss with an increase to 200 to 300 minutes per week for weight loss maintenance or the prevention of weight regain (2). Based upon these recommendations, physical activity on most, if not all, days of the week is an integral part of any weight management program.

Calorie restriction is the other primary recommendation for weight loss. The American College of Sports Medicine recommends reducing current intake by 500 to $1000 \mathrm{kcal}$ per day with a further suggestion to reduce dietary fat to less than $30 \%$ of total daily energy intake (90). Similarly, the 2013 AHA/ACC/TOS Guideline for Management of Overweight and Obesity in Adults suggests that a strong body of evidence exists for prescription of a reduced- calorie diet that creates a deficit of greater than or equal to $500 \mathrm{kcal}$ per day, typically induced through a prescription of $1,200-1,500 \mathrm{kcal}$ per day for women and 1,500 - 1,800 kcal per day for men (2). 
With adherence to these directives, participants can expect to achieve the caloric-restriction needed to create a negative energy balance and a reduced body weight.

\subsection{BEHAVIORAL WEIGHT MANAGEMENT PROGRAMS}

Behavioral weight management programs aim to assist participants with weight loss by aiding in the implementation of recommended lifestyle modifications as described above to reduce energy intake and increase energy expenditure through physical activity. In order to accomplish these behavioral modifications, successful weight management programs and other eating behavior change programs instruct participants on concepts such as barrier identification $(3,91)$, goal setting $(91,92)$, recognition of environmental cues $(91,92)$, motivation $(91)$, problem solving $(3,92)$, and social support (92) to achieve a minimal reduction in body weight of 5-12\% over the course of 312 months $(8,90)$. Utilization of these concepts to attain recommendations for weight management is the goal of successful weight management programs.

\subsubsection{Short Term Success Rates}

Lifestyle interventions and behavioral weight management programs are successful at helping participants to lose a recommended 5-10\% of body weight. For comprehensive lifestyle programs that utilize behavioral therapy to impact energy intake and diet, short-term success rates are relatively similar. The 2013 AHA/ACC/TOS Guidelines for the Management of Overweight and Obesity in Adults indicates that when these three components are implemented in a program (diet, physical activity, behavior therapy), there is strong evidence that an average weight loss of up to 
$8 \mathrm{~kg}$ can be achieved in 6 months (2). These guidelines also suggests that, when providing continued intervention contacts for an additional 6 months, comprehensive lifestyle programs can produce an average weight loss of $8 \mathrm{~kg}$ at 1 year (2). This was shown in a study by Gold et al., where a 6-month intervention resulted in a mean weight loss of $8.3 \pm 7.9 \mathrm{~kg}$ in the therapist-led group (4). In another investigation, a stepped-care intervention approach for weight loss conducted by Jakicic et al. resulted in an average of $9.6 \mathrm{~kg}$ weight loss over 6 months (3). Results from this study suggest that weight losses greater than $8 \mathrm{~kg}$ can be achieved in a 6-month time period. However, a longer-follow up period in this study demonstrates that short-term weight loss can be a challenge to maintain long term as will be described below.

\subsubsection{Long Term Success Rates}

While behavioral weight management programs are successful at producing weight loss in the short-term, longer-term follow-up and maintenance studies indicate that maintenance of weight loss remains a challenge. A previously described study by Jakicic et al. included a longer-term intervention of 18 months. Following an average weight loss of $9.6 \mathrm{~kg}$ at 6-months, an average of $2 \mathrm{kgs}$ was regained over the next 12 months (3). Other long-term intervention studies like those of Kramer et al. (93), Whelton et al. (94), and the HPT Research group (95), suggest that over time, weight regain continues, resulting in a net weight loss of $4 \%$ of baseline weight at 4 years (8). The 2013 AHA/ACC/TOS Guideline for the Management of Overweight and Obesity in adults indicates that strong evidence exists demonstrating that with bimonthly or more frequent intervention contacts after one year, gradual regains of 1 to $2 \mathrm{kgs}$ per year following weight loss achieved by 6 months can be expected (2). However, despite the tendency for long-term weight 
regain following participation in a behavioral weight loss program, weight loss at 1 year or more remains higher than that of usual care (2).

\subsubsection{Challenges and Implications for Practice}

While standard behavioral weight management programs and lifestyle interventions result in clinically meaningful weight loss outcomes in the short term, long-term maintenance of these weight losses is limited. In order to increase the long-term efficacy of these weight management programs, it has been suggested that future research should focus on improvements in both efficacy and efficiency of intervention delivery methods (2). Specifically, Jeffery et al. suggests that additional studies are needed to improve behavior patterns associated with changes in energy intake as well as those addressing behavioral phenotypes within obese populations (8). Because of the many factors affecting obesity (including genetics, physiological, and environmental cues), identifying specific subgroups or certain characteristics of obesity would be of clinical value (8). The concept of obesity phenotypes or a set of identified group of characteristics is further implicated and highlighted in the 2013 AHA/ACC/TOS Guideline for Obesity. These guidelines call for additional research that identifies and evaluates characteristics of low-responders as well as future studies which aid in the understanding of the most appropriate and effective weight loss strategies in key populations (2).

The current investigation aimed to address these research needs identified above by Jeffery et al. and Jensen et al. by comparing two behavioral eating strategies and their effect on acute energy intake. This could inform future investigations and behavioral weight management programs on the behaviors associated with changes in energy intake. In order to address and evaluate characteristics of responders (obesity phenotypes), that may improve weight loss there 
are exploratory aims that categorize participants by BMI, gender, and levels of dietary restraint. These exploratory analyses may help future clinicians to tailor their approach for participants presenting with certain characteristics, which could impact both short and long-term success rates of behavioral weight management programs.

\subsection{EATING STRATEGIES}

While there are many acute behavioral eating strategies used for the purpose of reducing energy intake, most strategies fit into one of five main categories: volumetrics, portion control, stimulus control, meal frequency, and mindfulness. Volumetrics, portion control, stimulus control, meal frequency, and mindful eating strategies are common ways for those who are trying to lose weight to consciously or subconsciously decrease their overall calorie consumption. For the purpose of this investigation, mindful eating and slow eating strategies are highlighted and reviewed below.

\subsubsection{Eating Rate}

Eating rate is one of many factors that has been suggested to impact body weight $(22,24,96)$. Gletsu-Miller and McCrory, in their summary of a 2014 symposium at the American Society of Nutrition and Annual Meeting at Experimental Biology, highlight alteration of meal timing as a novel approach for changing eating behavior (96). A systematic review and meta-analysis of 23 published studies (20 cross-sectional, 2 longitudinal, and one including both study designs) conducted by Ohkuma and colleagues found that eating at a faster rate was positively associated with increased body weight (22). Subjects classified as "eating quickly" via self-report had a 
significantly greater mean BMI than those subjects classified as "eating slowly" with a pooled estimate of mean difference in BMI of $1.78 \mathrm{~kg} / \mathrm{m}^{2}$. Results of the analysis also demonstrated a positive association between eating quickly and the likelihood of obesity, though the magnitude of the association was not homogeneous across included studies (22). In contrast, a prospective study of middle-aged women in New Zealand was published by Leong, Gray, and Horwath in 2015. Participants completed self-reported measures of eating rate at baseline and 3 years later. Women were asked "how would you describe your usual rate of eating?" with responses including: "very slow", "relatively slow", "medium", "relatively fast", or "very fast". Results from this study demonstrated that, unlike the results from other cross-sectional studies, there were no associations with eating speed and BMI: neither faster eating at baseline nor change in speed of eating over the 3 year period increased the risk of becoming overweight (24). Because the relationship between eating rate and body weight remains undefined, additional studies are warranted.

In order to more clearly explain the relationship between eating rate and body weight, investigators continue to use several behavioral strategies to decrease eating rate with the expectation of a subsequent reduction in body weight. Typical strategies implemented to slow eating rate in previous research include but are not limited to: taking smaller bites $(25,26,29,97$, 98), chewing each bite a recommended number of times before swallowing $(25,29,97,98)$, completely swallowing each bite before taking the next (26), using a smaller or less efficient utensil such as chopsticks $(25,29,97,99)$ and creating within-meal pauses by putting utensils down between bites $(25,29,97,98)$. The effect of these strategies on acute energy intake is discussed further in Section 2.6.1. 


\subsubsection{Mindfulness}

Mindfulness based eating strategies are derived from the overarching concept or practice of mindfulness. With roots in Buddhist and eastern traditions, the original purpose of mindfulness practice was to gain spiritual enlightenment from everyday experiences (100). However, contemporary western psychologists have found that the self-regulation behaviors embedded in mindfulness can be applied to a variety of disorders and conditions $(101,102)$. Jon Kabat-Zinn, a founding father of mindfulness in the west, has defined modern, western mindfulness as "paying attention in a particular way: on purpose, in the present moment, and non-judgmentally" (103). This description highlights 3 main components which differentiate mindfulness from other changebased treatment approaches to behavior modification: 1) purposeful attention, 2) awareness of the present moment, and 3) non-judgmental observation.

Purposeful attention that accompanies mindfulness based strategies involves increased situational or experiential awareness. Rather than objectively approaching a situation, as in traditional therapies, mindfulness-based strategies enable practitioners to focus on all aspects of an experience, including environment, external events, and internal states, which can be comprised of physical and emotional sensations and thoughts (102). This increased awareness of an entire experience allows mindfulness practitioners to make a fully informed choice of a reaction or a behavior based on internal and external cues rather than acting in response to external drivers alone.

Focus on the present moment is the second component of contemporary mindfulness that distinguishes these strategies from other behavior change approaches. The increased awareness of mindfulness happens on a moment-to-moment basis with the practitioner recognizing changes in internal thoughts, emotions, and physical sensations as well as external or environmental cues as 
they happen (102). Each moment of every experience brings a multitude of inputs upon which mindfulness practitioners can base their choice of action and make a subsequent change if they decide. Thus, mindfulness-based behavior strategies provide practitioners with a set of "microskills" or skills that can be utilized to make an actionable decision at moment's notice without having to plan ahead or rely on reactionary, post-situational compensatory behaviors. For example, a traditional change-based treatment approach may enable participants to use specific strategies to react to potentially high-risk situations that may arise in the future (102). Conversely, a mindfulness-based approach would allow practitioners to navigate stressful situations of any kind on a moment-by-moment basis.

Nonjudgmental observation is the third component of modern mindfulness that differentiates the practice from that of other behavioral therapies. Dutton suggests that mindfulness “involves an acceptance of one's thoughts, feelings, and physical sensations without any effort to react, evaluate, or change them" (102). Rather than challenging or changing negative thoughts, as is the goal of other change-based treatment approaches, mindfulness-based strategies do not attempt to alter thought content or interpretations but rather, observe thoughts without reaction (102). Without an initial reactionary response to negative thoughts, practitioners of mindfulness can notice those thoughts and integrate them into the decision-making process rather than using them to judge themselves or the situation. Dutton further asserts "Thoughts are not inherently harmful or destructive. Rather, it is our reaction to these thoughts that can become problematic" (102). Mindfulness-based strategies provide a system for practitioners to become less judgmental and reactionary towards their thoughts and emotions and more aware and observational. 
The modern mindfulness-based skillset enables practitioners to observe and notice their thoughts in every situation without judgment. Moreover, they may become fully aware of both internal and external inputs and become more equipped to make a conscious and informed actionable decision rather than have an immediate, thoughtless reaction.

While mindfulness-based strategies are now applied across a spectrum of behaviors including weight management, the roots of mindfulness in health behavior change lie in the areas of binge eating disorder (BED), stress management, and alcohol abuse, among others. Mindfulness-Based Eating Awareness Training (MB-EAT), a 12-session group treatment for BED, was developed by Kristeller and colleagues to examine the efficacy of a mindfulness-based treatment compared to a psycho-educational/cognitive-behavioral intervention and a wait-list control. 150 participants were randomized to receive either the wait list control, educational/cognitive-behavioral intervention or the mindfulness-based treatment, which involved guided meditation to increase awareness of hunger and satiety cues, sensory-specific satiety, and emotional and other triggers for eating. Results from the randomized controlled trial indicate that compared with the control, both intervention groups showed comparable improvement on binge episodes, the Binge Eating Scale, and depression. At a 4-month post-intervention follow-up, $95 \%$ of participants in the MB-EAT group no longer met the criteria for BED, compared with only $76 \%$ in the cognitive-behavioral group. Additionally, binges that did occur were more likely to be smaller in the MB-EAT group (53). In a 2014 study from Creswell et al. that studied mindfulness for stress reduction, 66 participants were randomized to a brief 3-day mindfulness meditation training or an analytic cognitive control training program. Results from this study show that participants in the mindfulness training group had significantly lower stress perceptions than those in the control group (50). Lastly, a study by Garland et al., investigated the effects of mindfulness 
training on psychological and physiological mechanisms associated with alcohol dependence in a randomized controlled trial. 18 participants completed the 10 -session mindfulness training intervention and 19 participants completed the 10-session alcohol support group intervention. Both groups resulted in significant decreases in perceived stress; however, the mindfulness training intervention resulted in a significantly larger reduction in perceived stress over 10 weeks than the alcohol support group (41). Foundational work in these areas paved the way for mindfulnessbased techniques to be applied in weight management settings.

With success in other behavior change areas, mindfulness-based practices have expanded to weight management with a focus on mindful-eating behaviors. Typical mindfulness-based eating strategies include but are not limited to: mindful eating meditation exercises $(45,47-49,51$, $56,104,105)$, bodyscans $(49,51,55,56)$, cognitive diffusion $(106,107)$, urge surfing $(106,107)$, and mindful eating tips such as chewing food thoroughly before swallowing, savoring the aroma and taste of food, and creating a pleasurable experience around food and eating which may include eating in a designated eating spot with minimal distractions $(39,47)$. Within the realm of mindful eating meditations, there are those that are focused on breathing $(49,104,105)$, awareness of the senses associated with eating in order to maximize enjoyment $(45,47,51,108)$, relaxation $(45)$, attention to internal hunger cues such as hunger and satiety $(45,48,49,51,56,105)$, and identification of emotional and external eating triggers $(49,56)$. The use of these strategies alone or in combination has been employed in many interventions investigating the effect of mindfulness-based strategies on eating behaviors. More detailed descriptions of strategies specifically related to acute energy intake are highlighted in Section 2.6.2. 


\subsection{EFFECT OF BEHAVIORAL EATING STRATEGIES ON ENERGY INTAKE}

As previously stated above, many behavioral strategies are implemented by those seeking weight loss in attempts to reduce energy intake. These strategies fit into five umbrella categories: volumetrics, meal frequency, portion control, stimulus control, and mindfulness. These strategies have been routinely investigated for their effects and potential benefits for reducing energy intake; however, evidence regarding some of these strategies remains uncertain. For the purposes of this investigation, two of these strategies: slow eating, a strategy aimed at reducing portion size, and mindfulness were examined. Evidence on these strategies and their effect on acute energy intake is highlighted below in Section 2.6.1 and Section 2.6.2.

\subsubsection{Eating Rate}

Eating rate has been suggested to impact body weight through a change in energy intake that may result from this decreased rate. Several studies have attempted to clarify the relationship between eating rate and energy intake. In a 2007 study conducted by Martin et al., investigators examined the effect of slow eating on acute energy intake. Participants included nonsmoking males and females, aged 18-65 and a BMI between $25.0 \mathrm{~kg} / \mathrm{m}^{2}$ and $35.0 \mathrm{~kg} / \mathrm{m}^{2}$. Subjects ate fried chicken when given an auditory prompt from a computer application that was used to modify eating rate. The protocol consisted of 4 meals: acclimation meal, baseline meal, reduced-rate meal (slowed by $50 \%$ from acclimation meal), and combined-rate meal (first half of the meal identical to the eating rate of the first half of the acclimation meal and second half of the meal 50\% slower than the acclimation meal) with meals randomized and counterbalanced following the acclimation 
meal. Results indicate that a slower eating rate in the reduced-rate and combined-rate meals was associated in a decreased food intake for men, compared to the baseline meal (30).

A year later, Andrade et al., examined the effect of slow eating on energy intake in 30 healthy women with a mean age of $22.9 \pm 7.1$ years and a mean BMI of $22.1 \pm 2.9 \mathrm{~kg} / \mathrm{m}^{2}$. Subjects participated in two eating visits in randomized order: quick or slow, and their energy intake was assessed using a digital food scale. For the slow condition, participants were instructed to take small bites using a small teaspoon, put down their spoon in between each bite and chew each bite 20 to 30 times. Results from this investigation demonstrate that meal duration was approximately 21 minutes longer in the slow condition and participants consumed significantly less calories than in the quick eating condition (25). A follow-up study by Andrade and colleagues in 2012, investigated the effects of slow eating on appetite and energy intake while controlling for water intake. Similar to their previous study, subjects were 30 healthy women $(22.7 \pm 1.2$ years, $\mathrm{BMI}=$ $22.4 \pm 0.4 \mathrm{~kg} / \mathrm{m}^{2}$ ) who consumed quick or slow test meals on two occasions. Women were instructed to take small bites using a small teaspoon, put their spoon down in between each bite, and chew each bite 20 to 30 times. Energy intake was assessed using a digital food scale and participants in both slow and quick conditions were instructed to consume the entirety of $300 \mathrm{ml}$ of water throughout the meal. Strategies utilized in the slow condition did significantly slow eating rate, however, there was no difference in energy intake between the slow and quick conditions (29).

Finally, in a 2014 study, Shah and colleagues also investigated the effect of slower eating speed on energy intake. Thirty-five normal weight men and women, aged 19 to 65 years were included in the study. In a randomized crossover design, participants ate lunch on 2 occasions with differing eating conditions: slow or fast eating speed. In order to slow eating rate, subjects 
were instructed to take small bites, chew each bite completely, and put their spoon down in between bites. Energy intake was calculated from food weight consumed during the meals. Eating rate was calculated by dividing energy intake in kcals by eating duration in minutes. A significant decrease in energy intake was seen in the slow eating condition compared with the fast eating condition in these normal weight subjects. Meal duration was significantly decreased in the slow eating condition compared with the quick eating condition, as expected (98).

While there is a significant amount of evidence to suggest that a decreased eating rate may decrease energy intake, other studies resulted in no difference in intake between quick and slow eating conditions. Because of this mixed evidence, the relationship between eating rate and energy intake remains unclear. Thus, additional studies examining this association are warranted.

\subsubsection{Mindfulness}

Previous research suggests that long-term or repeated practice of meditation can help a practitioner to more reliably achieve a mindful state, however, long-term practice is not required or necessary $(101,109)$. Literature involving mindfulness and eating behaviors also demonstrates this concept, with studies conducted utilizing both longer-term and brief mindfulness practice to influence eating behavior.

A 4-part study by Jordan et al. demonstrates both short-term and long-term mindfulness practice may affect energy intake. In one part of the study, 100 Canadian undergraduates completed the Mindful Attention and Awareness Scale (MAAS) in order to measure trait mindfulness as well as a measure for trait self-control. Participants were then randomized to a control or ego-depletion group and completed the e-crossing task, a standard ego-depletion manipulation which has been shown to impair self-control in subsequent tasks. After completion 
of the e-crossing task, participants were offered either a fruit (lower calorie: apple or orange) or sweet (higher calorie: Kit Kat or cookies) snack. Results indicated that trait mindfulness was able to predict snack choice, with participants rated high in trait mindfulness choosing the lower calorie fruit option more often (54). A second part of the study investigated the effects of a brief mindfulness intervention on energy intake. Sixty undergraduates from a U.S. college were randomly assigned to a mindfulness or a control task. Participants in the mindfulness group heard a portion of a mindfulness bodyscan which focused on breathing, sensations, and various body parts. Control participants listened to a relaxation recording of similar length that did not contain mindfulness instructions. Recordings in both conditions did not reference eating behavior. After the intervention, participants were instructed to "eat as many M\&Ms, pretzels, and almonds as you would like". Participants in the mindfulness condition ate $24 \%$ fewer calories than those in the control condition as measured by food weight (54). Results from these two sub-studies indicate that both trait mindfulness (indicative of potential "chronic" mindfulness) and a brief mindfulness based intervention were associated with decreased calorie intake.

Shorter-duration mindfulness-based interventions have also been shown to affect energy intake. In a 2014 study from Jenkins and Tapper, 137 college students were randomized to receive one of 3 conditions: 1) cognitive diffusion ("seeing your thoughts differently" handout and 5 minutes using one of 3 mindful strategies), 2) acceptance (“dealing with uncomfortable feelings" handout and 5 minute observation of feelings), and 3) control ("relaxation" handout and 5 minutes practicing muscle relaxation). Following these conditions, participants carried around a clear bag full of chocolates for 5 days, after which, consumption of chocolate was measured. The cognitive diffusion group, or those who participated in the 5 minute mindfulness practice, consumed the least amount of chocolate over the 5-day period (106). Fisher, Lattimore, and Malinowski also 
investigated the effects of a mindful attention induction on food intake. Forty adult women were randomly assigned to a standard food-cue exposure condition following an unrelated reading of similar duration or a food-cue exposure following a mindful attention induction, each lasting 10 minutes. Mindful attention participants were instructed to practice mindful breathing meditation during the 10 minutes following the post-exposure assessments. Participants were given a plate of cookies in order to measure food intake and the number of cookies consumed was compared between groups. Women in the standard group consumed significantly more cookies than the mindful attention group (104). Also in 2016, Arch et al. investigated the impact of a brief mindfulness intervention on energy intake. One hundred and two undergraduate students participated in the raisin-eating exercise popularized by Jon Kabat-Zinn that aims at focusing attention on the sensory experience of eating. The students were then asked to wait for the next part of the study while being offered 6 unpackaged snack choices: 1) Reese's Pieces, 2) Lay's potato chips, 3) Rold Gold pretzels, 4) M\&Ms, 5) almonds, and 6) carrot sticks. Participants were told to "try and eat something so that you're not starving". Participants in the mindfulness group consumed significantly fewer salty food calories, higher saturated fat calories, and total overall calories than the control group (108). Evidence from these investigations suggests that brief mindfulness-based interventions, even those lasting only 5 minutes, have the potential to positively impact eating behavior and decrease energy intake.

Three longer-term studies investigated the effects of "chronic" mindfulness on eating behaviors. In a study from Timmerman and Brown, 35 perimenopausal women who ate out at least 3 times per week were randomized to a mindful intervention or a wait list control. The intervention consisted of 6 weekly 2-hour sessions that included mindful eating meditations along with other related strategies. Mindful eating meditations included: 1) those that focused on 
awareness of sensations of the eating experience to increase satisfaction with smaller portions and optimize enjoyment, and 2) those that utilized relaxation and focus on internal cues such as hunger and satiety and eating triggers. Energy intake was assessed using the multiple-pass method for 24hour recall. Results demonstrated that compared with control, the mindfulness intervention group reported consuming significantly fewer calories over a 3-day period (45). Two studies by Alberts and colleagues (2010 and 2012) demonstrate the effect of mindfulness-based intervention on food cravings. In the 2010 study, 19 overweight and obese adults participated in a weight loss intervention in which 10 of the 19 participants also received an additional 7-week manual focused on acceptance. Instructions in the manual included a bodyscan, increasing awareness of eating behavior, and the total experience of food cravings (56). In the 2012 study, 12 women with disordered eating behavior participated in a mindfulness-based intervention that consisted of 5 core components: 1) mindful eating, 2) awareness of physical sensations, 3) awareness of thoughts and feelings related to eating, 4) acceptance non-judgement of sensations, thoughts, feelings and body, and 5) awareness and step-by-step change of daily patterns and habits of eating and physical activity (51). The results from both of these studies show a significant decrease in food cravings in the mindfulness group compared with the control group. A decrease in food cravings may be likely to result in decreased energy intake. Thus, longer-duration mindfulness based interventions which may result in chronic practice of mindfulness have the potential to positively impact energy intake.

However, despite the previously described evidence supporting the use of brief mindfulness-based interventions for reducing energy intake, other evidence suggests that this positive impact on eating behavior may be limited by the portion size effect. Cavanagh et al. investigated the effects of portion size in 96 undergraduate students. Participants were randomized 
to one of 3 groups: 1) education, 2) mindfulness, and 3) control. Participants in each condition received a brochure and a 6 minute activity related to information in the brochure. Specifically, the mindfulness group completed a mindfulness meditation exercise focused on awareness and attention to the sensations associated with a raisin. Participants were served either a small (350 g) or large (600 g) portion of pasta. Results show that, as expected, participants who were served the large portion of pasta consumed 34\% more pasta than those in the small portion condition. Additionally, neither the education nor the mindfulness exercises were effective in reducing the portion size effect (47). Additionally, Marchiori and Papies examined the effect of a brief mindfulness intervention on eating behaviors and portion size effect. 100 undergraduate students were randomized to one of two conditions: a control group (listening to an audio book) or a mindfulness group (listening to a typical bodyscan exercise). After taking part in the randomized condition, participants were served either $51 \mathrm{~g}$ or $153 \mathrm{~g}$ of chocolate chip cookies. Participants who were served the larger portion consumed more, regardless of hunger or mindfulness intervention (55). The results from these two studies suggest that while a brief mindfulness intervention may be effective at reducing energy intake, the effect may be limited to smaller portion sizes.

It has been suggested that while chronic use of mindfulness skills can enable practitioners to more easily obtain a mindful state, brief mindfulness exercise can also be effective $(101,109)$. Several studies investigating the effect of mindfulness-based interventions on energy intake and eating behaviors, whether short or long-term, have demonstrated that these interventions can have a positive impact on eating behavior. However, this effect may be limited to smaller portions and does not enable the practitioner to overcome the portion size effect. Because of the potential limitations of these interventions, further investigations are warranted. 


\subsection{PATHWAYS BY WHICH STRATEGIES EFFECT ENERGY INTAKE AND SATIETY}

\subsubsection{Eating Rate}

Slower eating rate, which can be attained through several eating and environmental modifications, is also thought to impact energy intake through satiety signaling. Slower eating is suggested to provide the brain time to recognize and act on satiety signals prior to the consumption of excess food. Research has demonstrated that the brain does not receive satiety signals from the gut until 10-30 minutes after food has begun to be ingested (69-72). Therefore, a faster ingestion rate would allow a person to consume more calories before the brain signals for meal termination. Conversely, a slow eating rate would allow the brain time to respond to chemical, mechanical, and hormonal satiety signals from the gut prior to the consumption of excess calories.

Chemical digestion of fat and carbohydrates begins in the mouth. Oral processing time, or the amount of time that food spends in the oral cavity, is suggested to impact satiety and acceleration of meal termination (68). A review of 33 studies indicates that increasing oro-sensory exposure results in a subsequent increase in satiety related hormone responses (67). However, decreasing eating rate does not necessarily guarantee an increase in oral processing time.

Physical and chemical peripheral biomarkers are associated with satiation, or the termination of a meal. These measures are related to stomach distention and satiety hormone response. Additionally, it is suggested that stomach distention and hormone response work in unison to suppress appetite and induce satiety $(65,110,111)$. Gut mechanoreceptors are loaded by the bulk of food passing through the stomach. An increase in the frequency of discharge by these mechanoreceptors has been shown to increase sensitivity to the satiety hormone cholecystokinin 
$(\mathrm{CCK})$ and cause a reduction in energy intake $(65,110,112)$. In addition to CCK, glucagon-like peptide-1 (GLP1) had been demonstrated to delay gastric emptying reducing ratings of hunger and future energy intake $(65,66)$. Slower eating rates allow for more time for physical and chemical processes to take place. This lengthening of time course would suggest a subsequent reduction in energy intake. Thus, this is the main mechanism through which this strategy may be effective.

\subsubsection{Mindfulness}

Research suggests two main pathways through which mindfulness practice may impact energy intake and satiety. The first pathway is through the body's stress response system. The influence of mindfulness on the stress response may more likely be realized through chronic mindfulness practice or those practices and meditations of longer duration. The second pathway by which mindfulness may reduce energy intake and increase satiety is through increased cognitive control stemming from increased awareness of internal states. Long-term or long duration mindfulness practice is not required to achieve the benefits of increased cognitive control, however, long-term practice may enable the practitioner to more easily achieve a mindful state $(101,109)$.

First, long-term mindfulness-based practices have been shown to decrease perceived stress $(48,50)$, thus, decreasing the hyper-reactivity of cortisol awakening response $(49,113)$, or the hypothalamic-pituitary-adrenal or HPA axis (114). Stress, whether emotional or physiological, causes an increase in corticotrophin-releasing factor (CRF) from the paraventricular nucleus in the hypothalamus. CRF signals the anterior pituitary to release adrenocorticotropic (ACTH) hormone systemically. As ACTH reaches the adrenal cortex, it is stimulated to release glucocorticoids, particularly cortisol, into the system (115). Cortisol binds to glucocorticoid receptors on adipocytes and activates the lipoprotein lipase, which converts circulating trigylcerides into free fatty acids in 
adipocytes (114). The combination of increased cortisol and increased insulin mobilizes amino acids and free fatty acids to the abdominal region for use by the liver for gluconeogenesis and ketones for energy use by the brain (116). This can cause an increase in abdominal fat. Also, stress can increase emotional eating, triggering an increase in the consumption of fat and sugar (73-77). This combination has been shown to cause an up-regulation of the neuropeptide $Y$ in rodents (117), which can lead to fat angiogenesis and proliferation and differentiation of new adipocytes (117, 118).

Additional research suggests that chronic mindfulness-based practice may alter telomerase activity. A pattern in correlations has been shown between increases in telomerase activity and improvements in psychological distress, eating behavior and metabolic health, suggesting that telomerase activity may be regulated in part by psychological and metabolic stress (38). Telomerase is an enzyme that helps to protect healthy cell function and long-term immune function by adding telemetric repeat sequences to chromosomal DNA ends, thereby protecting DNA from degradation, fusion and biological aging (119). Mindfulness practice may lessen the stress response and thus, these harmful effects.

Second, short duration or brief mindfulness-based approaches have also been thought to impact energy intake by increasing awareness of internal states and cognitive control of eating behaviors. Physiological causes of stress eating or other types of emotional eating include poor awareness of internal states and inability to differentiate between hunger cues and emotional arousal (78-81). The concept of mindfulness or a moment-to-moment awareness allows stress or emotional eaters to become aware of and differentiate between internal and external cues, thereby reducing the stress that may accompany eating situations (46). Mindfulness-based interventions have also been shown to improve self-efficacy (45) and reduce dichotomous "all or none" thinking, 
also called rigid restraint $(48,51)$. Restrained eaters who are rigid are able to cognitively control their eating behaviors under usual circumstances but seem to lose that control and overeat during stressful situations (120). Rigid restraint has been associated with increased risk for eating problems compared with flexible restraint (120). Unlike rigid restraint, flexible restraint is a less strict form of dietary control. Rather than "all or none" thinking, flexible restraint is focused on moderation and minimal consumption of less healthy choices without guilt. Additionally, flexible restraint has been associated with a healthier BMI $(121,122)$.

Eating is often utilized to cope with negative mental states such as anxiety and depression. The repeated use of eating as a coping strategy could increase the probability of conditioned urges to eat even when a need for energy is lacking (123). Results from studies employing mindfulnessbased strategies have shown an improvement in coping skills and an ability to deal with food cravings in the presence of internal or external stressors $(51,56)$.

\subsection{SUBJECT CHARACTERISTICS AFFECTING ENERGY INTAKE AND SATIETY}

Due to the complexity of eating behavior, several factors have the potential to affect the measurement of energy intake and satiety. Physiological confounders such as bodyweight, age, and gender can moderate the relationship between eating strategies and energy intake and satiety (32). Other behavioral confounders can also impact this relationship, including dietary restraint, social environment, prior knowledge about test foods, habitual diet, physical activity, and alcohol use (32). Because of this potential impact, these confounders should be addressed in studies investigating behavioral strategies and energy intake and satiety and will be discussed here. 


\subsubsection{Weight Status of Subjects}

Subjects of different weights may respond differently to behavioral eating strategies. First, subjects with increased body weight may have increased energy requirements compared with normal weight subjects. Second, some research suggests that the physiological factors affecting appetite control, including gastric distention (124) and gut and satiety hormones such as ghrelin (125) and peptide YY $(126,127)$, may differ between lean and obese people. These differences have the potential to influence the results of energy intake and satiety studies. A previously described study conducted by Shah et al., compared 35 overweight/obese men and women to individuals of normal weight. The results of this study indicate that, unlike normal weight men and women, overweight/obese men and women did not experience a significant reduction in energy intake when eating slowly compared with eating quickly (98). Because of the results from previous research, the weight status of participants should be taken into consideration as a potential physiological confounder.

\subsubsection{Gender of Subjects}

For several reasons, gender may be a potential physiological cofounder in energy intake and satiety research. As with those with a lower weight, women may have lower energy requirements than men. Because women are typically smaller than men, it is likely that their energy intake will be lower (32) and this difference is evidenced by NHANES data (89). Additionally, energy intake in females has been shown to fluctuate in concordance with hormonal changes during their menstrual cycle, with energy intake decreased during the luteal phase (128). For example, in a previously described 2007 study by Martin et al., the slow eating resulted in a decreased energy intake for 
men, but not women, indicating that gender may modify the effects of eating rate on acute energy intake (30). A study by Jordan et al. examined the ability of trait mindfulness to predict snack choice. Analysis from this study indicated that gender was related to mindfulness, with men statistically more mindful than women. This study was one part of a 4-part study and no gender effects were seen in the other 3 sub-studies (54). However, because of this finding and that of other studies, the effects of gender on energy intake should be taken into consideration. Also, menstrual cycle phase should be noted and controlled for as a potential confounder in energy intake research.

\subsubsection{Dietary Restraint}

Dietary restraint can be defined as "the tendency to restrict food intake in order to maintain or lose bodyweight" (32). Dietary restraint is commonly associated with other dieting behaviors and can impact energy intake as well as satiety. A 2012 study by Privitera, Cooper, and Cosco investigated the influence of eating rate on dietary intake in participants with high ratings of dietary restraint. Participants scoring 18 or greater on the Three-Factor Eating Questionnaire were considered to exhibit high dietary restraint and were included in two variations in this study. In variation 1, participants received instructions to eat fast or slow with participants in the slow group specifically instructed to take small bites and to completely swallow each bite before taking the next. In variation 2, no instructions were given other than to eat until they were full or satisfied. Energy intake was assessed as weight in grams and converted to calories. Results from this study indicate that in participants exhibiting high dietary restraint, eating slower did not lead to a decrease in energy intake (26). Because of the potential impact of dietary restraint on both energy intake and satiety, assessment of this characteristic is required. The Three-Factor Eating 
Questionnaire is commonly used by investigators to assess the potential impact of dietary restraint on aspects of eating behavior (32) and therefore, was also used for this investigation.

\subsection{EFFECT OF BEHAVIORAL EATING STRATEGIES ON SUBJECTIVE FEELINGS OF SATIETY}

\subsubsection{Eating Rate}

Several studies have concluded that a reduced eating rate can positively impact satiety. Martin et al., demonstrated that for both men and women, slower eating in the reduced-rate and combinedrate meals resulted in a decreased rating of desire to eat on a continuous visual analogue scale from 0 to 100 that was normalized for the amount of food consumed (30). In a 2008 Andrade et al. study, women who ate quickly rated their satiety sufficiently lower than women who ate slowly, despite having consumed more calories. For this study, satiety was measured using a validated 10-cm visual analogue scale anchored with the statements "not at all" and "extremely" (25). Their follow-up study in 2012 assessed satiety with the same validated 10 -cm visual analogue scale. Ratings for hunger, satiety, and desire to eat did not differ between slow and quick eating conditions (29). Also, Shah and colleagues demonstrated that there was no significant interaction effect of eating condition (slow and quick) by weight status (normal weight and overweight/obese). However, researchers found a significant effect of eating condition (slow and quick) by time in both normal weight and overweight/obese men and women for hunger, fullness, and desire to eat. Similar to other studies, this investigation assessed hunger, fullness and desire to eat with validated 100-mm visual analogue scales (98). A previously described study by Privitera et al. which 
manipulated eating rate in participants exhibiting high dietary restraint also resulted in enhanced satiety in the slow eating group (26). Based on the results from these studies, it can be concluded that a decreased eating rate has the potential to increase satiety, but additional research is warranted.

\subsubsection{Mindfulness}

Evidence also suggests that mindfulness-based eating strategies may positively impact satiety and fullness. In a previously described study by Fisher, Lattimore, and Malinowski, participants were randomized to a standard food cue exposure condition or a food cue exposure following a brief mindful attention induction. Not only did the brief mindful attention induction result in a significant decrease in energy intake but also in a significant increase in subjective fullness ratings on a $0-100 \mathrm{~mm}$ VAS compared with the standard group (104). However, similar to results on energy intake, the positive impact of mindfulness on satiety seems to be limited to smaller portions. In the 2014 study from Cavanagh et al., there was no difference between the mindful and control conditions on ratings of sensations of hunger, satiety or taste with neither group rating those sensations as more influential on food intake than the amount of food available (47). This evidence suggests that a brief mindfulness-based intervention may result in increased satiety when portion sizes remain small to moderate. The effect of these interventions in the presence of a larger portion size remains unclear. 


\subsection{CONCLUSION}

An understanding of the effect of recommended behavioral eating strategies on acute energy intake and satiety is of the utmost importance for behavioral weight management programs that focus on the treatment of obesity. However, while these recommendations to reduce intake are commonly prescribed, the relationship between these strategies and energy intake and satiety has not been fully investigated. Potential mechanisms driving these relationships have been described here, yet the effects of these behavioral strategies on energy intake and satiety remain unclear. As suggested by previous investigations, potential physiological and behavioral confounders warrant explorations. It is hypothesized that slow eating and mindful strategies will reduce energy intake and increase satiety, which could subsequently impact body weight. However, no studies have compared these two strategies. Thus, the current study aimed to investigate the effect of mindful and slow eating strategies on acute energy intake and satiety in adult men and women. 


\subsection{METHODOLOGY}

\subsection{SUBJECTS}

A total of 24 participants were recruited to participate in this study. Subjects were between the ages of 18 - 55 years and had a BMI between $18.5-39.9 \mathrm{~kg} / \mathrm{m}^{2}$. Subjects were also able to provide informed consent.

Exclusionary criteria for the study were:

1) Currently pregnant and/or lactating or pregnant and/or lactating during the previous 6 months

2) Current diagnosis of an eating disorder or current treatment for other psychological issues, taking psychotropic medications, or having received treatment with psychotropic medications within the previous 6 months

3) Current diagnosis of any medical condition that may alter metabolism (i.e., thyroid disease) and/or current use of medications that could affect weight or eating patterns (i.e. synthroid)

4) Reporting irregular menstrual cycles ( $<25$ days or $>35$ days between cycles)

5) Previous or current mindfulness practice ( $>1$ day of meditation per week over the past month) 
6) Self-report of current rate of slow eating (self-report of "very slow" usual eating rate compared to other people)

7) Allergy to any food ingredient included in the pre-load and condition meals (i.e., dairy, gluten, etc.)

8) Dislike of any food included in the pre-load and condition meals (i.e., macaroni and cheese and meal replacement shakes)

9) Currently trying to lose or gain weight

10) History of bariatric surgery (i.e., lap-band, Roux-en-Y gastric bypass, etc.)

\subsection{RECRUITMENT AND SCREENING PROCEDURES}

Participants were recruited through local advertisements and recruitment fliers and were instructed to call the Physical Activity and Weight Management Research Center (PAWMRC) for additional information and to see if they would be eligible to participate in the study. Callers who remained interested were taken through a brief phone screen to determine initial eligibility (APPENDIX B). Participants were recruited into 1 of 4 groups with 6 people in each group: 1) male and BMI $<30.0$ $\mathrm{kg} / \mathrm{m}^{2}$, 2) male and BMI $\geq 30.0 \mathrm{~kg} / \mathrm{m}^{2}, 3$ ) female and BMI $<30.0 \mathrm{~kg} / \mathrm{m}^{2}$, and 4) female and BMI $\geq 30.0 \mathrm{~kg} / \mathrm{m}^{2}$. If deemed initially eligible for the study, research participants were scheduled for an orientation/baseline assessment visit to provide consent and to confirm eligibility.

During the participant's orientation/baseline assessment visit, the study procedures were described in detail and participants were given the opportunity to ask any questions regarding the study prior to signing the consent document (APPENDIX A). The Institutional Review Board at the University of Pittsburgh approved all study procedures. 


\subsection{EXPERIMENTAL DESIGN}

Subjects reported to the PAWMRC on three separate occasions: 1) orientation/baseline assessment visit, 2) first test meal session, 3) second test meal session. This study implemented a randomized experimental design in which participants were block randomized by gender and BMI (1) male and $\left.\mathrm{BMI}<30.0 \mathrm{~kg} / \mathrm{m}^{2}, 2\right)$ male and $\mathrm{BMI} \geq 30.0 \mathrm{~kg} / \mathrm{m}^{2}$, 3) female and $\mathrm{BMI}<30.0 \mathrm{~kg} / \mathrm{m}^{2}$, and 4) female and BMI $\geq 30.0 \mathrm{~kg} / \mathrm{m}^{2}$ ) to an eating strategy condition after completion of the baseline assessment visit. Block randomization was conducted in this manner in congruence with previous research (129) and in order to address the exploratory aims. The two test meal sessions were separated by at least two days and were conducted between days 7 and 21 of a female participant's menstrual cycle in order to minimize the effect of hormone concentrations on satiety outcome measures.

\subsubsection{Baseline Assessment Visit}

Upon arrival to the research center and after providing informed consent, participants underwent formal baseline assessment of height and weight (APPENDIX C) and completed questionnaires including demographics and the Three-Factor Eating Questionnaire (TFEQ) (100) (APPENDIX D). After completion of the assessment visit, participants were provided with a standardized liquid meal replacement to take home and consume on the morning of their test meal sessions. The macronutrient composition of this meal replacement was 350 calories, $28 \%$ fat, $57 \%$ carbohydrate, and $15 \%$ protein. Participants were be given guidelines to adhere to prior to their test meal sessions (APPENDIX E). The guidelines included: 1) consume the liquid meal replacement on the morning of testing, 4 hours prior to their scheduled testing time, 2) abstain from all other food or beverages, 
with the exception of water, on the morning of the testing session, 3) abstain from structured moderate to vigorous intensity physical activity for 12 hours prior to their visit, 4) abstain from consuming alcohol for 12 hours prior to their visit, and 5) abstain from consuming caffeine for 12 hours prior to their visit. After the orientation/baseline assessment, participants were block randomized by previously described gender and BMI groups into 1 of 3 eating strategy conditions: EAT, MIND, or SLOW. See Figure 3.

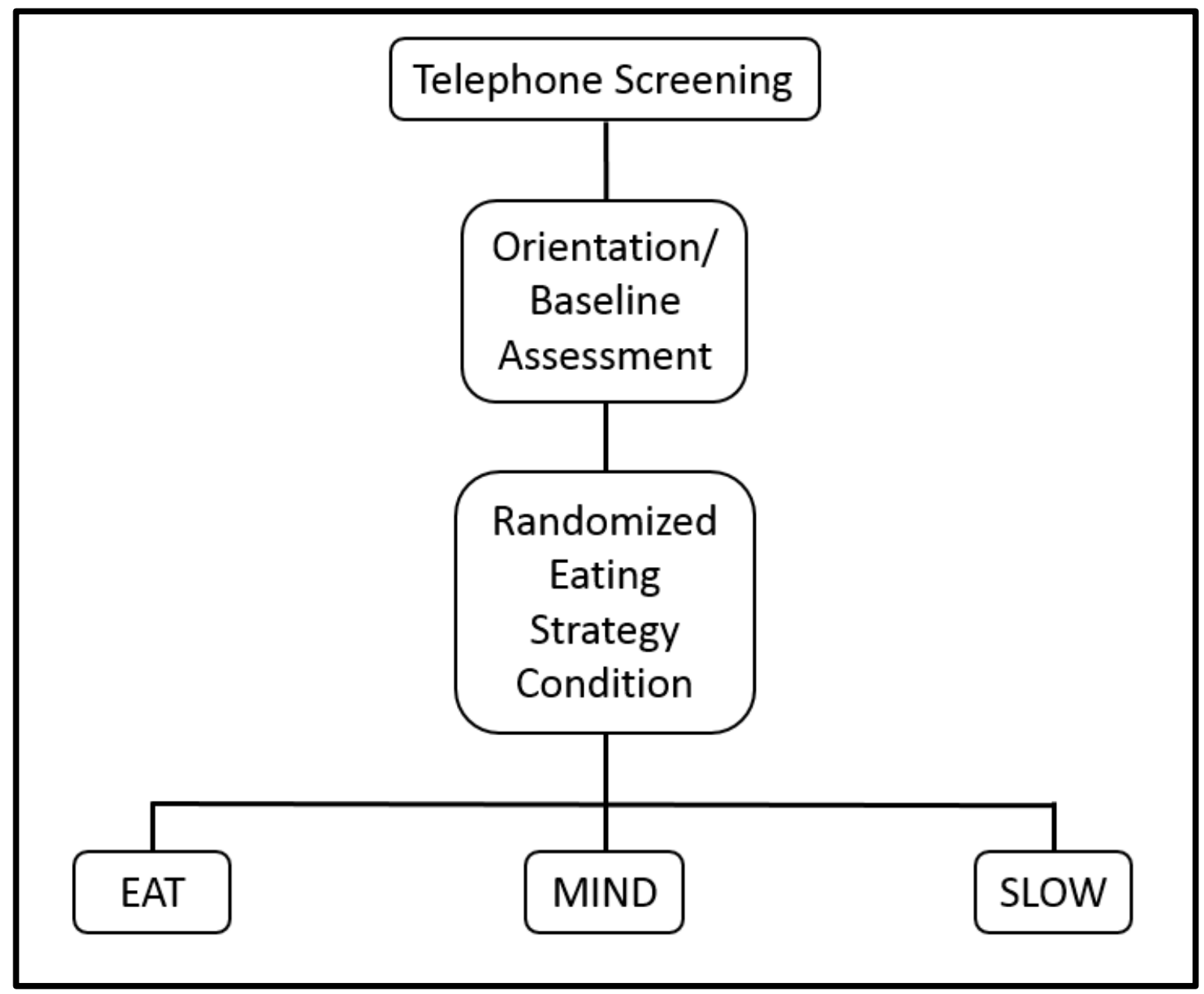

Figure 3. Experimental Flow Diagram 


\subsubsection{Test Meal Sessions}

Participants reported to the PAWMRC on the morning of their test meal sessions and adherence to the pre-testing guidelines was verified. If a participant did not follow the guidelines, he or she was rescheduled for another date. Following verification, each one was asked to complete the Positive and Negative Affect Scale (PANAS) (101) (APPENDIX I). Following the completion of this questionnaire, the participant was escorted to a small, private conference room and was seated alone. Each individual was instructed to place all of their personal items in a locked drawer. Testing procedures were reviewed and a member of the study staff read a standardized script with information and instructions regarding the test meal (APPENDIX $\mathrm{F}, \mathrm{G}$, and $\mathrm{H}$ ). In order to standardize meals across time and between groups and to ensure participants could eat until “comfortably full”, pre-portioned, packaged, family-size microwavable macaroni and cheese portions were served. The family-sized portion of Stouffer's macaroni and cheese had the following energy content and macronutrient composition: 1550 calories, $46 \%$ fat, $36 \%$ carbohydrate, and $17 \%$ protein. Test meals were prepared via microwave according to package instructions. Prior to distribution to the participant, test meals and provided water were weighed using a digital food scale. After the meal was distributed, participants listened to a standardized audio recording containing instructions for the test meal session. All participants took part in the "control eating session" during their second visit and their randomized condition on their third visit. All sessions were video recorded for later review to assess adherence to the eating strategies and to calculate meal duration. See Figure 4. 
Visit 1: Orientation/Baseline Assessment

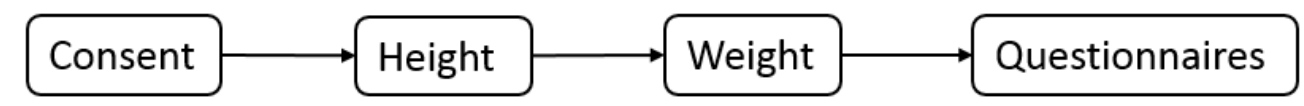

Also during this visit, subjects:

- Scheduled 2 test meal sessions

- Were given a liquid meal replacement for the morning of their testing visit

\section{Visit 2 \& 3: Control and Randomized Test Meal Sessions}

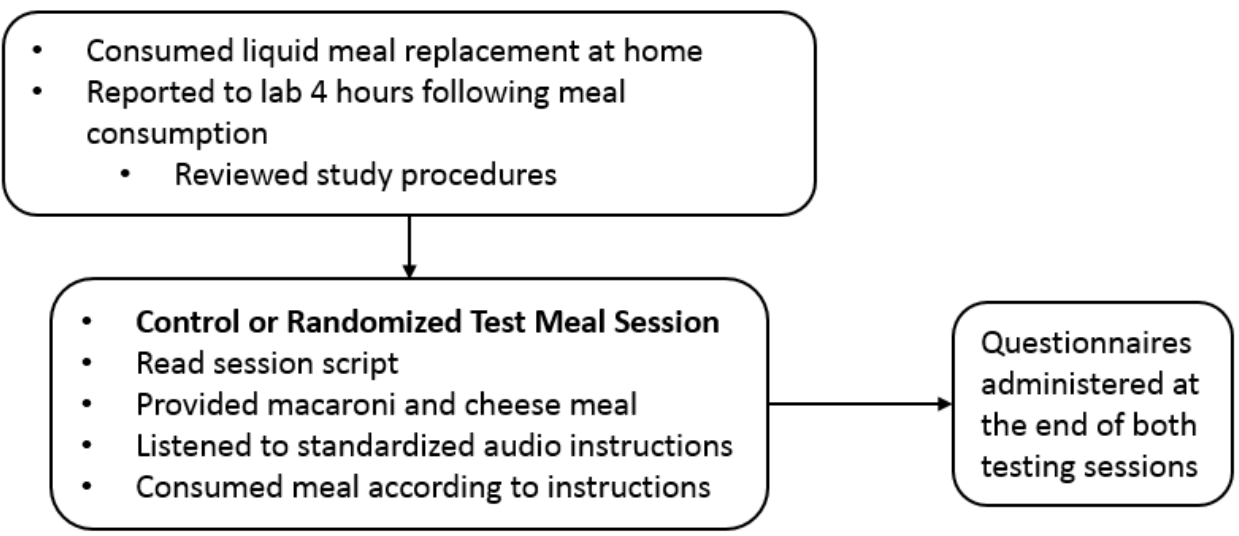

Figure 4. Experimental Design

\subsubsection{Control Eating Strategy Condition (EAT)}

Participants randomized to the EAT condition followed the study protocol depicted in Figure 5. This group served as the control condition. During visit 2, participants listened to a standardized audio recording (APPENDIX F) that contained information for the test meal including a neutral, non-eating-related passage on the national park system and instructions to eat until they are "comfortably full" and to consume as much or as little water as they would like.

On their third visit, participants randomized to the "EAT" condition also followed the instructions as just described; however, for the third visit, the neutral, non-eating-related passage was about tiny vacation homes. See APPENDIX F for scripts and data collection forms. 


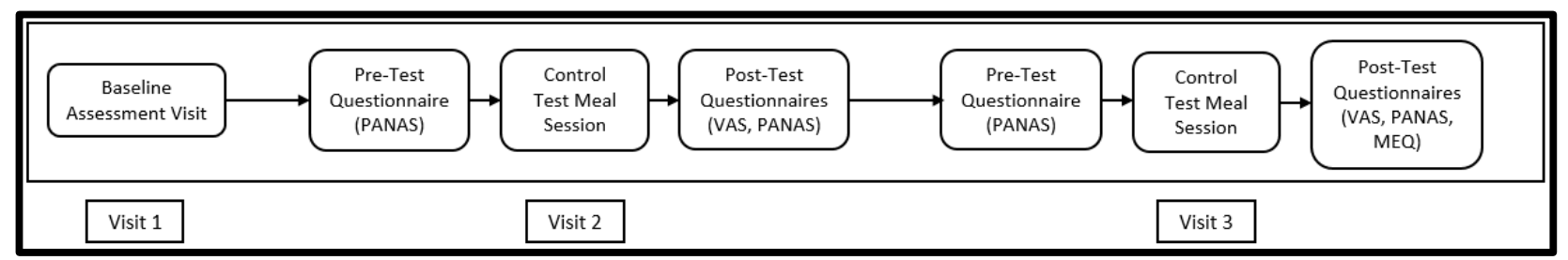

Figure 5. Protocol for EAT condition

\subsubsection{Slow Eating Strategy Condition (SLOW)}

Participants randomized to the SLOW condition followed the study protocol depicted in Figure 6. For those subjects randomized to the SLOW condition, they participated in the control test meal session on their second visit. During the control test meal session, participants listened to a standardized audio recording (APPENDIX F) that contained information for the test meal including a neutral, eating-unrelated passage on the national park system and instructions to eat until they are "comfortably full" and to consume as much or as little water as they would like.

Then, they participated in the slow eating test meal session on their third visit. During the slow eating test meal session, participants listened to a standardized audio recording (APPENDIX G) that contained information for the test meal including instructions to put their fork down in between bites, chew each bite at least 15-30 times, and swallow completely before picking up their fork for the next bite. The recording also instructed participants to eat until they are "comfortably full" and to consume as much or as little water as they would like. See APPENDIX G for scripts and data collection forms.

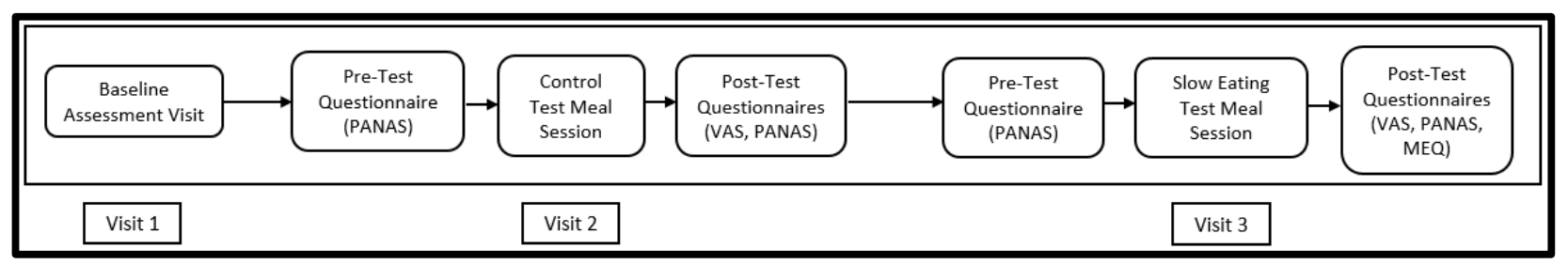

Figure 6. Protocol for SLOW condition 


\subsubsection{Mindful Eating Test Meal Session (MIND)}

Participants randomized to the MIND condition followed the study protocol depicted in Figure 7. For subjects randomized to the MIND condition, subjects participated in the control test meal session on their second visit. During the control test meal session, participants listened to a standardized audio recording (APPENDIX F) that contained information for the test meal including a neutral, eating-unrelated passage on the national park system and instructions to eat until they are "comfortably full" and to consume as much or as little water as they would like.

The third visit consisted of a mindful eating test meal session. During the mindful eating test meal session, participants listened to a standardized audio recording (APPENDIX $\mathrm{H}$ ) that contained information for the test meal including instructions on how to consume the meal mindfully, including taking deep breaths, staying aware of and rating their hunger, and savoring the meal by focusing on the taste, smell, texture, and color of the food. The recording also instructed participants to eat until they are "comfortably full" and to use the provided water to cleanse their palate between bites. See APPENDIX H for script and data collection form.

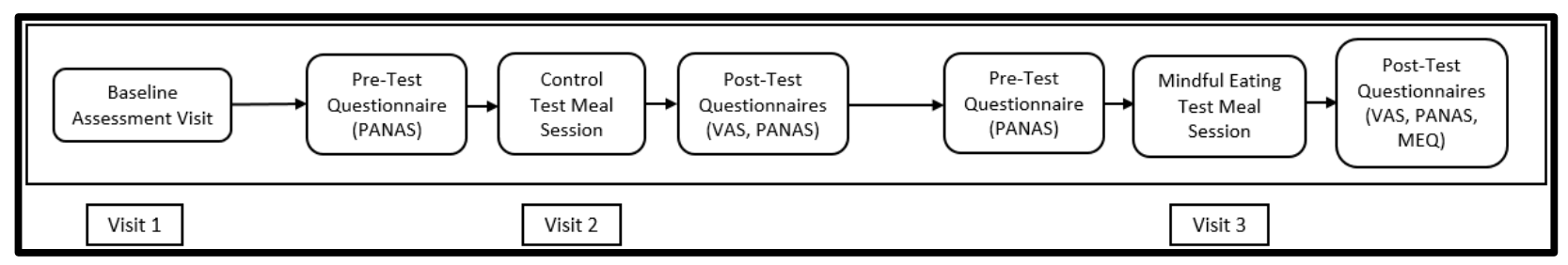

Figure 7. Protocol for MIND condition

\subsubsection{Post-Test Meal Session Questionnaires}

After completion of each test meal session (visits 2 and 3), the participant completed the PANAS questionnaire (APPENDIX I), and visual analogue scales for hunger, satiety (APPENDIX I) and meal satisfaction (APPENDIX I). Additionally, after the second meal session (visit 3), all participants also completed the awareness and distraction subscales of the Mindful Eating 
Questionnaire (MEQ) (129). This questionnaire was not given after the first meal test session due to the possibility of a carryover effect.

In order to blind subjects to the fact that energy intake was the primary outcome of the study, a meal satisfaction and enjoyment questionnaire was given to participants after each test meal session (visits 2 and 3). After the participant departed the PAWMRC (following visits 2 and 3), food and water was weighed again using a digital food scale.

\subsection{ASSESSMENT COMPONENTS}

Assessments and test meal sessions were conducted at the University of Pittsburgh Physical Activity and Weight Management Research Center (PAWMRC) on weekdays and between the hours of 10:00 am and 3:00 pm. Each assessment took approximately 30-45 minutes to complete. Participants were given a stipend of $\$ 50$ upon completion of all test meal sessions.

The following measures were completed at the baseline assessment visit only:

\subsubsection{Height}

Height was measured using a wall-mounted stadiometer. This measurement was used to calculate body mass index (BMI). The subject's height was measured to the nearest $0.1 \mathrm{~cm}$. An average of two heights was taken. If the first two height measurements differed by more than $0.5 \mathrm{~cm}$, a third measurement was taken and the average of the two closest height measurements was used for BMI computation. 


\subsubsection{Body Weight}

Body weight was measured using a Tanita digital scale with participants wearing light-weight clothing with shoes and pocket items removed. The participant's weight was measured to the nearest $0.2 \mathrm{~kg}$. If the first two weight measurements differed by more than $0.5 \mathrm{~kg}$, a third measurement was taken and the average of the two closest weight measurements was used to compute BMI.

\subsubsection{Dietary Restraint}

Eating (cognitive) restraint, eating disinhibition, and perceived hunger was assessed with the 51item Three Factor Eating Questionnaire (TFEQ) developed to assess behaviors conducive to weight management (100). Cognitive restraint, defined as conscious attempts to monitor and regulate food intake, was assessed from 21 items. Eating disinhibition, defined as dysregulation of eating in response to cognitive or emotional cues, was assessed from 16 items. Hunger, or perceptions of hunger, was assessed from 14 items on this questionnaire. Dietary restraint as measured by the TFEQ has been suggested to be associated with 'disinhibition' and therefore, a potential behavioral confounder in studies investigating satiety (32).

The following measure was completed prior to and after each test meal session:

\subsubsection{Positive and Negative Affect}

Positive and negative affect was measured prior to and following each test meal session using the Positive and Negative Affect Schedule (PANAS) (101). The PANAS is comprised of 2-10 item 
mood scales that have been shown to be both reliable and valid. Because the scale was completed both pre and post-test meal session, moment instructions were used to gauge how participants felt in the present moment. For moment instructions, internal consistency reliability is 0.89 for the positive and 0.85 for the negative affect scale.

The following measures were taken immediately after each test meal session:

\subsubsection{Measurement of Energy Intake}

Energy intake (kcals) was assessed based upon the subject's food consumption during the test meal sessions. During the test meal sessions, participants were provided with macaroni and cheese and were instructed to eat until they were "comfortably full" following the standardized audio recording instructions. Participants were unaware that their food intake was being monitored. The macaroni and cheese was weighed prior to distribution to the participant and then again after the participant's departure from the PAWMRC. The difference in weights between the portion provided and the portion remaining after the test meal session was used to calculate energy intake (APPENDIX F, G, H).

\subsubsection{Satiety Questionnaire}

Satiety was assessed using a categorical visual analogue scale (VAS) format that has been modified from previous studies $(103,104)$ (APPENDIX I). It has been established that the measurement of satiety can be accomplished both through the direct measurement of food intake and through self-reported feelings of satiety. The VAS is typically used to document fullness or satiety (32). For example, participants are asked, "how full do you feel right now?" with responses 
including "not full at all", "not full”, "not very full”, "neutral”, "full”, "very full”, or "very, very full".

\subsubsection{Meal Satisfaction/Enjoyment Questionnaire}

Meal satisfaction and enjoyment were measured after each test meal session. These questions used a categorical visual analogue scale format that has been modified from previous studies $(103,104)$ (APPENDIX I). For example, participants were asked questions similar to "how satisfied were you with the visual appeal of the macaroni and cheese?" Responses included "not satisfied at all", "not satisfied", "not very satisfied", "neutral", "satisfied", "very satisfied", and "very, very satisfied".

The following measure was completed after the second test meal session only:

\subsubsection{Mindful Eating Adherence}

In order to measure adherence to the mindful eating test meal session and to examine if general awareness increased across groups, all participants (EAT, MIND, and SLOW) completed the awareness and distraction subscales of the Mindful Eating Questionnaire (MEQ) (129) (APPENDIX I). Participants in the MIND condition were considered adherent if their mean MEQ score was $\geq 2.5$, indicating that adherence during the test meal session was more often than "sometimes". 


\subsubsection{Slow Eating Adherence}

The videotape recording was used to measure adherence to the slow eating strategy. Apriori, participants who followed the strategy for $\geq 80 \%$ of the slow eating test meal session were considered to be adherent. However, review of these videotapes showed that $100 \%$ of participants were adherent to the slow eating strategy.

\subsection{STATISTICAL ANALYSIS}

Descriptive analyses were performed for subject characteristics (age, BMI, race, ethnicity, education) as well as dietary restraint. Several one-way analysis of variance (ANOVA) were conducted to determine differences between baseline descriptive characteristics and randomized eating strategy conditions. Mean or median energy intake and satiety level was reported for each time point.

First, a 3 X 2 mixed (ANOVA) was used to examine acute energy intake at two test meal time points and between three strategy conditions. The main effect of condition (strategy) was examined to determine if there was a significant difference in intake between EAT, MIND, and SLOW conditions averaged across the two test meals. The main effect of time was examined to determine if there was a significant difference in energy intake between time points (first and second test meal session) averaged across eating strategy conditions (EAT, MIND, SLOW). An interaction effect was analyzed to determine if the difference in energy intake between the first test meal session (control eating session) and second test meal session (randomized eating session) was different among strategy conditions (EAT, MIND, SLOW). If differences were found, post-hoc 
tests using a Bonferroni adjustment were conducted. The assumption of normality was checked using the Shapiro-Wilk test and the assumption of homogeneity of variance was tested using the Brown-Forsythe test.

Second, to determine if satiety or eating rate were different between conditions (EAT, MIND, SLOW) over time (test meal session 1, test meal session 2), mixed 3 X 2 ANOVAS were performed. The main effect of condition, the main effect of time, and the time $\mathrm{X}$ condition interaction were analyzed and post-hoc analysis were performed when differences existed.

Finally, to address the exploratory analysis and in order to determine if BMI (time X condition $\mathrm{X} \mathrm{BMI}$ ), gender (time $\mathrm{X}$ condition $\mathrm{X}$ gender), or dietary restraint (time $\mathrm{X}$ condition $\mathrm{X}$ level of dietary restraint) moderated these findings, multiple ( 2 X 3 X 2) ANOVAS were performed using satiety or eating rate.

Pearson or Spearman correlations were performed between the continuous descriptive variables and energy intake or satiety at either time point to examine if any of these variables needed to be controlled for in the primary analysis. ANOVAs were performed between categorical descriptive variables and energy intake or satiety at either time point to examine if any of these variables needed to be controlled for in the primary analysis. If a variable was found to be significantly correlated with one of the primary outcome measures, an ANOVA and an ANCOVA (ANOVA including the variable as a covariate) was performed and results from the ANCOVA were reported if the covariate was found to impact the results. All statistical analysis were performed using SPSS for Windows (SPSS Inc., Chicago, IL) and the alpha level was set at $\mathrm{p}<$ 0.05 . 


\subsection{POWER ANALYSIS}

The primary aim of the study was to determine whether the implementation of two behavioral eating strategies had an effect on energy intake compared to a no-strategy control. Therefore, a power analysis was performed to provide an estimate of sample size. We considered a minimal clinically meaningful difference in energy intake between test meal sessions to be 65 calories. Based upon previous research comparing eating rates, the standard deviation of baseline calorie intake is 155 kcals during an acute laboratory meal (29). Using this information as a proxy for variability in change, the power calculation was based on a moderate effect size of 0.42 . Power analysis was performed using G*Power 3.1.9.2 (Faul, Erdfelder, Lang, \& Buchner, Universität Kiel, Germany). Correlation of repeated measures was set at 0.5 and nonsphericity correction $\varepsilon$ at 1.0 assuming that the assumption of sphericity will be met. A total of 24 subjects needed to participate to detect an effect size of 0.42 when statistical power was set at 0.80 and alpha at 0.05 . Therefore, a total of 24 subjects were recruited for this study and 8 participants were randomized to each condition. 


\subsection{RESULTS}

The purpose of this study was to examine the effects of a mindful and a slow eating strategy on acute energy intake and to compare these strategies to a no-strategy control. This study utilized a randomized control design and the results from this investigation are presented in the sections below.

\subsection{SUBJECTS}

Twenty-four normal weight to obese men and women (median BMI: 29.1 (24.3- 36.70 kg/m²) between the ages of 18 and 55 (median: $24.0\left[25^{\text {th }}, 75^{\text {th }}\right.$ percentiles: $\left.21.0,31.8\right]$ years) were recruited for this study. An equal number of subjects (12) were classified as having a BMI $<30.0$ $\mathrm{kg} / \mathrm{m}^{2}$ and $\mathrm{BMI} \geq 30.0 \mathrm{~kg} / \mathrm{m}^{2}$. Participants were not equally distributed among BMI classifications with 10 subjects classified as normal weight (BMI: $18.5-24.9 \mathrm{~kg} / \mathrm{m}^{2}$ ), 2 subjects classified as overweight (BMI: 25.0 - $29.9 \mathrm{~kg} / \mathrm{m}^{2}$ ), 3 subjects classified as Class I obese (BMI: 30.0 - 34.9

$\mathrm{kg} / \mathrm{m}^{2}$ ), and 9 subjects classified as Class II obese (BMI: $\left.35.0-39.9 \mathrm{~kg} / \mathrm{m}^{2}\right)$. Complete data were collected for all 24 subjects (see Figure 8). 


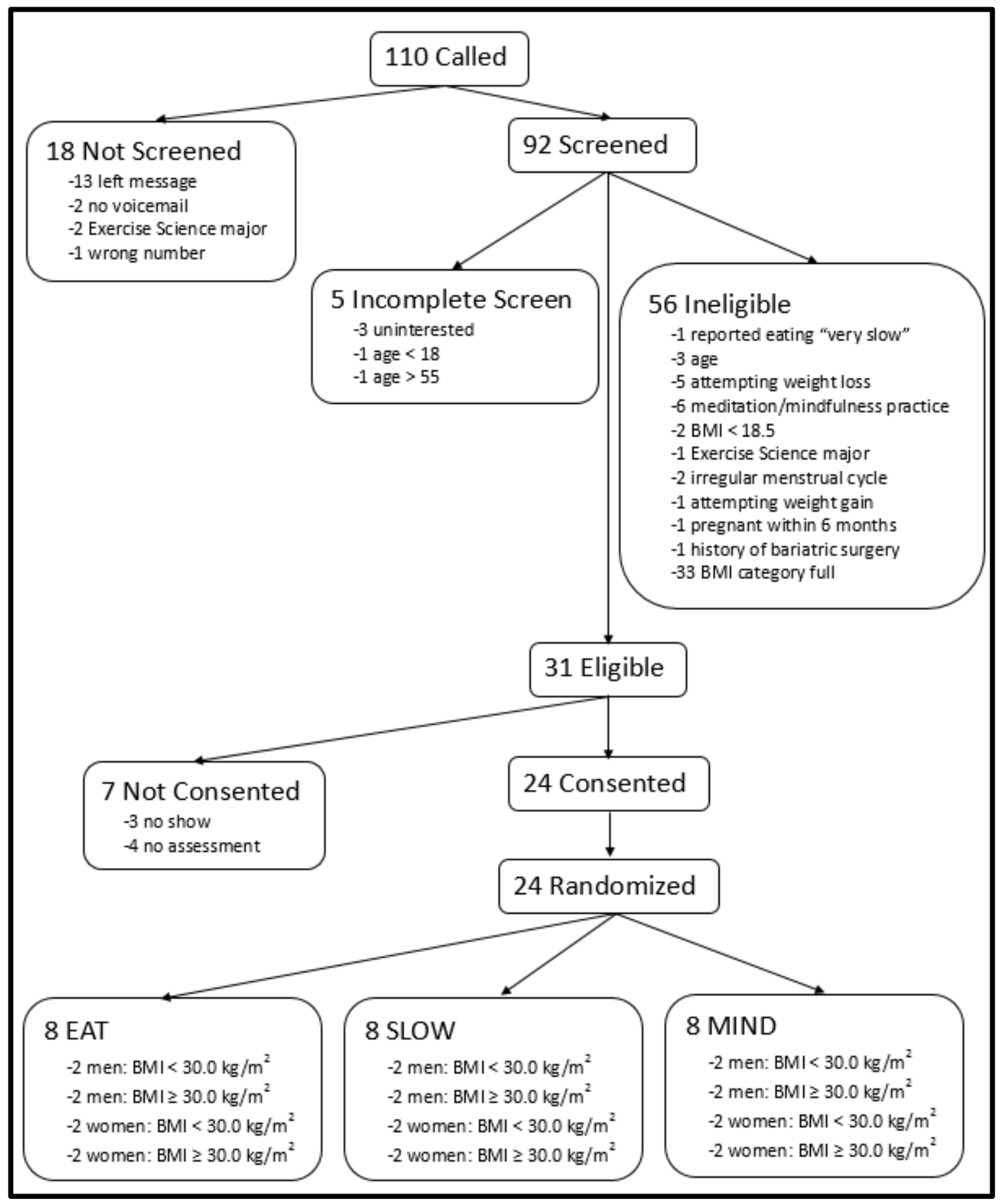

Figure 8. Study enrollment and randomization

Baseline characteristics for the total sample and for each randomized eating condition are shown in Table 1. There were no significant differences between randomized eating condition 
groups and age, BMI, gender, race, ethnicity, education, and measures of dietary restraint. By design, an equal number of males and females were randomized into each condition.

Table 1. Baseline Characteristics

\begin{tabular}{|c|c|c|c|c|c|}
\hline & $\begin{array}{l}\text { All groups } \\
(n=24)\end{array}$ & $\begin{array}{c}\text { EAT } \\
(n=8)\end{array}$ & $\begin{array}{l}\text { MIND } \\
(n=8)\end{array}$ & $\begin{array}{l}\text { SLOW } \\
(n=8)\end{array}$ & p-value \\
\hline Age (years) ${ }^{*}$ & $\begin{array}{c}24.0(21.0,31.8) \\
{[20.0-54.0]}\end{array}$ & $\begin{array}{c}24.0(21.0,31.3) \\
{[20.0-44.0]}\end{array}$ & $\begin{array}{c}28.0(22.0,33.5) \\
{[21.0-54.0]}\end{array}$ & $\begin{array}{c}21.5(21.0,24.8) \\
{[21.0-33.0]}\end{array}$ & 0.292 \\
\hline BMI $\left(\mathrm{kg} / \mathrm{m}^{2}\right)^{*}$ & $\begin{array}{c}29.1(24.3,36.7) \\
{[21.0-39.3]}\end{array}$ & $\begin{array}{c}31.7(25.2,37.2) \\
{[22.0-37.3]}\end{array}$ & $\begin{array}{c}29.1(24.4,35.7) \\
{[22.3-39.2]}\end{array}$ & $\begin{array}{c}27.4(23.5,38.2) \\
{[21.0-39.3]}\end{array}$ & 0.906 \\
\hline Gender** & $\begin{array}{l}12(50.0 \%) \\
12(50.0 \%)\end{array}$ & $\begin{array}{l}4(50.0 \%) \\
4(50.0 \%)\end{array}$ & $\begin{array}{l}4(50.0 \%) \\
4(50.0 \%)\end{array}$ & $\begin{array}{l}4(50.0 \%) \\
4(50.0 \%)\end{array}$ & 1.00 \\
\hline Race $^{* *}$ & $\begin{array}{c}4(16.7 \%) \\
4(16.7 \%) \\
16(66.7 \%)\end{array}$ & $\begin{array}{l}1(12.5 \%) \\
1(12.5 \%) \\
6(75.0 \%)\end{array}$ & $\begin{array}{l}1(12.5 \%) \\
2(25.0 \%) \\
5(62.5 \%)\end{array}$ & $\begin{array}{l}2(25.0 \%) \\
1(12.5 \%) \\
5(62.5 \%)\end{array}$ & 0.828 \\
\hline $\begin{array}{l}\text { Ethnicity }^{* *} \\
\qquad \begin{array}{c}\text { Hispanic } \\
\text { Non-Hispanic }\end{array}\end{array}$ & $\begin{array}{c}1(4.2 \%) \\
23(95.8 \%)\end{array}$ & $\begin{array}{c}0(0 \%) \\
8(100 \%)\end{array}$ & $\begin{array}{c}0(0 \%) \\
8(100 \%)\end{array}$ & $\begin{array}{l}1(12.5 \%) \\
7(87.5 \%)\end{array}$ & 0.385 \\
\hline $\begin{array}{l}\text { Education }{ }^{* *} \\
\text { Finished some high school } \\
\text { High School graduate or GED } \\
\text { Some college or Associate Degree } \\
\text { College graduate or Baccalaureate Degree } \\
\text { Masters or doctoral Degree }\end{array}$ & $\begin{array}{c}1(4.2 \%) \\
3(12.5 \%) \\
8(33.3 \%) \\
9(37.5 \%) \\
3(12.5 \%)\end{array}$ & $\begin{array}{l}1(12.5 \%) \\
2(25.0 \%) \\
2(25.0 \%) \\
2(25.0 \%) \\
1(12.5 \%)\end{array}$ & $\begin{array}{c}0(0 \%) \\
0(0 \%) \\
2(25.0 \%) \\
4(50.0 \%) \\
2(25.0 \%)\end{array}$ & $\begin{array}{c}0(0 \%) \\
1(12.5 \%) \\
4(50.0 \%) \\
3(37.5 \%) \\
0(0 \%)\end{array}$ & 0.108 \\
\hline Cognitive Restraint Construct ${ }^{* * *}$ & $8.3 \pm 4.1$ & $6.5 \pm 4.7$ & $8.4 \pm 4.3$ & $10.1 \pm 2.9$ & 0.222 \\
\hline Disinhibition Construct*** & $5.5 \pm 2.7$ & $5.3 \pm 3.1$ & $5.9 \pm 2.5$ & $5.3 \pm 2.8$ & 0.877 \\
\hline Hunger Construct $* * *$ & $5.6 \pm 3.0$ & $5.8 \pm$ & $6.0 \pm 3.2$ & $5.0 \pm 3.2$ & 0.800 \\
\hline
\end{tabular}

\subsection{ANALYSIS OF DATA BY SPECIFIC AIM}

\subsubsection{Specific Aim 1: Comparison of Energy Intake in Three Eating Strategy Conditions}

The primary aim of this study was to compare acute energy intake in 3 eating strategy conditions:

a no-strategy control (EAT), a mindful eating strategy (MIND), and a slow eating strategy (SLOW). These data are presented in Table 2. 


\subsubsection{Energy Served}

While all provided study meals were from the same manufacturer, during data collection it was noted that not all meals had the same initial weight. Therefore, an additional repeated measures ANOVA was performed to examine differences in the amount of energy served across conditions and over time. There was no significant difference in energy served among eating strategy conditions (EAT, MIND, SLOW) at either test meal session (see Table 2).

Table 2. Condition differences in energy served, meal duration, and energy intake between test meal sessions

\begin{tabular}{|c|c|c|c|c|c|c|c|}
\hline & $\begin{array}{l}\text { All groups } \\
(n=24)\end{array}$ & $\begin{array}{c}\text { EAT } \\
(n=8)\end{array}$ & $\begin{array}{l}\text { MIND } \\
(\mathrm{n}=8)\end{array}$ & $\begin{array}{l}\text { SLOW } \\
(\mathrm{n}=8)\end{array}$ & Condition & Time & $\begin{array}{c}\text { Condition } \\
\text { X Time }\end{array}$ \\
\hline Energy Served (kcals) & & & & & 0.094 & 0.130 & 0.812 \\
\hline Test Meal Session 1 & $\begin{array}{c}1353 \\
(1323,1378)\end{array}$ & $\begin{array}{c}1363 \\
(1326,1381)\end{array}$ & $\begin{array}{c}1340 \\
(1303,1355)\end{array}$ & $\begin{array}{c}1363 \\
(1329,1378)\end{array}$ & & & \\
\hline Test Meal Session 2 & $\begin{array}{c}1345 \\
(1326,1356)\end{array}$ & $\begin{array}{c}1356 \\
(1331,1367)\end{array}$ & $\begin{array}{c}1324 \\
(1302,1344)\end{array}$ & $\begin{array}{c}1352 \\
(1332,1355)\end{array}$ & & & \\
\hline Eating Time $(\mathrm{sec})^{* *}$ & & & & & 0.094 & 0.004 & 0.019 \\
\hline Test Meal Session 1 & $\begin{array}{c}527.0 \\
(449.0,739.8)\end{array}$ & $\begin{array}{c}462.0 \\
(420.5,503.5)\end{array}$ & $\begin{array}{c}660.0 \\
(467.5,965.0)\end{array}$ & $\begin{array}{c}545.5 \\
(484.0,733.25)\end{array}$ & & & \\
\hline Test Meal Session 2 & $\begin{array}{c}623.5 \\
(478.8,799.8)\end{array}$ & $\begin{array}{c}486.0 \\
(389.0,578.8)\end{array}$ & $\begin{array}{c}673.5 \\
(495.5,1063.0)\end{array}$ & $\begin{array}{c}738.5 \\
(639.3,1124.8)\end{array}$ & & & \\
\hline Energy Intake (kcals) & & & & & 0.786 & 0.705 & 0.133 \\
\hline Test Meal Session 1 & $\begin{array}{c}778 \\
(617,958)\end{array}$ & $\begin{array}{c}785 \\
(503,953)\end{array}$ & $\begin{array}{c}772 \\
(550,945)\end{array}$ & $\begin{array}{c}738 \\
(627,1010)\end{array}$ & & & \\
\hline Test Meal Session 2 & $\begin{array}{c}763 \\
(627,964)\end{array}$ & $\begin{array}{c}848 \\
(704,1071)\end{array}$ & $\begin{array}{c}673 \\
(485,846)\end{array}$ & $\begin{array}{c}756 \\
(611,1076)\end{array}$ & & & \\
\hline
\end{tabular}

*All data presented as Median $\left(25^{\text {th }}, 75^{\text {th }}\right.$ percentile)

** p-values are based on analysis of log-transformed data

\subsubsection{Process Measures}

To measure adherence to the MIND eating strategy condition, all participants completed the Mindful Eating Questionnaire (MEQ) after the second test meal session. There was no significant difference in MEQ scores across eating strategy conditions $(\mathrm{p}=0.692)$, indicating that the MIND group did not report eating more mindfully than either the SLOW or EAT groups (see Table 3). 
Table 3. Condition differences in Mindful Eating score

\begin{tabular}{|l|l|l|l|l|l|}
\hline & $\begin{array}{c}\text { All groups } \\
(\mathbf{n}=\mathbf{2 4})\end{array}$ & \multicolumn{1}{|c|}{ EAT $(\mathbf{n}=\mathbf{8})$} & MIND (n=8) & SLOW $(\mathbf{n}=\mathbf{8})$ & p-value \\
\hline MEQ Score & $2.7(1.7,3.7)$ & $2.5(1.7,3.7)$ & $2.7(1.4,3.2)$ & $2.7(2.1,3.4)$ & 0.692 \\
\hline
\end{tabular}

${ }^{*}$ All data presented as Median $\left(25^{\text {th }}, 75^{\text {th }}\right.$ percentile $)$

To examine if general awareness increased across eating strategy conditions and over time (between test meal sessions), a repeated measures ANOVA was performed using change in alertness and attentiveness scores as measured by the PANAS (see Table 4). Alertness and attentiveness did not change over time. There was no significant difference in change in alertness or change in attentiveness among eating strategy conditions.

Table 4. Condition differences in change in alertness and change in attentiveness between test meal sessions

\begin{tabular}{|c|c|c|c|c|c|c|c|}
\hline & $\begin{array}{l}\text { All groups } \\
(\mathrm{n}=24)\end{array}$ & $\begin{array}{c}\text { EAT } \\
(n=8)\end{array}$ & $\begin{array}{l}\text { MIND } \\
(n=8)\end{array}$ & $\begin{array}{l}\text { SLOW } \\
(n=8)\end{array}$ & Condition & Time & $\begin{array}{c}\text { Condition } \\
\text { x Time }\end{array}$ \\
\hline Change in Alertness & & & & & 0.616 & 0.112 & 0.423 \\
\hline Test Meal Session 1 & $\begin{array}{c}-1.0 \\
(-1.0,0.0)\end{array}$ & $\begin{array}{c}-0.5 \\
(-1.0,1.5)\end{array}$ & $\begin{array}{c}-0.5 \\
(-1.8,0.0)\end{array}$ & $\begin{array}{c}-1.0 \\
(-1.0,0.0)\end{array}$ & & & \\
\hline Test Meal Session 2 & $\begin{array}{c}0.0 \\
(-1.0,1.0)\end{array}$ & $\begin{array}{c}0.0 \\
(-0.8,1.0)\end{array}$ & $\begin{array}{c}0.0 \\
(-1.0,0.0)\end{array}$ & $\begin{array}{c}0.0 \\
(-1.0,1.0)\end{array}$ & & & \\
\hline $\begin{array}{l}\text { Change in } \\
\text { Attentiveness }\end{array}$ & & & & & 0.450 & 0.279 & 0.178 \\
\hline Test Meal Session 1 & $\begin{array}{c}0.0 \\
(-1.0,0.8)\end{array}$ & $\begin{array}{c}0.0 \\
(-0.8,1.0)\end{array}$ & $\begin{array}{c}0.0 \\
(-1.5,0.8)\end{array}$ & $\begin{array}{c}-1.0 \\
(-2.0,0.0)\end{array}$ & & & \\
\hline Test Meal Session 2 & $\begin{array}{c}0.0 \\
(-1.0,1.0)\end{array}$ & $\begin{array}{c}0.0 \\
(-0.8,0.8)\end{array}$ & $\begin{array}{c}0.0 \\
(-1.0,0.8)\end{array}$ & $\begin{array}{c}0.0 \\
(-0.8,1.0)\end{array}$ & & & \\
\hline
\end{tabular}

*All data presented as Median $\left(25^{\text {th }}, 75^{\text {th }}\right.$ percentile)

\subsubsection{Meal Duration}

Results from the Shapiro-Wilk test indicated that the assumption of normality for meal duration was violated. Therefore, data for meal duration was transformed using the natural log. The transformed meal duration data was normal and was used for analysis. Data presented in Table 2 
have been back transformed. The assumption of sphericity was met using Mauchly's test. Following a review of the test meal session video recordings, it was established that all participants in the SLOW condition had 100\% adherence to the prescribed strategy (putting the fork down in between each bite). There was a significant effect of time on meal duration between the first and second test meal sessions $(\mathrm{p}=.004)$ with the second test meal session lasting longer than the first for all conditions. Additionally, there was a significant condition $\mathrm{X}$ time interaction effect $(\mathrm{p}=$ 0.019; Figure 9) and post-hoc testing indicated that meal duration was significantly longer during the second test meal session in the SLOW condition $[12.3(10.7,18.7) \mathrm{min}]$ compared to the EAT [8.1 (6.5, 9.6) $\mathrm{min}]$ and MIND [11.2 (8.3, 17.7) $\mathrm{min}]$ conditions $(\mathrm{p}=.005)$ (see Table 2).

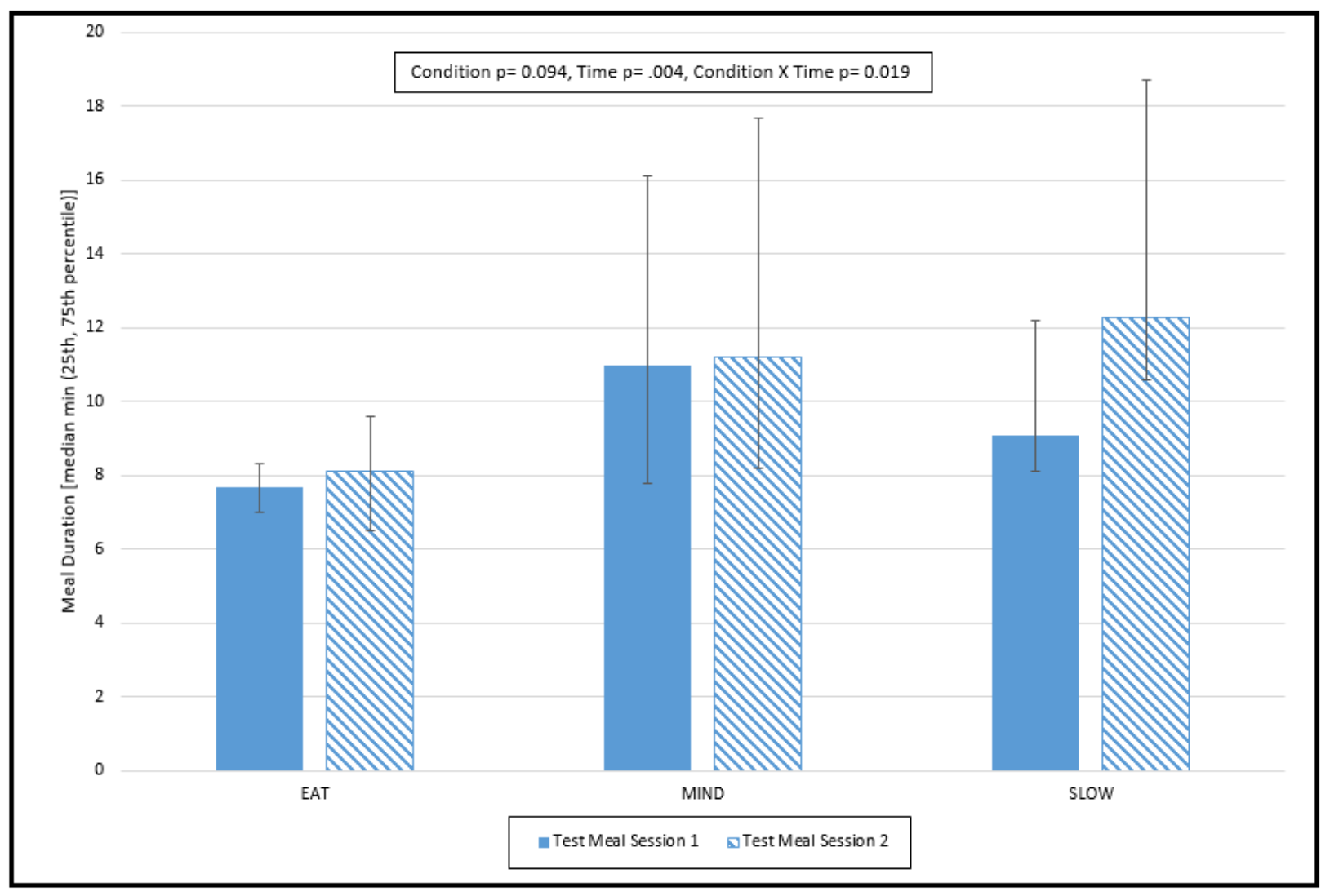

Figure 9. Condition differences in meal duration between test meal sessions

To examine the effect of BMI, gender, and dietary restraint on the relationship between eating strategy conditions and meal duration, three exploratory $2 \times 3 \times 2$ analyses (time $X$ 
condition $\mathrm{X}$ factor) were performed. For BMI effects, the time $\mathrm{X}$ condition $\mathrm{X}$ BMI interaction effect was not significant nor were there any significant time X BMI interaction effects or condition X BMI effects for meal duration. For gender effects, time $\mathrm{X}$ condition $\mathrm{X}$ gender ANOVA was performed for meal duration and were no significant differences.

During the baseline assessment, participants completed the Three Factor Eating Questionnaire (TFEQ) as a measure of dietary restraint. To group participants by high and low dietary restraint, a cut point score of 13 on the TFEQ restraint scale was implemented. This grouping is consistent with previous literature that attempts to characterize scores for dietary restraint using the TFEQ $(130,131)$. Participants with a score of 13 or higher were categorized as "high restraint". Participants with a score of 12 or lower were categorized as "low restraint". In this sample, only 5 participants were categorized as having a level of "high restraint", three of which were female and two were male. Due to the small sample of participants exhibiting high dietary restraint ( 1 in the EAT conditions, and 2 each in the MIND and SLOW conditions) additional exploratory analyses were not conducted.

\subsubsection{Energy Intake}

There were no significant differences in energy intake across eating strategy conditions at either test meal session (see Table 2). Energy intake at test meal session 1 was significantly different between black and white participants, with white participants consuming more than black participants $(\mathrm{p}=0.019)$. Analyses were conducted with and without race as a covariate. Results were not different between ANOVA and ANCOVA; therefore, race was not included in the model. Though not statistically significant $(\mathrm{p}=0.133)$, the MIND condition was the only eating strategy to reduce energy intake (mean change in energy intake: $-64.4 \pm 178.4 \mathrm{kcals}$ ) from the first to the second test meal session, while the SLOW (mean change in energy intake: $2.6 \pm 107.9$ kcals) 
condition remained virtually unchanged, and the EAT (mean change in energy intake: $98.3 \pm 169.6$ kcals) condition increased intake from the first to the second test meal session (Figure 10). Furthermore, there was no significant difference in energy intake $(\mathrm{p}=0.519)$ during the second test meal session between participants (across all conditions) who were considered "mindful" and those considered "not mindful" based upon an MEQ mid-point score of 2.5.

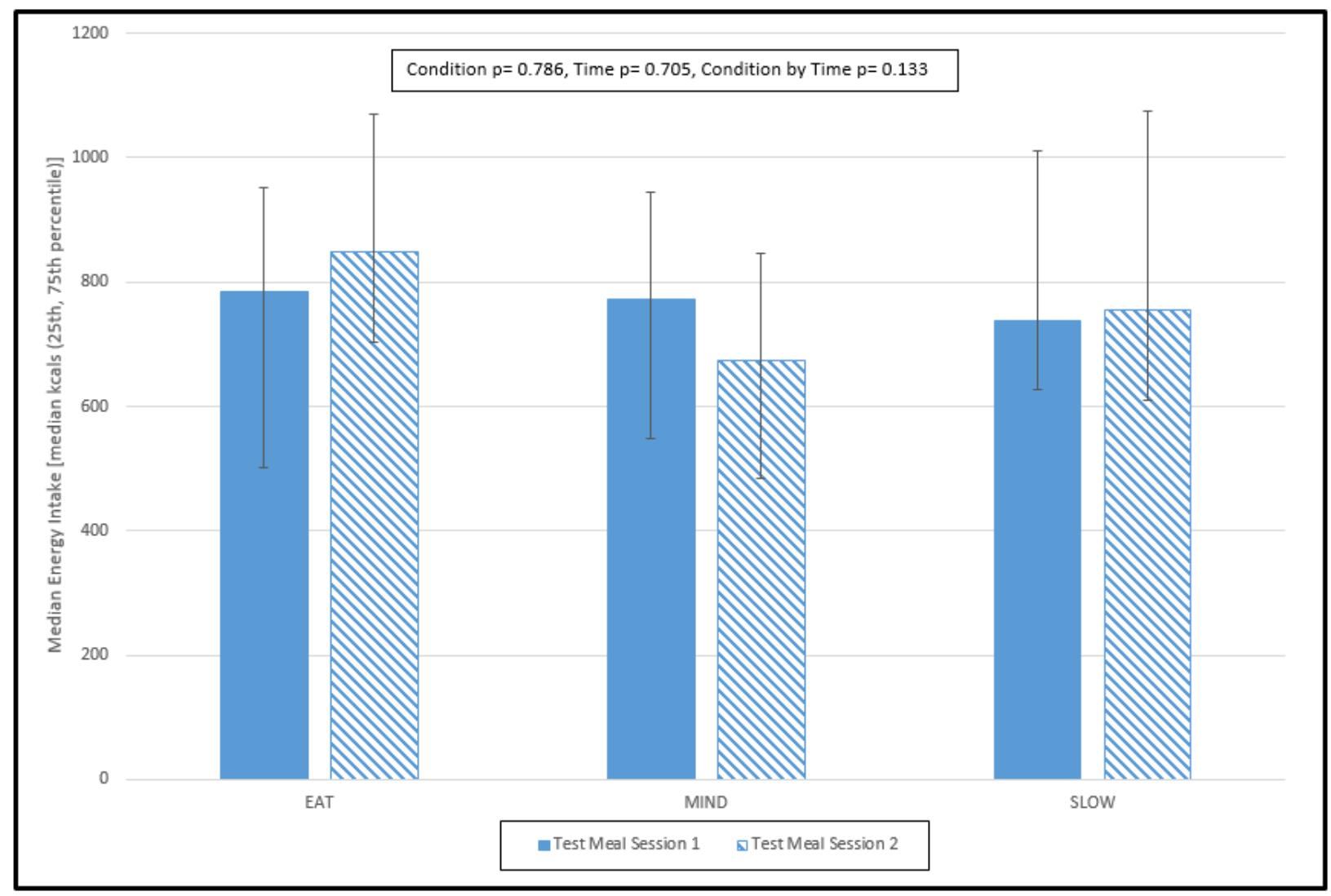

Figure 10. Condition differences in energy intake between test meal sessions

To examine the effect of BMI and gender on the relationship between eating strategy conditions and energy intake, two exploratory analyses were performed. For BMI effects, the condition X BMI X time interaction effect was not significant nor were there any significant time X BMI interaction effects or condition by BMI effects for energy intake. 
Table 5. BMI Classification differences in energy intake between test meal sessions

\begin{tabular}{|c|c|c|c|c|c|c|c|c|c|c|}
\hline & $\begin{array}{l}\text { All groups } \\
(\mathrm{n}=\mathbf{2 4 )}\end{array}$ & $\begin{array}{c}\mathrm{BMI}<30.0 \\
\mathrm{~kg} / \mathrm{m}^{2} \\
(\mathrm{n}=12)\end{array}$ & $\begin{array}{c}\mathrm{BMI} \geq 30.0 \\
\mathrm{~kg} / \mathrm{m}^{2} \\
(\mathrm{n}=12)\end{array}$ & Time & Condition & BMI & $\begin{array}{l}\text { Condition } \\
\text { X BMI }\end{array}$ & $\mid \begin{array}{c}\text { Time } \mathbf{X} \\
\text { Condition }\end{array}$ & $\begin{array}{c}\text { Time X } \\
\text { BMI }\end{array}$ & $\begin{array}{c}\text { Time X } \\
\text { Condition } \\
\text { X BMI }\end{array}$ \\
\hline $\begin{array}{l}\text { Energy Intake } \\
\text { (kcals) }\end{array}$ & & & & 0.716 & 0.806 & 0.745 & 0.699 & 0.158 & 0.372 & 0.766 \\
\hline EAT & $\begin{array}{c}848 \\
(704-1071)\end{array}$ & $\begin{array}{c}848 \\
(452-964)\end{array}$ & $\begin{array}{c}925 \\
(704-1275)\end{array}$ & & & & & & & \\
\hline MIND & $\begin{array}{c}673 \\
(485-846)\end{array}$ & $\begin{array}{c}651 \\
(485-817)\end{array}$ & $\begin{array}{c}731 \\
(361-1155)\end{array}$ & & & & & & & \\
\hline SLOW & $\begin{array}{c}756 \\
(611-1076)\end{array}$ & $\begin{array}{c}801 \\
(748-1076)\end{array}$ & $\begin{array}{c}636 \\
(510-1181)\end{array}$ & & & & & & & \\
\hline
\end{tabular}

*All data presented as Median $\left(25^{\text {th }}, 75^{\text {th }}\right.$ percentile)

For gender effects, a 2 X 3 X 2 (time X condition X gender) ANOVA was performed for energy intake. Analysis showed that there was a significant main effect of gender $(\mathrm{p}=0.024)$ on energy intake indicating that overall, men tended to consume more calories than women. Also significant was a time $X$ gender interaction $(p=0.041)$ suggesting that men (mean change in energy intake: $-47 \pm 38$ kcals) tended to decrease energy intake from the first test meal session to the second while women (mean change in energy intake: $71 \pm 38$ kcals) tended to increase energy intake from the first test meal session to the second. The time $\mathrm{X}$ condition $\mathrm{X}$ gender interaction approached significance $(\mathrm{p}=0.059)$ (see Table 6).

Table 6. Gender differences in energy intake between test meal sessions

\begin{tabular}{|c|c|c|c|c|c|c|c|c|c|c|}
\hline & $\begin{array}{c}\text { All } \\
\text { groups } \\
(n=24)\end{array}$ & $\begin{array}{l}\text { Males } \\
(n=12)\end{array}$ & $\begin{array}{c}\text { Females } \\
(\mathrm{n}=\mathbf{1 2})\end{array}$ & Time & Condition & Gender & $\begin{array}{l}\text { Condition } \\
\text { X Gender }\end{array}$ & $\begin{array}{c}\text { Time X } \\
\text { Condition }\end{array}$ & $\begin{array}{l}\text { Time X } \\
\text { Gender }\end{array}$ & $\begin{array}{c}\text { Time X } \\
\text { Condition } \\
\text { X Gender }\end{array}$ \\
\hline $\begin{array}{l}\text { Energy } \\
\text { Intake } \\
\text { (kcals) }\end{array}$ & & & & 0.654 & 0.753 & 0.024 & 0.668 & 0.068 & 0.041 & 0.059 \\
\hline EAT & $\begin{array}{c}52 \\
(-27,272)\end{array}$ & $\begin{array}{c}3 \\
(-69,56) \\
\end{array}$ & $\begin{array}{c}207 \\
(22,370) \\
\end{array}$ & & & & & & & \\
\hline MIND & $\begin{array}{c}-49 \\
(-101,39)\end{array}$ & $\begin{array}{c}-100 \\
(-363,-71)\end{array}$ & $\begin{array}{c}37 \\
(-19,129)\end{array}$ & & & & & & & \\
\hline SLOW & $\begin{array}{c}0.7 \\
(-60,65)\end{array}$ & $\begin{array}{c}0.7 \\
(-13,135)\end{array}$ & $\begin{array}{c}-11 \\
(-161,65)\end{array}$ & & & & & & & \\
\hline
\end{tabular}

*All data presented as Median $\left(25^{\text {th }}, 75^{\text {th }}\right.$ percentile) 


\subsubsection{Specific Aim 2: Comparison of Satiety in Three Eating Strategy Conditions}

This study aimed to compare subjective ratings of satiety using a categorical VAS during an acute eating bout in 3 eating strategy conditions: a no-strategy control (EAT), a mindful eating strategy (MIND), and a slow eating strategy (SLOW). These data are presented in Table 7.

Because data were not normally distributed for hunger or satiety, natural log and log base 10 transformations resulted in data that violated the normality assumption to a greater extent by Q-Q plots, histograms, and the Shapiro-Wilk test. Only small differences existed between mean and median. As a sensitivity analysis, we compared change in hunger and satiety (which was normal) across groups using one-way ANOVA. Results are consistent with factorial ANOVA using raw hunger and satiety scores at both time points; thus raw hunger and satiety data were used in the repeated measures ANOVA and the median $\left(25^{\text {th }}, 75^{\text {th }}\right.$ percentile $)$ is reported. Because baseline values for the hunger construct were found to be significantly correlated with satiety following the first test meal session $(\mathrm{r}=0.525, \mathrm{p}=0.008)$ both an ANOVA and an ANCOVA were performed and there was no significant difference when the hunger construct was used as a covariate; therefore, it was not included in the model.

A 3 X 2 repeated measures ANOVA indicated that there were no significant differences in subjective ratings of satiety between both the MIND and SLOW eating strategy conditions compared to the EAT eating strategy condition at either test meal session. However, there was a significant main effect of time on subjective ratings of hunger following the test meal between the first and second test meal sessions $(\mathrm{p}<0.001)$ with the second test meal session resulting in decreased ratings of hunger compared with the first test meal session. 
Table 7. Condition differences in hunger and satiety between test meal sessions

\begin{tabular}{|l|c|c|c|c|c|c|c|}
\hline & $\begin{array}{c}\text { All groups } \\
(\mathbf{n}=\mathbf{2 4})\end{array}$ & $\begin{array}{c}\text { EAT } \\
(\mathbf{n}=\mathbf{8})\end{array}$ & $\begin{array}{c}\text { MIND } \\
(\mathbf{n}=\mathbf{8})\end{array}$ & $\begin{array}{c}\text { SLOW } \\
(\mathbf{n}=\mathbf{8})\end{array}$ & Condition & $\begin{array}{c}\text { Time } \\
\text { Condition } \\
\mathbf{X} \text { Time }\end{array}$ \\
\hline Hunger & & & & 0.571 & $<0.001$ & 0.209 \\
\hline Test Meal Session 1 & $\begin{array}{c}2.0 \\
(1.0,2.0)\end{array}$ & $\begin{array}{c}1.5 \\
(1.0,2.0)\end{array}$ & $\begin{array}{c}2.0 \\
(1.3,2.0)\end{array}$ & $\begin{array}{c}2.0 \\
(1.0,2.0)\end{array}$ & & & \\
\hline Test Meal Session 2 & $\begin{array}{c}1.0 \\
(0.0,1.0)\end{array}$ & $\begin{array}{c}1.0 \\
(0.3,1.8)\end{array}$ & $\begin{array}{c}1.0 \\
(1.3,2.0)\end{array}$ & $\begin{array}{c}0.5 \\
(0.0,1.0)\end{array}$ & & & \\
\hline Satiety & $\begin{array}{c}4.0 \\
(4.0,4.0)\end{array}$ & $\begin{array}{c}4.0 \\
(4.0,4.0)\end{array}$ & $\begin{array}{c}4.0 \\
(3.3,4.8)\end{array}$ & $\begin{array}{c}4.0 \\
(4.0,4.8)\end{array}$ & & 0.732 & 0.258 \\
\hline Test Meal Session 1 & $\begin{array}{c}4.0 \\
(4.0,4.0)\end{array}$ & $\begin{array}{c}4.0 \\
(4.0,5.0)\end{array}$ & $\begin{array}{c}4.0 \\
(4.0,4.0)\end{array}$ & & & & \\
\hline Test Meal Session 2 & $4.0,4.0)$ & & & \\
\hline
\end{tabular}

*All data represented at Median $\left(25^{\text {th }}, 75^{\text {th }}\right.$ percentile)

To examine the effect of BMI, gender, and dietary restraint on the relationship between eating strategy conditions and satiety, three exploratory analyses were performed. An (condition X BMI $\mathrm{X}$ time) ANOVA was performed for BMI and satiety. The condition X BMI X time interaction effect was not significant nor were there any significant time X BMI interaction effects or condition by BMI effects for satiety. An (condition X gender X time) ANOVA was performed for gender and satiety and there were no significant differences. 


\subsubsection{Correlations between Primary Endpoints and Descriptive Variables}

Additional analyses showed that BMI, age, education, dietary disinhibition, and cognitive dietary restraint measured at baseline were not significantly correlated with differences in energy intake or satiety at either test meal session (see Table 8). The hunger construct was found to be significantly correlated with satiety following the first test meal session $(r=0.525, \mathrm{p}=0.008)$.

Table 8. Correlational matrix for energy intake, satiety, and descriptive variables

\begin{tabular}{|c|c|c|c|c|}
\hline & $\begin{array}{c}\text { Energy Intake } \\
\text { (Test Meal Session 1) }\end{array}$ & $\begin{array}{c}\text { Satiety } \\
\text { (Test Meal Session 1) } \\
\end{array}$ & $\begin{array}{c}\text { Energy Intake } \\
\text { (Test Meal Session 2) }\end{array}$ & $\begin{array}{c}\text { Satiety } \\
\text { (Test Meal Session 2) }\end{array}$ \\
\hline \multicolumn{5}{|c|}{ 然 } \\
\hline Correlation & 0.233 & 0.064 & 0.249 & 0.270 \\
\hline p-value & 0.274 & 0.766 & 0.240 & 0.202 \\
\hline \multicolumn{5}{|l|}{ Age } \\
\hline Correlation & -0.311 & -0.202 & -0.217 & -0.117 \\
\hline p-value & 0.140 & 0.344 & 0.308 & 0.587 \\
\hline \multicolumn{5}{|l|}{ Education } \\
\hline Correlation & -0.094 & 0.193 & -0.122 & 0.113 \\
\hline p-value & 0.661 & 0.367 & 0.569 & 0.598 \\
\hline \multicolumn{5}{|l|}{ Hunger Construct } \\
\hline Correlation & 0.072 & 0.525 & -0.107 & 0.324 \\
\hline p-value & 0.78 & 0.008 & 0.620 & 0.122 \\
\hline \multicolumn{5}{|l|}{ Disinhibition Construct } \\
\hline Correlation & 0.220 & 0.300 & 0.221 & 0.340 \\
\hline p-value & 0.302 & 0.154 & 0.299 & 0.105 \\
\hline \multicolumn{5}{|c|}{ Cognitive Restraint Construct } \\
\hline Correlation & -0.360 & 0.300 & -0.349 & -0.194 \\
\hline p-value & 0.084 & 0.154 & 0.095 & 0.364 \\
\hline
\end{tabular}




\subsection{DISCUSSION}

\section{$5.1 \quad$ INTRODUCTION}

Obesity is a public health epidemic in the United States (1). Several comorbidities such as diabetes, hypertension, cancer, and cardiovascular disease are associated with obesity (2); thus, it is important and necessary to understand the intricate dynamics driving obesity. Typical behavioral weight management programs aimed at treating obesity typically recommend a decrease in caloric intake combined with an increase in physical activity $(3,9)$. However, common strategies to decrease energy intake suggested as part of these weight management programs have not been fully investigated.

An existing body of evidence suggests that both slow eating $(25,28)$ and mindful eating $(45,46)$ strategies may be effective at reducing acute energy intake. Additionally, it has been proposed that these strategies may reduce energy intake by increasing meal duration to an extent that would be sufficient to allow hormonal signals regulating hunger and satiety to reach the brain and alter intake $(67,68,132)$. However, it is currently unknown whether these strategies actually decrease acute energy intake or increase satiety.

Therefore, the purpose of this study was to determine: 1) if these strategies (mindful and slow eating) are effective at reducing acute energy intake, 2) if one strategy is more effective than the other, and 3) for which populations each strategy may be more or less effective. 


\subsection{SUMMARY OF MAJOR FINDINGS}

\subsubsection{Comparison of a slow eating strategy with a no-strategy control}

The two strategies recommended in the SLOW condition to increase meal duration (putting the fork down in between bites and chewing at least 15-30 times) were successful at increasing meal duration compared with the EAT condition (12.3 minutes in the SLOW condition vs. 8.1 minutes in the EAT condition). This indicates that specific instruction mechanics have an acute effect on duration. These findings are similar to previous research in that these two slow eating strategies were successful in increasing meal duration $(25,29,97)$.

Despite this increase in meal duration, there was no significant differences in acute energy intake compared with the EAT condition (mean change in energy intake for the SLOW condition: $2.6 \pm 107.9$ kcals vs. mean change in energy intake for the EAT condition: $98.3 \pm 169.6$ kcals). These results align with a previous study from Andrade et al. (29) in that slow eating strategies did not decrease energy intake compared with fast eating in healthy women when water intake was controlled (29). Additionally, another study has found that implementing within-meal pauses to increasing meal duration actually increased energy intake. Using a computer to create within-meal pauses and slow eating rate (interrupted eating condition), Yeoman and colleagues demonstrated that energy intake was greater during interrupted eating conditions than continuous eating conditions (no within meal computer interruptions) (31).

However, unlike the results from the current study, other research supports the hypothesis that slow rates of eating decrease acute energy intake. An earlier study by Andrade et al. showed that slower rates of eating, utilizing the same strategies implemented in this study, resulted in 
smaller acute energy intakes in a population of pre-menopausal healthy women (quick: $645.7 \pm$ $155.9 \mathrm{kcal}$; slow: $579.0 \pm 154.7 \mathrm{kcal})(\mathrm{p}<0.05)$ when compared to quick eating $(25)$.

Similar to energy intake, no significant differences in subjective ratings of satiety were found between the SLOW and EAT conditions, indicating the increase in meal duration did not appear to influence self-reported satiety. These results are inconsistent with previously described studies by Koidis et al. (97) and Andrade et al. (29). Andrade and colleagues found that females in a slow eating condition tended to have lower "desire-to-eat" and greater satiety ratings (29). However, the decreased ratings of satiety in the slow eating condition were evidenced at 1 hour following the meal but not immediately after meal completion. In addition, work by Koidis et al. demonstrated a trend toward lower perceived fullness after eating quickly compared with slower eating in 14 males and females (97). These may explain the differences in the current study, as satiety was measured immediately post-meal.

It has been postulated that potential mechanisms through which slow eating may decrease energy intake are increased oral processing time $(67,68,132)$ and increased meal duration $(69-72)$ leading to an increased recognition of satiety signaling and shorter time to satiation. While participants in the SLOW condition in the current study were successful at putting their fork down in between each bite and meal duration was significantly longer compared with the EAT condition, there were no differences in energy intake between groups. This may be due to the fact that participants in the SLOW condition had a median meal duration of just over 12 minutes. Women in the slow conditions in the Andrade et al. studies took a mean of 29.2 minutes (25) and 26.1 minutes (29), respectively, to eat their meal. These times are longer than the 20 minute duration proposed by Rolls, Liddle et al., Moran et al., and Cummings et al., which may be necessary to impact satiety (69-72). Both lean and obese participants in the Koidis et al. study also surpassed 
this delay with mean eating times of 30 minutes for overweight/obese and 29 minutes for lean participants (97). This difference in meal duration between these prior studies and the current study could explain the inconsistent results. It is possible that the meal duration in the current study was not long enough for satiety signals to reach the brain; thus explaining why a hypothesized decrease in energy intake was not realized even in the presence of a longer meal duration. Also, other studies have compared slow eating conditions to quick conditions while the current investigation compared slow eating with a standard eating condition where participants were not specifically instructed to eat quickly. It is possible that because participants in the EAT condition were not instructed to eat "quickly", there was not enough difference in meal duration between groups to realize a difference in energy intake.

Furthermore, satiety ratings in the Andrade et al. study were taken every 5 minutes for the first 30 minutes and then also at 45 and 60 minutes following meal completion and increased satiety ratings were only evidenced at the 60 minute time point. There is the possibility that satiety may have increased in the SLOW eating group of the current study at a later time point, but additional follow-up measurements were not recorded. Therefore, it is unknown if satiety increased past meal completion in the current investigation.

Other studies suggest that variables such as gender, weight status, and level of dietary restraint may influence the relationship between meal duration and acute energy intake (32). While the current study was not powered to specifically examine these variables, exploratory analyses indicate that there was no effect of BMI on satiety or energy intake. These results are not consistent with those of Shah et al. (98) who found that slow eating significantly lowered energy intake in normal weight, but not overweight/obese participants (98). In the same study, researchers also found that slower eating resulted in increased ratings of satiety in normal weight participants at a 
1 hour follow-up measurement, but not in overweight/obese subjects (98). Both the Shah study and the current study used similar methods to successfully increase meal duration. However, the Shah study had a substantially larger sample size with 70 participants (35 normal weight and 35 overweight/obese). Because of the small sample in the current investigation, it is possible that the suggested impact of BMI on the relationship between eating strategies and energy intake was not seen.

Additionally, there was no significant effect of gender on the association between a slow eating strategy and energy intake or satiety. This result is not consistent with work from Martin et al. who found that a computer-prompted decreased eating rate led to decreased energy intake in men, but not women (30). The results from these two studies suggest that the impact of gender on the relationship between slow eating and energy intake and satiety remains unclear. It could be possible that the strategies utilized by these investigations to slow eating have no influence on energy intake in women.

Due to small numbers of participants with a high level of dietary restraint, there were no additional analyses conducted for this variable in the current study. Thus, it is unable to be determined how the current study compares to prior studies in this regard.

\subsubsection{Comparison of a mindful eating strategy with a no-strategy control}

A brief mindfulness practice focused on eating was implemented in the current study. This brief practice included a short breathing meditation, rating of physiological hunger, and instruction to focus on the sensory experience of eating. Despite a mean decrease in energy intake between the two test meal sessions compared to the EAT condition (mean change in energy intake for the mind condition: $-64.4 \pm 178.4$ kcals vs. mean change in energy intake for the EAT condition: $98.3 \pm$ 
169.6 kcals) the MIND condition did not result in a statistically significant decrease in energy intake. These results are consistent with those from Cavanagh and colleagues, who found that while participants randomized to a brief mindfulness exercise tended to eat less of both a small and a large portion of pasta compared with education and control conditions, the result was not statistically significant (47).

In contrast, other studies involving brief mindfulness trainings have resulted in decreased energy consumption. In a study from Forman and colleagues, training in mindful decision making that consisted of a 60 minute in-person group session, led to decreased salty snack food consumption in the 7 days following the intervention (133). However, participants self-reported their snack food consumption and energy intake was not objectively measured. Arch et al. (108) conducted a series of 3 experiments examining the impact of a brief mindfulness intervention. The mindfulness intervention instructed subjects to focus on the sensory experience of eating and was delivered via audiorecording, similar to the exercise completed by participants in the MIND condition in the current study. Participants in the mindfulness condition in the Arch et al. study consumed fewer calories from sweet foods, salty foods, and from saturated fat than participants in the distraction and no-instruction control conditions. Those subjects in the mindfulness condition also did not compensate for the decrease in energy intake from "junk" foods by consuming more calories from healthier options like unsalted almonds and carrot sticks (108). Results from these more recent studies involving brief mindfulness interventions suggest that mindfulness training may result in decreased energy intake of snack foods.

Moreover, no significant differences in subjective ratings of satiety were found between a mindful eating condition (MIND) and a no-strategy control (EAT). The results from this study are similar to those from a previously described study by Cavanagh et al. (47) who found no difference 
between mindful and control conditions on ratings of sensations of hunger, satiety or taste with neither group rating those sensations as more influential on food intake than the amount of food available (47). Similar to the current investigation, participants in part of the Cavanagh study were served a large portion of pasta. However, in a previously described study by Fisher, Lattimore, and Malinowski, a brief mindful attention induction resulted in not only a significant decrease in energy intake (measured as number of cookies eaten) but also in a significant increase in subjective fullness ratings on a 0-100 mm visual analog scale compared with the standard group (104).

Both the current investigation and the Cavanagh study (47) involved consumption of large portion sizes. The similarity of results between the current study and the Cavanagh study suggest that brief mindfulness exercises may not be effective at producing significant decreases in energy intake of large portion sizes or at meal settings. However, Arch et al. showed that a brief mindfulness intervention was able to impact energy intake in the presence of smaller, snack sized portions (108). Because increased portion sizes are well known to increase energy intake $(47,55)$, it is possible that the external cues resulting from increased portion sizes have a greater impact on energy intake than internal cues highlighted through mindfulness practice and thus, mindfulnessbased intervention may not be significant enough to overcome a portion size effect. Additionally, significant effects of brief mindfulness interventions on energy intake were found when participants were exposed to snack-like eating episodes. Thus, it is possible that these interventions may be more effective at decreasing energy intake from snacking, rather than in a full meal setting.

Interestingly, while participants in the MIND condition tended to eat less than those in the EAT and SLOW conditions, they did not rate themselves as more mindful based upon MEQ scores. Additionally, participation in the MIND condition did not result in an increase in alertness or attentiveness as measured by the PANAS. Because participants in the MIND condition did not 
report being more mindful, more alert, more attentive or more satiated than the other groups, it is possible that the brief mindfulness exercises used in this investigation were not sufficient enough to create a mindful state. This is a potential explanation for why there were no significant differences in energy intake or satiety between the MIND and EAT conditions.

While not powered specifically to examine gender differences, exploratory analyses in the current study revealed a trend suggesting that men in the MIND eating strategy condition were more likely to decrease energy intake than other groups. An additional analysis suggested that men (mean change in energy intake: $-47 \pm 38$ kcals) tended to decrease energy intake while women (mean change in energy intake: $71 \pm 38 \mathrm{kcals}$ ) tended to increase energy intake at the second session. It has been suggested that gender may influence the relationship between other eating strategies and energy intake (30), yet, this result has not been realized in prior studies investigating the impact of a brief mindfulness strategy.

Gender is a variable that has the potential to impact these relationships because women typically have lower energy requirements and different hormonal fluctuations than men (32); however, by utilizing a repeated measures design and scheduling sessions during the luteal phase of female participants' menstrual cycles, this effect would be minimized. While an explanation for this trend was not able to be determined by the current investigation, another study has suggested that decreased energy intake in men may be due to the fact that, overall, men consume more calories and therefore, have more room for a potential decline in intake (30). If there is a threshold of energy intake that must be reached in order for a decrease in intake to occur, it may be that only women who regularly reach this threshold or consume excess calories would benefit from these strategies and that those who do not reach the threshold have no room for decline. 


\subsubsection{Comparison of a slow eating strategy with a mindful eating strategy}

This study also aimed to compare differences in energy intake and satiety between a slow eating strategy (SLOW) and a mindful eating strategy (MIND). Prior to the current investigation, it does not appear that these two eating strategies have been directly compared. Results from the current study indicate that there were no significant differences in change in meal duration, energy intake or satiety between these two eating strategies. Though not statistically significant, there was a small difference in mean change in energy intake for the MIND condition (mean change in energy intake for the mind condition: $-64.4 \pm 178.4$ kcals vs. mean change in energy intake for the SLOW condition: $2.6 \pm 107.9$ kcals).

Despite a lack of statistical significance, both the SLOW and MIND conditions did not experience a similar increase in caloric intake with that from the EAT condition (mean change in energy intake for the EAT condition: $98.3 \pm 169.6 \mathrm{kcals})$. This lack of increase in caloric intake suggests that these strategies may be effective at preventing a potential increase in caloric intake experienced when no strategy is implemented. Limiting an increase in calorie intake can be a beneficial method for prevention of weight gain, if not for weight loss. Thus, these strategies may remain a useful recommendation for behavioral weight management programs.

\subsection{LIMITATIONS AND RECOMMENDATIONS FOR FUTURE RESEARCH}

While this study exhibited many strengths, such as: presence of a control condition; wide range of BMI classifications, ages, gender, and races; a controlled breakfast meal; and repeated measures design; some limitations may decrease the application of the results to other populations and eating 
scenarios. Both genders were equally represented in this study, yet, distribution across BMI classifications was not similar and only those aged 18 to 55 participated in the current investigation. Thus, generalization of these findings to other populations is limited. Moreover, the current study had other limitations that may have contributed to the experimental results and are listed here below:

1) While this study attempted to standardize intake prior to each test meal session with an isocaloric breakfast shake consumed 4 hours before each session, it is unclear how this may have affected the response in each of the experimental conditions. Additional studies should consider the size, timing, and content of a pre-load meal when examining acute energy intake.

2) While this study was powered to detect a significant difference in energy intake between the three eating strategy conditions, the sample size was small. A mean decrease in energy intake between test meal sessions of $64.4 \pm 178.4 \mathrm{kcals}$ in the MIND condition and a virtually unchanged intake of $2.6 \pm 107.9 \mathrm{kcals}$ in the SLOW condition did not result in a statistically significant difference over the increase of $98.3 \pm 169.6 \mathrm{kcals}$ in the EAT group. Thus, these data may be important for future studies in determining more precise estimates of sample size.

3) This study utilized basic questionnaires and visual analog scales to measure adherence to the mindful eating instructions, hunger, satiety, and change in awareness and attentiveness. It is possible that participants in this condition may not have been adherent to the directions or perhaps the MEQ, PANAS, and visual analog scales were not a sensitive enough measure for an acute mindful eating session. Future studies should aim to utilize more advanced or objective 
methodology, such as fMRI and blood markers for hunger and satiety hormones, to ensure that subjects eat more mindfully or objectively measure effectiveness of mindful eating strategies.

4) This study was conducted in a tightly controlled laboratory setting. This type of setting is relatively unnatural and not similar to typical eating situations that occur outside of a laboratory setting. Thus, the applicability of the results to "free-living" eating situations is limited. Future studies should aim to incorporate these strategies into a more naturalistic environment.

5) This study was an acute eating study that included only 2 brief eating sessions with immediate follow-up and only one type of food. While all participants reported that they liked macaroni and cheese, utilizing just one food type may have limited the impact of satiety and energy intake. Future research on the effects of these strategies should aim to examine a variety of foods, include satiety measurements that extend beyond immediate measures only, perhaps over the course of time or over several meals.

6) While participants in the SLOW condition increased meal duration compared with those in the EAT condition, no groups approached the period of time suggested by Rolls, Liddle et al., Moran et al., and Cummings et al. (69-72) that may be necessary to influence satiety. Future investigations should aim to ensure that slow eating strategies achieve this suggested time to enhance our understanding of the relationship between slow eating and satiety and the subsequent effects on energy intake. 
7) This study utilized only a large portion size to investigate differences in energy intake and satiety between conditions. However, other studies have examined these strategies in the presence of smaller portion sizes. Future investigations should consider studying the effect of these strategies in a variety of portion sizes.

8) While exploratory in nature, the current study was underpowered to detect significant differences in energy intake between subjects in each BMI category, by gender, and across levels of dietary restraint. To adequately examine the impact of these variables on the relationship between eating strategies and energy intake, future investigations should be appropriately powered to detect potential differences resulting from BMI, gender, and dietary restraint.

\subsection{IMPLICATIONS FOR WEIGHT MANAGEMENT}

The results from the current investigation did not show a statistically significant difference in energy intake or self-reported satiety between the three eating strategy conditions (EAT, MIND, SLOW). However, participants in the MIND condition tended to consume less calories overall, with a small decrease in energy intake of 64 calories. There was virtually no change in energy intake in the SLOW condition. Compared with the EAT condition, which resulted in an increase in energy intake at the second test meal session, both the SLOW and MIND eating strategies proved to be beneficial in preventing this increase. While a difference of 64 calories is small, this difference was realized only during one meal. There is the potential for these small changes to occur at each meal and that over time, they may accumulate. This accumulation could lead to a larger decrease in energy intake and a subsequent positive impact on weight. Longer-term studies 
incorporating training on mindful eating have been conducted, which investigate the potential of these small changes to accumulate over time. A study conducted by Dalen et al. showed that a 6week mindfulness training group for obese individuals resulted in statistically significant decreases in weight (48). However, this may not be directly tied to the effect of mindfulness on acute energy intake and satiety. Results from this study indicate that the benefits of mindfulness training may extend beyond what was seen in this small, acute laboratory study.

Currently, the longer-term studies involving mindfulness do not result in increased weight loss when compared with a control group. A recently conducted thesis project at the University of Minnesota investigated the effect of appetite awareness training compared with a no-treatment control and a nutrition education group in a 3 week intervention with 4 week follow-up booster session. While appetite awareness training does not incorporate all aspects of mindfulness training, like mindful eating, it encourages participants to draw increased awareness to internal hunger and satiety cues. Participants in the appetite awareness training group showed statistically significant greater weight loss compared with the no-treatment control but there was no difference between the appetite awareness and nutrition education groups (134). A study by Goldbacher and colleagues showed that there was no significant difference in 5 month weight loss between standard behavioral treatment and mindfulness enhanced behavioral treatment for participants who engaged in emotional eating (135). Similar results were seen in the SHINE study from Daubenmier and colleagues who found that weight loss was not significantly different between a 5.5 month mindfulness-based and a 5.5 month standard weight loss program for 194 obese participants (136). Results from these three studies indicate that long-term mindfulness or appetite awareness training may not lead to improved weight loss outcomes. Future studies should be 
aimed at incorporating mindfulness based training with a longer term follow-up or as part of a longer-term weight loss maintenance program.

While the impact of mindfulness-based training on weight loss may remain unclear, evidence suggesting benefits beyond that of weight loss is more consistent. In the previously described studies from Vieaux, Dalen and Daubenmier, participants in the mindfulness groups reported increases in cognitive restraint (48), increases in the ability to resist eating in high food situations (134), increased confidence in controlling eating during TV watching (134), decreased eating of sweets (137) and improved fasting glucose levels (137). This suggests that while mindfulness-based training may or may not impact weight to a greater extent than a standard program, those practicing mindfulness may experience benefits in other positive health-related behaviors.

Additionally, benefits of slow eating may also be realized beyond acute eating scenarios and into the long-term. Both a systematic review and meta-analysis by Ohkuma et al. (22) and a cross-sectional study from Lee et al. (138) suggest that eating quickly may have negative longterm effects on body weight. Eating quickly was shown to increase the risk of being overweight both independently and in combination with late evening meals and skipping breakfast (138) and was also positively associated with excess body weight (22). Thus, while slow eating did not affect acute energy intake in this small sample, it appears that over time, this strategy may aid in prevention of weight gain.

Despite the lack of statistical significance of the change energy intake, the small decrease in energy intake in the MIND condition and the unchanged energy intake in the SLOW condition may be clinically meaningful. Results demonstrated a decrease in energy intake of $64.4 \pm 178.4$ calories in the MIND condition, which approximates the hypothesized difference of $65.0 \pm 155.0$ 
kcal realized in an earlier study (29). The current study was powered to detect a difference of 65 kcals between conditions based upon previous literature that suggests that smaller deficits in energy intake may be meaningful for weight management. It has been proposed that while an energy gap of just $100 \mathrm{kcals} /$ day may not be effective for substantial weight loss, this gap may prevent excess weight gain (139). Termed the "small change approach", this gap of $100 \mathrm{kcals} /$ day has been suggested to be more realistic and maintainable than the larger energy gap of 175-480 $\mathrm{kcal} /$ day needed to maintain weight loss $(140,141)$. The change in energy intake achieved by participants in the MIND condition during one lunch meal in the current study may contribute to the $100 \mathrm{kcal} /$ day deficit proposed by the small change approach whether through a single eating event or over the course of a day.

Moreover, participants in the SLOW condition did not increase their energy intake during the second test meal session while participants in the EAT condition did increase their energy intake. Because the SLOW condition was effective at maintaining caloric intake between the two test meal sessions, it has potential to be an effect strategy for the prevention of weight gain or for weight control. Thus, the benefit in the strategies implemented as part of this investigation may prove to be more beneficial for prevention of weight gain than for weight loss.

\subsection{CONCLUSIONS}

Slow and mindful eating strategies are commonly recommended as part of behavioral weight management programs, yet their effects on acute energy intake and satiety are unclear. Studies previously conducted in this area of research are often small, study one specific population (women and obese populations in particular), and investigate the impact of one strategy compared with a 
no-strategy control. This study was conducted to determine if two eating strategies (mindful and slow eating) resulted in a decrease in energy intake or increase in satiety during an acute laboratory meal compared with a no-strategy control. Results from the current study indicate that overall, neither a mindful nor slow eating strategy produced a statistically significant decrease in energy intake or an increase in satiety when compared to no strategy at all. However, there was a small, non-significant decrease in energy intake for participants in the MIND condition, indicating that over time, small decreases in energy intake could accumulate, resulting in a larger energy gap. Additionally, strategies utilized in the SLOW condition were effective at preventing increased energy intake, as experienced in the EAT group. This suggests that mindful and slow eating behaviors may be beneficial for weight management if continued over time. Mindful and slow eating strategies should continue to be recommended as effective strategies to help maintain weight or prevent excess weight gain. Future studies investigating the effectiveness of these strategies for weight loss and prevention of weight gain are warranted. 
APPENDIX A: INFORMED CONSENT DOCUMENTS 


\title{
University of Pittsburgh
}

\author{
Scbool of Education \\ Pbysiaal Activity and Weigbt Management Researcb Center
}

Onk Hill Commons 32 Cak HI Court

Patsburgh, PA 15261

412-383-4020

Fox $412-383-4045$

\section{CONSENT TO ACT AS A SUBJECT IN A RESEARCH STUDY}

TITLE: Comparison of Eating Strategies on Meal Satisfaction and Enjoyment

PRINCIPAL INVESTIGATOR: Anna Peluso, M.S.

Department of Health and Physical Activity

Physical Activity and Weight Management Research Center

University of Pittsburgh

32 Oak Hill Court

Pittsburgh, PA 15261

Telephone: $412-383-4046$

CO-INVESTIGATORS:

Kelliann Davis, Ph.D.

Department of Health and Physical Activity

Physical Activity and Weight Management

Research Center

University of Pittsburgh

32 Oak Hill Court

Pittsburgh, PA 15261

Telephone: 412-383-4003

Bethany Barone Gibbs, Ph.D.

Department of Health and Physical Activity

Physical Activity and Weight Management

Research Center

University of Pittsburgh

32 Oak Hill Court

Pittsburgh, PA 15261

Telephone: 412-383-4002
John M. Jakicic, Ph.D.

Department of Health and Physical Activity

Physical Activity and Weight Management Research

Center

University of Pittsburgh

32 Oak Hill Court

Pittsburgh, PA 15261

Telephone: 412-383-4001

Elizabeth Venditti, Ph.D.

Department of Psychiatry

University of Pittsburgh

100 N. Bellefield Ave.

$8^{\text {th }}$ Floor, Suite 830

Pittsburgh, PA 15213

Telephone: 412-647-5200

SOURCE OF SUPPORT: School of Education and Council of Graduate Students in Education, University of Pittsburgh

Page 1 of 8

\begin{tabular}{|c|c|c|}
\hline $\begin{array}{l}\text { University or Ritsburgh } \\
\text { Institutional Reviow Board }\end{array}$ & $\begin{array}{l}\text { App roval Date: } 34112016 \\
\text { Renewal Date: SH02017 }\end{array}$ & IRB il: PRO10020052 \\
\hline
\end{tabular}




\section{DESCRIPTION:}

Research has shown that the environment and situations in which we eat can effect meal satisfaction and enjoyment. Therefore, the primary purpose of this study is to examine the effect of different eating scenarios on meal satisfaction and enjoyment.

You are being invited to take part in this research study because you have been determined to be initially eligible to participate through completing the telephone screen, you, you are within the body weight range for this study, and do not have any medical conditions that would affect the way in which you eat. People invited into this study are people between 18-55 years of age. This study is being performed on a total of 39 individuals and will be conducted at a University of Pittsburgh facility.

If you decide to take part in this research study, you will undergo the following procedures that are not part of your standard medical care:

\section{Screening and Experimental Procedures:}

Procedures to determine if you are eligible to take part in a research study are called "screening procedures". These procedures will take place at the Physical Activity and Weight Management Research Center at the University of Pittsburgh and will be completed in approximately 15 minutes. The following screening procedures will be implemented:

- You will be required to accurately report whether you are pregnant to the investigators prior to beginning this study and during the study if your status should change. Participants cannot be pregnant because the effects of pregnancy on the study outcomes are not known.

As part of the initial screening procedures, a baseline assessment will be performed as outlined below. If it is found after this baseline assessment that you qualify to participate in this study, the following experimental procedures described below will be as listed:

- Body Weight and Height (5 minutes): Your body weight will be measured using a calibrated electronic scale. Your height will be measured with a ruler that is attached to a flat wall.

- Questionnaires (10 minutes): You will first be asked to complete a series of questionnaires and return these to the investigators, and it is estimated that you will be able to complete these questionnaires in approximately 10 minutes. These questionnaires will provide information about your demographic information and eating behaviors.

\section{Eating Testing Sessions:}

After completing these assessments, if you are still eligible to participate, you will be asked to schedule two visits to the Physical Activity and Weight Management Research Center. These visits will be separated by at least 2 days and be within days 7 and 21 of your menstrual cycle, if you are a female. You will be randomly assigned to one of three groups: eating group 1, eating 
group 2, or eating group 3 . Random assignment is similar to flipping a coin to determine the group that you will be in. These groups are described below:

A. Eating Group 1: Prior to both visits, you will be asked to abstain from caffeine, structured exercise, and alcohol for 12 hours prior to your test meal sessions, and to consume a liquid meal replacement, which will be in the form of a commercially available shake, at home 4 hours prior to arriving at the research facility. This shake will be provided to you on the day of your assessment visit. Upon arrival, all testing procedures will be reviewed and the following will occur, and these procedures will take approximately a total of 45 minutes to complete.

1. Testing Visit 1

i. You will then be asked to complete a questionnaire related to your mood and other factors related to how you feel on that day.

ii. During the testing session, you will listen to an audio recording that will give you instructions on how to consume your meal. Your plate and hands, but not your face, will be video recorded during the session for quality control.

iii. Upon completion of the meal, you will again be asked a series of questions related to mood, hunger, and satisfaction and enjoyment of the meal.

2. Testing Visit 2

i. You will then be asked to complete a questionnaire related to your mood and other factors related to how you feel on that day.

ii. During the testing session, you will listen to an audio recording that will give you instructions on how to consume your meal. Your plate and hands, but not your face, will be video recorded during the session for quality control.

iii. Upon completion of the meal, you will again be asked a series of questions related to mood, hunger, general awareness, and satisfaction and enjoyment of the meal.

B. Eating Group 2: Prior to both visits, you will be asked to abstain from caffeine, structured exercise, and alcohol for 12 hours prior to your test meal sessions, and to consume a liquid meal replacement, which will be in the form of a commercially available shake, at home 4 hours prior to arriving at the research facility. This shake will be provided to you on the day of your assessment visit. Upon arrival, all testing procedures will be reviewed and the following will occur, and these procedures will take approximately a total of 45 minutes to complete.

1. Testing Visit 1

i. You will then be asked to complete a questionnaire related to your mood and other factors related to how you feel on that day.

ii. During the testing session, you will listen to an audio recording that will give you instructions on how to consume your meal. Your plate and hands, but not your face, will be video recorded during the session for quality control.

iii. Upon completion of the meal, you will again be asked a series of questions related to mood, hunger, and satisfaction and enjoyment of the meal.

2. Testing Visit 2

i. You will then be asked to complete a questionnaire related to your mood and other factors related to how you feel on that day.

ii. During the testing session, you will listen to an audio recording that will give you instructions on how to consume your meal more slowly by chewing more

Page 3 of 8

IRB I: PRO16020052 
and putting your fork down in between bites. Your plate and hands, but not your face, will be video recorded during the session for quality control.

iii. Upon completion of the meal, you will again be asked a series of questions related to mood, hunger, general awareness, and satisfaction and enjoyment of the meal.

C. Eating Group 3: Prior to both visits, you will be asked to abstain from caffeine, structured exercise, and alcohol for 12 hours prior to your test meal sessions, and to consume a liquid meal replacement, which will be in the form of a commercially available shake, at home 4 hours prior to arriving at the research facility. This shake will be provided to you on the day of your assessment visit. Upon arrival, all testing procedures will be reviewed and the following will occur, and these procedures will take approximately a total of 45 minutes to complete.

1. Testing Visit 1

i. You will then be asked to complete a questionnaire related to your mood and other factors related to how you feel on that day.

ii. During the testing session, you will listen to an audio recording that will give you instructions on how to consume your meal. Your plate and hands, but not your face, will be video recorded during the session for quality control.

iii. Upon completion of the meal, you will again be asked a series of questions related to mood, hunger, and satisfaction and enjoyment of the meal.

2. Testing Visit 2

i. You will then be asked to complete a questionnaire related to your mood and other factors related to how you feel on that day.

ii. During the testing session, you will listen to an audio recording that will give you instructions on how to consume your meal more mindfully by savoring the taste of food and experiencing the moment. Your plate and hands, but not your face, will be video recorded during the session for quality control.

iii. Upon completion of the meal, you will again be asked a series of questions related to mood, hunger, general awareness, and satisfaction and enjoyment of the meal.

\section{RISKS and BENEFITS:}

The possible risks of this research study may be due to the test meal session that you will be participating in and the assessments that will be performed.

\section{$\underline{\text { Risks }}$}

A. Risk of Consuming a Breakfast Shake: As described above, you will be provided with a breakfast shake to consume on the morning of testing. There is a possibility that you may not like the taste of the breakfast shake. Also, consuming it may result in bloating, gas, and indigestion. This is rare and occurs in less than $1 \%$ of people (less than 1 out of 100 people). In order to minimize this risk, you will be asked if you have ever had an adverse reaction to an Ensure breakfast shake and if you are allergic to any ingredients in the breakfast shake. A dietitian will be on staff at the research center to confirm if any potential allergens are included in the shake.

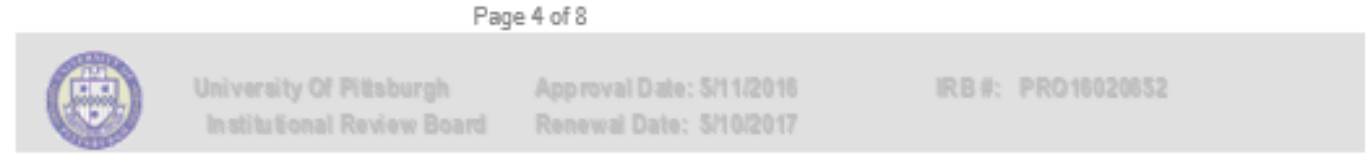


B. Risk Associated with Completion of Questionnaires: You may experience nonphysical risks such as boredom, frustration, stress, and time constraints when completing the questionnaires. The risk of this happening to you is likely because this occurs in more than $25 \%$ of people (more than 25 out of 100 people). You may experience the occurrence of breach of confidentiality with regard to information that is provided on the questionnaires. The risk of this happening is low because it occurs in less than $1 \%$ of people (less than 1 out of 100 people). We will attempt to ensure confidentiality of your personal information by assigning an ID number to each questionnaire and storing the information linking you to the ID number in a separate secure location.

\section{Benefits:}

There are no direct benefits that you will receive from participating in this study.

\section{NEW INFORMATION:}

You will be promptly notified if any new information develops during the conduct of this research study, which may cause you to change your mind about continuing to participate.

\section{COSTS and PAYMENTS:}

You will not be charged for the costs of any of the procedures performed for the purpose of this research study. These costs will be paid by the research study.

You will receive payment in the form of a We Pay debit card. You will be paid $\$ 50$ for completing all of the testing procedures which include the baseline assessment visit, the first testing visit, and the second testing visit. Thus, a total of $\$ 50$ can be earned for your participation in this study.

\section{COMPENSATION FOR INJURY:}

University of Pittsburgh researchers and their associates who provide services at the University of Pittsburgh Medical Center (UPMC) recognize the importance of your voluntary participation in their research studies. These individuals and their staffs will make reasonable efforts to minimize, control, and treat any injuries that may arise as a result of this research. If you believe that you are injured as a result of the research procedures being performed, please contact immediately the Principal Investigator listed on the first page of this form.

Emergency medical treatment for injuries solely and directly related to your participation in this research study will be provided to you by the hospitals of UPMC. It is possible that UPMC may bill your insurance provider for the costs of this emergency treatment, but none of these costs will be charged directly to you. If your research-related injury requires medical care beyond this emergency treatment, you will be responsible for the costs of this follow-up care unless otherwise specifically stated below. There is no plan for monetary compensation. You do not, however, waive any legal rights by signing this form.

Page 5 of 8

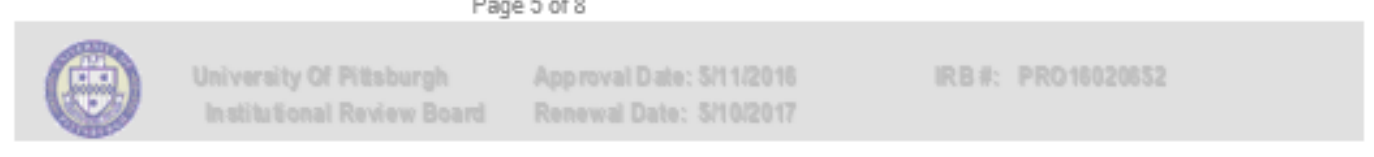




\section{CONFIDENTIALITY:}

Any information about you obtained from this research will be kept as confidential (private) as possible. All records related to your involvement in this research study will be stored in a locked file cabinet. Your identity on these records will be indicated by a case number rather than by your name, and the information linking these case numbers with your identity will be kept separate from the research records. In addition, all research databases will have password controlled access, and this will be controlled by the researchers. Only the researchers listed on the first page of this form and their staff will have access to your research records. However, other scientist may request data obtained by this study. We will allow data to be released to qualified researchers only after ensuring that your name and other identifying information is not given to these researchers. You will not be identified by name in any publication of research results unless you sign a separate form giving your permission (release).

In addition to the investigators listed on the first page of this authorization (consent) form and their research staff, the following individuals will or may have access to identifiable information related to your participation in this research study:

Authorized representatives of the University of Pittsburgh Research Conduct and Compliance Office may review your identifiable research information (which may include your identifiable medical record information) for the purpose of monitoring the appropriate conduct of this research study.

In unusual cases, your research records may be required to release identifiable information (which may include your identifiable medical record information) related to your participation in this research study in response to an order from a court of law. If the researchers learn that you or someone with whom you are involved is in serious danger or potential harm, they will need to inform, as required by Pennsylvania law, the appropriate agencies.

The investigators may continue to use and disclose, for the purposes described above, identifiable information (which may include your identifiable medical record information) related to your participation in this research study for 7 years following the completion of this study, as per University policy, or when such is approved by the sponsor of this study, whichever should occur last.

\section{RIGHT TO PARTICIPATE OI WITHDRAW FROM PARTICIPATION:}

Your participation in this research study, to include the use and disclosure of your identifiable information for the purposes described above, is completely voluntary. (Note, however, that if you do not provide your consent for the use and disclosure of your identifiable information for the purposes described above, you will not be allowed, in general, to participate in the research study.) Whether or not you provide your consent for participation in this research study will have no affect on your current or future relationship with the University of Pittsburgh. Whether or not you provide your consent for participation in this research study will have no effect on your current or future medical care at a UPMC hospital or affiliated health care provider or your current or future relationship with a health care insurance provider.

You may withdraw, at any time, your consent for participation in this research study, to include 
the use and disclosure of your identifiable information for the purposes described above. (Note, however, that if you withdraw your consent for the use and disclosure of your identifiable information for the purposes described above, you will also be withdrawn, in general, from further participation in this research study.) Any identifiable research information recorded for, or resulting from, your participation in this research study prior to the date that you formally withdrew your consent may continue to be used and disclosed by the investigators for the purposes described above.

To formally withdraw your consent for participation in this research study you should provide a written and dated notice of this decision to the principal investigator of this research study at the address listed on the first page of this form. Your decision to withdraw your consent for participation in this research study will have no effect on your current or future relationship with the University of Pittsburgh. Your decision to withdraw your consent for participation in this research study will have no effect on your current or future medical care at a UPMC hospital or affiliated health care provider or your current or future relationship with a health care insurance provider.

It is possible that you may be removed from the research study by the researchers if, for example, your health status changes and it does not appear that it is safe for you to continue to participate. You will also be removed if you should become pregnant during this study.

\begin{tabular}{|c|c|c|c|}
\hline$(0)$ & $\begin{array}{l}\text { Univeraity Of Pitsburgh } \\
\text { Inutitutional Roviow Board }\end{array}$ & $\begin{array}{l}\text { App roval Date: SH112016 } \\
\text { Ronowal Date: SH02017 }\end{array}$ & IRB I: PRO16020652 \\
\hline
\end{tabular}




\section{VOLUNTARY CONSENT}

The above information has been explained to me and all of my current questions have been answered. I understand that I am encouraged to ask questions, voice concerns or complaints about any aspect of this research study during the course of this study, and that such future questions, concerns or complaints will be answered by a qualified individual or by the investigator(s) listed on the first page of this consent document at the telephone number(s) given. I understand that I may always request that my questions, concerns or complaints be addressed a listed investigator. I understand that I may contact the Human Subject Protection Advocate of the IRB Office, University of Pittsburgh (1-866-212-2668) to discuss problems, concerns, and questions; obtain information; offer input; or discuss situations in the event that the research team is unavailable.

By signing this form, I agree to participate in this research study. A copy of this consent form will be given to me.

Participant's Signature

Date

ADDITIONAL AUTHORIZATION FOR VIDEO RECORDING OF INDIVIDUAL SESSIONS:

In order to ensure quality control and adherence to the condition strategies, the individual sessions will be video recorded. I authorize the use on an video participant

recorder during my individual sessions. I understand that this authorization is completely voluntary and if I choose not to sign this particular authorization, I will be excluded from the study.

Participant's Signature

Date

\section{CERTIFICATION OF INFORMED CONSENT}

I certify that I have explained the nature and purpose of this research study to the above-named individual, and I have discussed the potential benefits and possible risks of study participation. Any question the individual has about this study have been answered, and we will always be available to address future questions, concerns or complaints as they arise. I further certify that no research component of this protocol was begun until after this consent form was signed.

Printed Name of Person Obtaining Consent

Signature of Person Obtaining Consent
Role in Research Study

Date

Page 8 of 8

Univeraity Or Ritsburgh
Approval Dato: SH12010

Figure 11. Informed Consent Document 
Title: Comparison of Slow and Mindful Eating Strategies on Acute Energy Intake

\begin{tabular}{|ll|c|c|}
\cline { 3 - 4 } \multicolumn{1}{l|}{} & YES & NO \\
\hline $1 \quad$ Research Center? & $\square$ & $\square$ \\
\hline $2 \quad$ Explain to me what you will be doing when you come for each session. & & \\
\hline $3 \quad$ What are the three possible groups that you could be randomized into? & $\square$ & $\square$ \\
\hline $4 \quad$ How much will you be paid if you complete all visits? & $\square$ & $\square$ \\
\hline
\end{tabular}

If the participant provides a reasonable response, check "yes" to indicate that they understand the procedure. If any boxes are checked "no", the participant was unable to provide informed consent and is ineligible to participate. 
APPENDIX B: TELEPHONE SCREENING FORM 


\section{RECRUITMENT FORM:}

- Introduction:

Thank you for your interest in our study. My name is and I am a student in the Department of Health and Physical Activity at the University of Pittsburgh. I would briefly like to tell you about our research study.

- Procedure for Describing the Study and Obtaining Verbal Consent to Conduct the Phone Screen: A description of the study will be read to participants, and this description includes important components of the informed consent process (see attached script). Individuals who express an interest in participating in this study will be told the following to obtain verbal consent:

\section{- Investigators Component of Informed Consent:}

This study is being conducted by Anna Peluso at the University of Pittsburgh. Her mentors Dr. John Jakicic and Dr. Kelli Davis from the Department of Health and Physical Activity will be overseeing this project.

\section{- Source of Support Component of Informed Consent:}

Funding for this study is provided by the University of Pittsburgh School of Education and the Council of Graduate Students in Education.

\section{- Description Component of Informed Consent:}

We are interested in recruiting 39 men and women who are 18 to 55 years of age to participate in this study. This study will investigate differences in eating behaviors and their effect on meal satisfaction. If you are eligible for this study, you will complete measures of your height and weight. You will complete these measures at the beginning of the study. You will report to the Physical Activity and Weight Management on three occasions: one to obtain your height and weight and have you answer questionnaires about your eating habits, and two sessions where you will be eating macaroni and cheese. Also, you will be randomly assigned to one of three eating groups with randomization being similar to flipping a coin to decide what group you will be in. One group will eat as they normally would and the other two groups will be assigned a behavior to implement while eating.

If you complete this study you can earn up to $\$ 50$. There is the possibility that you may not like the taste of the meals provided or that you may experience gas, bloating, and indigestion from consuming these meals. You may also experience boredom, frustration, and stress from completing questionnaires. However, these risks are rare. If you are still interested in participating in this study, I will need to ask you a few questions about your demographic background, physical health, and medical history to determine if you appear to be eligible to participate in this study. It will take approximately 5 minutes to ask you all of the questions. If we complete the interview, I will ask you for some specific information (name, 
phone number, and mailing address) so that we can contact you regarding your participation in the study. If eligible, I will then schedule you for an initial assessment session that will explain all of the procedures of this study in greater detail.

\section{- Confidentiality Component of Informed Consent:}

If your answer to a particular question tells me clearly that you will not be eligible for this study, I will stop the interview, and not ask you any more personal questions.

\section{- Right to Participate or Withdraw from Participation Component of Informed} Consent:

Your responses to these questions are confidential and the information related to your health history or current behaviors that you are about to give me will be destroyed after this interview even if you are found to be eligible.

Do you have any questions related to any of the information that I have provided to you?

- Staff member will answer any questions or will defer these questions to the Principal Investigator or Co-investigator when appropriate prior to procedure. If the individual would like to think about their participation prior to proceeding with the Phone Screen, they will be provided with the telephone number that they can call if they decide to participate in the future.

\section{- Voluntary Consent Component of Informed Consent:}

Do you agree that the procedures that will be used to conduct this Phone Screen have been described to you, all of your questions have been answered, and you give me permission to ask you questions now as part of the initial Phone Screen?

- If "YES" indicate the participant's agreement with this statement on the top of the Phone Screen, and sign your name and date the form. Then complete the Phone Screen. If "NO", thank the individual for calling and do not complete the Phone Screen. 


\section{Contact Tracking Form}

Date: ___ I__ Staff Member Completing Form:

Name:

Street Address:

City:

State: __ Zip Code

Home Phone

Work Phone: 


\section{Subject ID\#}

Phone Screening FORM:

1. Gender: $\square$ Male $\square$ Female

2. Age: $\square \square(18-55)$

3. Which of the following best describes your racial heritage? (you may choose more than one category):

O American Indian or Alaska Native

O Asian

O Black or African-American

O Hispanic, Latino, or Cape Verdean

Native Hawaiian or Other Pacific Islander

O White

O Other (Specify:

4. How did you hear about the study?

O Flyer Location:

Word of Mouth

O Other

5. Current Weight: $\square \square \square$ pounds

6. Current Height: $\square$ feet $\square \square \square_{\text {inches }}$

Office Use: $B M I=$ $\left(18.5-39.9 \mathrm{~kg} / \mathrm{m}^{2}\right)$ 
7. Does someone else make your medical decisions for you? (ie., guardian or proxy) $\square$ YES $\square$ No

8. Have you ever been told by a doctor or other medical person that you have any conditions that may affect body weight or eating patterns? (i.e., thyroid disease)

If "yes", Specify:

$\square$ YES $\square$ No

9. Are you currently being treated for an eating disorder?

If "yes", Specify:

$\square$ YES $\square$ No

10. Have you undergone bariatric surgery? (i.e., lap-band, Roux-en- $Y$ gastric bypass, etc.)

$\square$ YES $\square$ No

11. Are you currently trying to lose or gain weight?

If "yes", Specify:

$\square$ YES $\square$ No

12. Are you presently being treated by a doctor or other medical person for any other physical or psychological problems? If "yes", specify:

$\square$ Yes $\square$ No

13. Do you take any over the counter or prescription medications (includes psychotropics) (i.e. synthroid)?

\section{$\square$ Yes $\square$ No}

If "yes", specify the following:

\begin{tabular}{|l|l|}
\hline Medication Name & Used to Treat: \\
\hline & \\
\hline & \\
\hline & \\
\hline
\end{tabular}

14. How would you describe your usual rate of eating compared to other people?

$\square$ very slow $\square$ relatively slow $\square$ average $\square$ relatively fast $\square$ very fast

15. Do you regularly practice meditation or mindfulness? ( $>1$ day of meditation per week over the past month)

If "yes", specify:

$\square$ Yes $\square$ No

16. Are you currently participating in other research studies?

$\square$ Yes $\square$ No If "yes", specify:

17. a. Are you currently pregnant?

b. Have you been pregnant in the last 6 months?

c. Are you currently lactating?

d. Do you have regular menstrual cycles? (25-35 days between cycles)

$\square$ YES $\square$ №

$\square$ YES $\square$ No

$\square$ YES $\square$ No

$\square$ Yes $\square$ NO

18. Do you like macaroni and cheese?

$\square$ Yes $\quad$ 口NO

19. Do you like meal replacement shakes?

$\square$ Yes $\mathrm{aNO}$

20. Are you allergic macaroni and cheege, meal replacement shakes, or any ingredients contained in these foods? (i.e., dairy, gluten, etc)

$\square$ YES $\square$ No

Figure 13. Recruitment and Telephone Screening Form 


\section{APPENDIX C: BASELINE ASSESSMENT DATA COLLECTION FORM}


SAME Study

Physical Assessment Form

Participant ID:

Date of Evaluation:

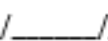

\section{PARTICIPANT VISIT CHECKLIST}

The participant needs to provide the following information/documentation prior to beginning their assessment session today.

$\square$ Informed Consent

$\square$ Contact Screening Form

$\square$ Needs to meet with Principal Investigator

The assessments must be completed in the following order. Under no circumstances is this protocol to be altered unless approved by the Principal Investigator for this participant.

$\square$ Greet Participant

$\square$ Height

$\square$ Weight

$\square$ Questionnaires

$\square$ First check at assessment visit

$\square$ Second check after assessment visit

$\square$ Distribute Pre-test Guidelines and Meal Replacement Shake
Initial:

Initial:

Initial:

Initial:

Initial:

Initial: 


\section{SAME Study}

Physical Assessment Form
Participant ID:

Date of Evaluation:

\section{SECTION I: HEIGHT ASSESSMENT}

Body Height: measured to the nearest $0.1 \mathrm{~cm}$

\begin{tabular}{|l|l|l|}
\hline $1^{\text {st }}$ Measurement & $2^{\text {nd }}$ Measurement & $3^{\text {rd }}$ Measurement \\
\hline & & \\
\hline
\end{tabular}

* If the $1^{\text {st }}$ and $2^{\text {nd }}$ measurements differ by $>0.5 \mathrm{~cm}$, then a $3^{\text {rd }}$ measurement is to be taken.

\section{SECTION II: WEIGHT ASSESMENT}

Body Weight: measured to the nearest $0.1 \mathrm{~kg}$

\begin{tabular}{|l|l|l|}
\hline $1^{\text {st }}$ Measurement & $2^{\text {nd }}$ Measurement & $3^{\text {rd }}$ Measurement \\
\hline & & \\
\hline
\end{tabular}

*If the $1^{\text {tt }}$ and $2^{\text {nd }}$ measurements differ by $.0 .2 \mathrm{~kg}$, then a $3^{\text {rd }}$ measurement is to be taken.

\section{SECTION III: BMI CALCULATION}

BMI: calculated as $\mathrm{kg} / \mathrm{m}^{2}$

$$
\text { BMI }\left(\mathrm{kg} / \mathrm{m}^{2}\right)
$$

*BMI calculated as the mean of weight measurements divided by the mean of height measurements squared.

\section{Figure 14. Baseline Assessment Data Collection Form}


APPENDIX D: BASELINE QUESTIONNAIRES 


\section{DEMOGRAPHICS}




\section{DEMOGRAPHICS}

Office Use Only

Subject ID \#:

1. Are you of Hispanic or Latino origin?

$\square$ Yes

$\square$ No

2. Which race best describes you? (Check all that apply)

$\square$ White or Caucasian

$\square$ Black or African American

$\square$ American Indian/Native American

$\square$ Native Hawaiian or other Pacific Islander

$\square$ Asian

$\square$ Other:

3. What is your gender? (Check one)

$\square$ Male
$\square$ Female

4. Date of birth: 1

5. What is the highest grade in school that you have finished? (Check one)

$\square$ Did not finish elementary school

$\square$ Finished middle school ( $8^{\text {tn }}$ grade)

$\square$ Finished some high school

$\square$ High School graduate or G.E.D

$\square$ Vocational of training school after high school

$\square$ Some College or Associate degree

$\square$ College graduate or Baccalaureate Degree

$\square$ Masters of Doctoral Degree (PhD, MD, JD, etc)

Figure 15. Demographics Questionnaire 
APPENDIX E: PRE-TEST GUIDELINES 


\section{PRE TEST GUIDELINES}

PLEASE FOLLOW THE INSTRUCTIONS BELOW PRIOR TO YOUR SESSION ON

1. CONSUME THE LIQUID MEAL REPLACEMENT SHAKE 4 HOURS BEFORE YOUR SCHEDULED ARRIVAL TIME

2. ABSTAIN FROM ALL OTHER FOOD OR BEVERAGES (WITH THE EXCEPTION OF WATER) THE MORNING OF YOUR SESSION

3. ABSTAIN FROM STRUCTURED MODERATE TO VIGOROUS PHYSICAL ACTIVITY FOR 12 HOURS PRIOR TO YOUR SESSION

4. ABSTAIN FROM CONSUMING ALCOHOL FOR 12 HOURS PRIOR TO YOUR SESSION

5. ABSTAIN FROM CONSUMING CAFFEINE FOR 12 HOURS PRIOR TO YOUR VISIT

It is very important that you adhere to these guidelines in order to participate in the test meal sessions so we ask that you make a conscious effort to do so. We will confirm that these guidelines were followed prior to your testing session. If you have any questions about any testing guidelines or procedures, do not hesitate to call Anna Peluso at 412-383-4046. If you are unable to keep your appointed time, please call the main number for the Physical Activity and Weight Management Research Center at 412-383-4020 to reschedule. Thank you again for your participation in this study!

Figure 16. Pre-Test Guidelines 
APPENDIX F: CONTROL EATING STRATEGY CONDITION DATA COLLECTION FORM AND SCRIPTS 


\section{CONTROL TEST MEAL SESSION DATA COLLECTION FORM}


1. Did you consume the provided shake 4 hours prior to your arrival?
$\square$ Yes $\rightarrow$ continue
$\square$ No $\rightarrow$ reschedule

2. Have you consumed alcohol or caffeine within the last 12 hours?
$\square$ Yes $\rightarrow$ reschedule
$\square$ No $\rightarrow$ continue

3. Have you participated in physical activity or exercise in the last 12 hours?

$$
\begin{aligned}
& \square \text { Yes } \rightarrow \text { reschedule } \\
& \square \text { No } \rightarrow \text { continue }
\end{aligned}
$$

Script:

Thank you for taking part in the SAME research study. We are interested in examining the differences in effectiveness between eating scenarios on measures of meal satisfaction and enjoyment. Please feel free to take as much time to eat your lunch as you would like. Following your lunch, we will ask you a few questions regarding your satisfaction with the meal. Any questions?

In this scenario, you will be listening to a brief audio passage with instructions on how to eat your lunch today. Please do not start eating until the audio recording is complete.

Time at Meal Initiation

Time at Meal Termination

Duration of Meal

4. Did the participant comply with condition instructions?
$\square$ Yes
$\square$ No Explain: 
SAME Study

CONTROL Session

Participant ID

Date of Evaluation:

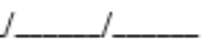

\section{Acute Energy Intake}

\begin{tabular}{|l|l|}
\hline Weight at Meal Initiation $(\mathrm{g})$ & \\
\hline Weight at Meal Termination $(\mathrm{g})$ & \\
\hline Total Volume of Food Consumed $(\mathrm{g})$ & \\
\hline Total Energy Intake (kcals) & \\
\hline
\end{tabular}

Water Intake

Water at Meal Initiation (fl oz)

Water at Meal Termination (fl oz)

Total Volume of Water Consumed ( $\mathrm{fl} \mathrm{oz}$ )

Figure 17. Control Test Meal Session Data Collection Form 
CONTROL TEST MEAL SESSION SCRIPTS 


\title{
Control Test Meal Session
}

Thank you for taking part in the SAME research study. We are interested in examining the differences in effectiveness between eating scenarios on measures of meal satisfaction and enjoyment. Please feel free to take as much time to eat your lunch as you would like. Water will be provided with your meal. Feel free to drink as much or as little as you would like. Following your lunch, we will ask you a few questions regarding your satisfaction with the meal.

Any questions?

Serve Food

In this scenario, you will be listening to a brief audio passage with instructions on how to eat your lunch. Please do not start eating until audio is complete.

\section{RECORDING:}

Hello and thank you for eating your lunch with us today! In this scenario, we are going to ask you to listen to a brief news story before eating your lunch. This story is about the National Park Service from CNN.

\begin{abstract}
"As the National Park Service celebrates its centennial anniversary this year, new numbers show that more people visited America's national park sites in 2015 than ever before. The park service's sites around the country hosted a record-breaking 307.2 million visits, according to NPS data released Wednesday. The Blue Ridge Parkway took the top spot in the National Park Service's list of the most visited places in the park system, which includes the 59 headliner national parks as well as historic sites, lakeshores, seashores and more. Great Smoky Mountains National Park was the most popular of the 59 sites officially called national parks. The National Park Service's 410 park sites encompass more than 84 million acres around the country. "That kind of takes your breath away for a second," said National Park Service Director Jonathan B. Jarvis. "But we're also getting ready to welcome even more people -- the next generation of park visitors, supporters and advocates -- in this, the centennial year of the National Park Service."'
\end{abstract}

We would now like you to eat until you are comfortably full.

When you have decided that you are finished, please alert us by opening the door.

Please take the cover off of your meal and begin to eat.

Prompt (after 3 minutes): The National Park System covers more than 84 million acres.

Prompt (after 5 minutes): There are 410 parks in the National Park System.

\section{Figure 18. Control Test Meal Session 1 Script}




\section{Control Test Meal Session Passage 2}

\section{RECORDING:}

Hello and thank you for eating your lunch with us today! In this scenario, we are going to ask you to listen to a brief news story before eating your lunch. This story is about Tiny House Vacations from CNN.

"Getaway, a tiny house vacation startup born in Harvard University's Innovation Lab, wants to steer guests away from the tendency to hop on TripAdvisor and plan out every moment of their precious time away. That's why it doesn't disclose the exact locations of its 160 square-foot houses -- all three of which are within a couple of hours of Boston -- to visitors until 24 hours before their trip. Getaway sees its tiny houses as a true escape, a way to disconnect from work "but also a way to disconnect from standard vacations, which tend to stress people out more than they should, given their purpose," CEO and co-founder Jon Staff said. "We really want you to just drop your bags and be there and read a book or play a board game or have a conversation with your loved one," Staff said. Staff, a Harvard Business School student, founded the company with Harvard Law student Pete Davis. Harvard Graduate School of Design students design the houses. The spare, wooden tiny homes are situated in quiet, rural settings complete with fire pits outside ready for s'mores. The Getaway houses rent for an average of $\$ 99$ per night. The cabins are stocked with food and supplies that guests can purchase."

We would now like you to eat until you are comfortably full.

When you have decided that you are finished, please alert us by opening the door.

Please take the cover off of your meal and begin to eat.

Prompt (after 3 minutes): The movement around tiny houses emphasizes small homes -- usually less than 400 square feet - that facilitate simple, economical living.

Prompt (after 5 minutes): Many of the tiny house rentals popping up on sites like Airbnb are in cities with tons of activities to jump into, but there are quiet, commune-with-nature-and-your-loved-ones options, too.

\section{Figure 19. Control Test Meal Session 2 Script}




\section{APPENDIX G: SLOW EATING STRATEGY CONDITION DATA COLLECTION}

FORM AND SCRIPT 


\section{SLOW TEST MEAL SESSION DATA COLLECTION FORM}


SAME Study

SLOW Session

Participant ID:

Date of Evaluation:

1. Did you consume the provided shake 4 hours prior to your arrival?
$\square$ Yes $\rightarrow$ continue
$\square$ No $\rightarrow$ reschedule

2. Have you consumed alcohol or caffeine within the last 12 hours?
$\square$ Yes $\rightarrow$ reschedule
$\square$ No $\rightarrow$ continue

3. Have you participated in physical activity or exercise in the last 12 hours?

$$
\begin{aligned}
& \square \text { Yes } \rightarrow \text { reschedule } \\
& \square \text { No } \rightarrow \text { continue }
\end{aligned}
$$

Script:

Thank you for taking part in the SAME research study. We are interested in examining the differences in effectiveness between eating scenarios on measures of meal satisfaction and enjoyment. Please feel free to take as much time to eat your lunch as you would like. Following your lunch, we will ask you a few questions regarding your satisfaction with the meal. Any questions?

In this scenario, you will be listening to a brief audio passage with instructions on how to eat your lunch today. Please do not start eating until the audio recording is complete.

\begin{tabular}{|l|l|}
\hline Time at Meal Initiation & \\
\hline Time at Meal Termination & \\
\hline Duration of Meal & \\
\hline
\end{tabular}

1. Did the participant comply with condition instructions?
$\square$ Yes
$\square$ No Explain: 
SAME Study

SLOW Session

Participant ID:

Date of Evaluation:

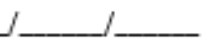

Acute Energy Intake

\begin{tabular}{|l|l|}
\hline Weight at Meal Initiation $(\mathrm{g})$ & \\
\hline Weight at Meal Termination $(\mathrm{g})$ & \\
\hline Total Volume of Food Consumed $(\mathrm{g})$ & \\
\hline Total Energy Intake (kcals) & \\
\hline
\end{tabular}

\section{Water Intake}

Water at Meal nitiation (fl oz)

Water at Meal Termination (fl oz)

Total Volume of Water Consumed (fl oz)

Figure 20. Slow Test Meal Session Data Collection Form 


\section{SLOW TEST MEAL SESSION SCRIPT}




\section{Slow Eating Test Meal Session}

Thank you for taking part in the SAME research study. We are interested in examining the differences in effectiveness between eating scenarios on measures of meal satisfaction and enjoyment. Please feel free to take as much time to eat your lunch as you would like. Water will be provided with your meal. Feel free to drink as much or as little as you would like. Following your lunch, we will ask you a few questions regarding your satisfaction with the meal.

Any questions?

Serve Food

In this scenario, you will be listening to a brief audio passage with instructions on how to eat your lunch. Please do not start eating until audio is complete.

RECORDING:

Hello and thank you for eating your lunch with us today! In this scenario, we are going to ask you to eat in a way that may not be completely natural for you, but we ask that you follow the instructions as closely as possible. As you eat, we would like for you to put your fork down onto the plate after each and every time that you take a bite of your meal. Make sure to put the fork completely down. Try chewing each bite of food at least 15 to 30 times before swallowing. Don't pick up your fork again until the bite you have in your mouth is chewed completely and swallowed. Once that bite has been completely swallowed and is gone from your mouth, then you can pick up the fork, take another bite, and put the fork down again.

Continue on with this process for the entire lunch until you feel as if you are comfortably full.

When you have decided that you are finished, please alert us by opening the door.

Please take the cover off of your meal and begin to eat.

Prompt (after 3 minutes): Remember to put your fork down in between each bite. Chew each bite at least 15 to 30 times and completely swallow before taking your next bite.

Prompt (after 5 minutes): Remember to put your fork down in between each bite. Chew each bite at least 15 to 30 times and completely swallow before taking your next bite.

\section{Figure 21. Slow Test Meal Session Script}


APPENDIX H: MINDFUL EATING STRATEGY CONDITION DATA COLLECTION FORM AND SCRIPT 
MINDFUL EATING TEST MEAL DATA COLLECTION FORM 
SAME Study

MIND Session
Participant ID:

Date of Evaluation:

1. Did you consume the provided shake 4 hours prior to your arrival?
$\square$ Yes $\rightarrow$ continue
$\square$ No $\rightarrow$ reschedule

2. Have you consumed alcohol or caffeine within the last 12 hours?
$\square$ Yes $\rightarrow$ reschedule
$\square$ No $\rightarrow$ continue

3. Have you participated in physical activity or exercise in the last 12 hours?

$$
\begin{aligned}
& \square \text { Yes } \rightarrow \text { reschedule } \\
& \square \text { No } \rightarrow \text { continue }
\end{aligned}
$$

Script

Thank you for taking part in the SAME research study. We are interested in examining the differences in effectiveness between eating scenarios on measures of meal satisfaction and enjoyment. Please feel free to take as much time to eat your lunch as you would like. Following your lunch, we will ask you a few questions regarding your satisfaction with the meal. Any questions?

In this scenario, you will be listening to a brief audio passage with instructions on how to eat your lunch today. Please do not start eating until the audio recording is complete.

Time at Meal Initiation

Time at Meal Termination

Duration of Meal

1. Did the participant comply with condition instructions?
$\square$ Yes
$\square$ No Explain: 


\section{SAME Study}

MIND Session

Participant ID:

Date of Evaluation:

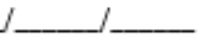

\section{Acute Energy Intake}

\begin{tabular}{|l|l|}
\hline Weight at Meal Initiation $(\mathrm{g})$ & \\
\hline Weight at Meal Termination $(\mathrm{g})$ & \\
\hline Total Volume of Food Consumed $(\mathrm{g})$ & \\
\hline Total Energy Intake (kcals) & \\
\hline
\end{tabular}

\section{Water Intake}

Water at Meal Initiation (fl oz)

Water at Meal Termination (fl oz)

Total Volume of Water Consumed (fl oz)

Figure 22. Mindful Test Meal Session Data Collection Form 
MINDFUL TEST MEAL SESSION SCRIPT 


\section{Mindfulness Test Meal Session}

Thank you for taking part in the SAME research study. We are interested in examining the differences in effectiveness between eating scenarios on measures of meal satisfaction and enjoyment. Please feel free to take as much time to eat your lunch as you would. Following your lunch, we will ask you a few questions regarding your satisfaction with the meal.

Any questions?

Serve Food

In this scenario, you will be listening to a brief audio passage with instructions on how to eat your lunch. Please do not start eating until audio is complete.

\section{RECORDING:}

Hello and thank you for eating your lunch with us today! In this scenario, we are going to ask you to eat in a way that may not be completely natural for you, but we ask that you follow the instructions as closely as possible. Before you begin eating, we would like for you to take two deep breaths in through your nose and out of your mouth. Then, take a brief moment to become aware of how hungry you are right now. Using a scale from 1 to 10 , with 1 being not hungry at all and 10 being as hungry as you have ever been, rank your current hunger level. Then before taking a bite, take a look at the food on your plate, noticing the colors, textures, shapes, and smells. When you are ready to begin eating, we want you to try to eat like a fine wine connoisseur tastes wine. First smell the food, anticipating the taste. Then once you put the food into your mouth, pay attention to the flavors and textures of the food. Notice if the flavor changes as you begin to chew. Savor the taste as you roll it around your mouth and feel the saliva burst forth as you prepare to swallow. Then swallow your bite. If you wish, you may take a sip of water to cleanse the palate. Continue to eat the meal in this manner, savoring each bite. Occasionally throughout the meal, check in with your hunger using the same scale as before. If you should notice at any point in the meal that you are eating without tasting, stop and pause to look at the food again. Take a moment to appreciate the food in front of you and the energy and nourishment that it is giving your body.

Continue on with this process for the entire lunch until you feel as if you are comfortably full.

When you have decided that you are finished, please alert us by opening the door.

Please take the cover off of your meal and begin to eat.

Prompt (after 3 minutes): Remember to notice the flavors, textures, and smells of your food; savoring each bite. If you should notice at any point in the meal that you are eating without tasting, stop and pause to look at the food again.

Prompt (after 5 minutes): Remember to notice the flavors, textures, and smells of your food; savoring each bite. If you should notice at any point in the meal that you are eating without tasting, stop and pause to look at the food again.

Figure 23. Mindful Test Meal Session Script 
APPENDIX I: POST-TEST QUESTIONNAIRES 
MINDFUL EATING QUESTIONNAIRE 
Directions: Check the box that best describes how you ate your meal. Check only one box per question.

I noticed when there were subtle flavors in the foods I ate.

never/rarely sometimes often

Before I ate, I took a moment to appreciate the colors and smells of my food. never/rarely sometimes often usually/always

I appreciated the way the food looked on my plate. never/rarely sometimes often usually/always

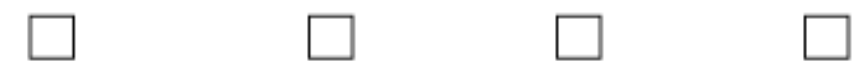

When eating the meal, I noticed if I felt relaxed.

never/rarely sometimes often usually/always

I tasted every bite of food that I ate.

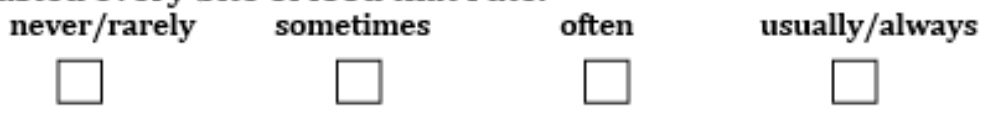

I noticed when the food I ate affected my emotional state.
never/rarely
sometimes
often
usually/always
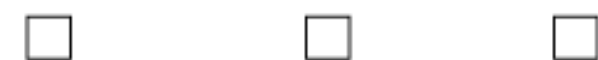

I noticed when the food or drink was too salty.

$\begin{array}{cccc}\text { never/rarely sometimes } & \text { often } & \text { usually/always } \\ \square & \square & \square & \square\end{array}$

My thoughts tended to wander while I was eating.
never/rarely
sometimes
often
usually/always

I thought about things that I need to do while I was eating. never/rarely

sometimes

often

usually/always

I ate so quickly that I didn't taste what I was eating.

never/rarely sometimes often

Figure 24. Mindful Eating Questionnaire 
SATIETY VISUAL ANALOGUE SCALE 
Directions: Check the box that best describes how you feel right now. Check only one box per question.

\section{How hungry do you feel right now?}

$\begin{array}{ccccccc}\begin{array}{c}\text { Not hungry } \\ \text { At all }\end{array} & \begin{array}{c}\text { Not } \\ \text { Hungry }\end{array} & \begin{array}{c}\text { Not Very } \\ \text { Hungry }\end{array} & \text { Neutral } & \text { Hungry } & \begin{array}{c}\text { Very } \\ \text { Hungry }\end{array} & \begin{array}{c}\text { Very, very } \\ \text { Hungry }\end{array} \\ \square & \square & \square & \square\end{array}$

\section{How full do you feel right now?}

\begin{tabular}{lllllll} 
Not full at all & Not full & Not very full & Neutral & Full & Very Full & $\begin{array}{c}\text { Very, very } \\
\text { full }\end{array}$ \\
\hline & $\square$ & $\square$ & $\square$
\end{tabular}

Figure 25. Satiety Visual Analog Scale 
MEAL SATISFACTION VISUAL ANALOGUE SCALE 
Directions: Check the box that best describes your level of satisfaction. Check only one box per question.

How satisfied were you with the visual appeal of the macaroni and cheese?

$\begin{array}{ccccccc}\begin{array}{c}\text { Not Satisfied } \\ \text { At all }\end{array} & \begin{array}{c}\text { Not } \\ \text { Satisfied }\end{array} & \begin{array}{c}\text { Not Very } \\ \text { Satisfied }\end{array} & \text { Neutral } & \text { Satisfied } & \begin{array}{c}\text { Very } \\ \text { Satisfied }\end{array} & \begin{array}{c}\text { Very, very } \\ \text { Satisfied }\end{array} \\ \square & \square & \square & \square & \square & \square\end{array}$

How satisfied were you with the smell of the macaroni and cheese?

$\begin{array}{ccccccc}\begin{array}{c}\text { Not Satisfied } \\ \text { At all }\end{array} & \begin{array}{c}\text { Not } \\ \text { Satisfied }\end{array} & \begin{array}{c}\text { Not Very } \\ \text { Satisfied }\end{array} & \text { Neutral } & \text { Satisfied } & \begin{array}{c}\text { Very } \\ \text { Satisfied }\end{array} & \begin{array}{c}\text { Very, very } \\ \text { Satisfied }\end{array} \\ \square & \square & \square & \square & \square & \square & \square\end{array}$

How satisfied were you with the taste of the macaroni and cheese?

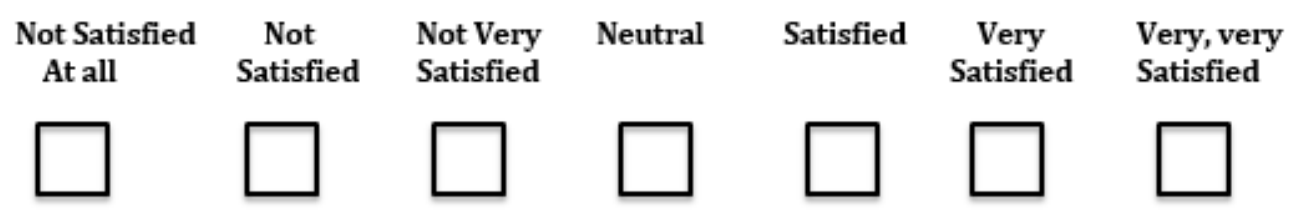

How satisfied were you with the aftertaste of the macaroni and cheese?

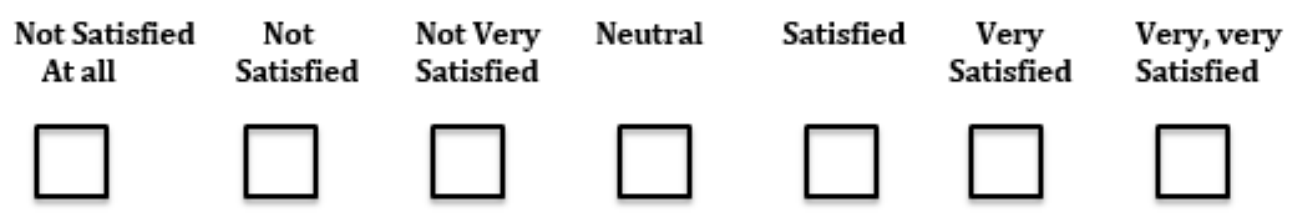

Figure 26. Meal Satisfaction Visual Analog Scale 


\section{BIBLIOGRAPHY}

1. Ogden CL, Carroll MD, Kit BK, Flegal KM. Prevalence of childhood and adult obesity in the United States, 2011-2012. JAMA. 2014;311(8):806-14.

2. Jensen MD, Ryan DH, Apovian CM, Ard JD, Comuzzie AG, Donato KA, et al. AHA/ACC/TOS guideline for the management of overweight and obesity in adults. Obesity 2013. 2013.

3. Jakicic JM, Tate DF, Lang W, Davis KK, Polzien K, Rickman AD, et al. Effect of a stepped-care intervention approach on weight loss in adults: a randomized clinical trial. JAMA. 2012;307(24):2617-26.

4. Gold BC, Burke S, Pintauro S, Buzzell P, Harvey-Berino J. Weight loss on the web: A pilot study comparing a structured behavioral intervention to a commercial program. Obesity. 2007;15(1):155-.

5. Appel LJ, Clark JM, Yeh H-C, Wang N-Y, Coughlin JW, Daumit G, et al. Comparative effectiveness of weight-loss interventions in clinical practice. New England Journal of Medicine. 2011;365(21):1959-68.

6. Wantland DJ, Portillo CJ, Holzemer WL, Slaughter R, McGhee EM. The effectiveness of Web-based vs. non-Web-based interventions: a meta-analysis of behavioral change outcomes. Journal of medical Internet research. 2004;6(4).

7. Wing RR, Tate DF, Gorin AA, Raynor HA, Fava JL. A self-regulation program for maintenance of weight loss. New England Journal of Medicine. 2006;355(15):1563-71.

8. Jeffery RW, Epstein LH, Wilson GT, Drewnowski A, Stunkard AJ, Wing RR. Long-term maintenance of weight loss: current status. Health psychology. 2000;19(1S):5.

9. ACSM's guidelines for exercise testing and prescription. 9th ed. New York: Lippincott Williams \& Wilkins; 2013.

10. Venditti EM, Wylie-Rosett J, Delahanty LM, Mele L, Hoskin MA, Edelstein SL, et al. Short and long-term lifestyle coaching approaches used to address diverse participant barriers to weight loss and physical activity adherence. International Journal of Behavioral Nutrition and Physical Activity. 2014;11(1):16. 
11. Burke LE, Wang J, Sevick MA. Self-monitoring in weight loss: a systematic review of the literature. Journal of the American Dietetic Association. 2011;111(1):92-102.

12. Akers JD, Cornett RA, Savla JS, Davy KP, Davy BM. Daily self-monitoring of body weight, step count, fruit/vegetable intake, and water consumption: a feasible and effective long-term weight loss maintenance approach. Journal of the Academy of Nutrition and Dietetics. 2012;112(5):685-92. e2.

13. Donnelly JE, Blair SN, Jakicic JM, Manore MM, Rankin JW, Smith BK. American College of Sports Medicine Position Stand. Appropriate physical activity intervention strategies for weight loss and prevention of weight regain for adults. Medicine and science in sports and exercise. 2009;41(2):459-71.

14. Levine JA. Measurement of energy expenditure. Public health nutrition. 2005;8(7a):112332.

15. Davis NJ, Ma Y, Delahanty LM, Hoffman HJ, Mayer-Davis E, Franks PW, et al. Predictors of sustained reduction in energy and fat intake in the Diabetes Prevention Program Outcomes Study intensive lifestyle intervention. Journal of the Academy of Nutrition and Dietetics. 2013;113(11):1455-64.

16. Andreyeva T, Long MW, Henderson KE, Grode GM. Trying to lose weight: diet strategies among Americans with overweight or obesity in 1996 and 2003. Journal of the American Dietetic Association. 2010;110(4):535-42.

17. (AHA). AHA. About fruit and vegetables (on-line).

18. Teixeira PJ, Silva MN, Coutinho SR, Palmeira AL, Mata J, Vieira PN, et al. Mediators of Weight Loss and Weight Loss Maintenance in Middle-aged Women. Obesity. 2010;18(4):725-35.

19. Unick JL, Jakicic JM, Marcus BH. Contribution of behavior intervention components to 24-month weight loss. Medicine and science in sports and exercise. 2010;42(4):745.

20. Coughlin J, Gullion C, Brantley P, Stevens V, Bauck A, Champagne C, et al. Behavioral mediators of treatment effects in the weight loss maintenance trial. Annals of Behavioral Medicine. 2013;46(3):369-81.

21. Fisk PS, Middaugh AL, Rhee YS, Brunt AR. Few favorable associations between fruit and vegetable intake and biomarkers for chronic disease risk in American adults. Nutrition Research. 2011;31(8):616-24.

22. Ohkuma T, Hirakawa Y, Nakamura U, Kiyohara Y, Kitazono T, Ninomiya T. Association between eating rate and obesity: a systematic review and meta-analysis. International Journal of Obesity. 2015.

23. Spiegel TA, Wadden TA, Foster GD. Objective measurement of eating rate during behavioral treatment of obesity. Behavior Therapy. 1992;22(1):61-7. 
24. Leong SL, Gray A, Horwath CC. Speed of eating and 3-year BMI change: a nationwide prospective study of mid-age women. Public health nutrition. 2015:1-7.

25. Andrade AM, Greene GW, Melanson KJ. Eating slowly led to decreases in energy intake within meals in healthy women. Journal of the American Dietetic Association. 2008;108(7):1186-91.

26. Privitera GJ, Cooper KC, Cosco AR. The influence of eating rate on satiety and intake among participants exhibiting high dietary restraint. Food \& nutrition research. 2012;56.

27. Ferriday D, Bosworth ML, Lai S, Godinot N, Martin N, Martin AA, et al. Effects of eating rate on satiety: A role for episodic memory? Physiology \& behavior. 2015;152:389-96.

28. Almiron-Roig E, Tsiountsioura M, Lewis HB, Wu J, Solis-Trapala I, Jebb SA. Large portion sizes increase bite size and eating rate in overweight women. Physiology \& behavior. 2015;139:297-302.

29. Andrade AM, Kresge DL, Teixeira PJ, Baptista F, Melanson KJ. Does eating slowly influence appetite and energy intake when water intake is controlled? Int J Behav Nutr Phys Act. 2012;9(1):135-.

30. Martin CK, Anton SD, Walden H, Arnett C, Greenway FL, Williamson DA. Slower eating rate reduces the food intake of men, but not women: implications for behavioral weight control. Behaviour research and therapy. 2007;45(10):2349-59.

31. Yeomans MR, Gray RW, Mitchell CJ, True S. Independent effects of palatability and within-meal pauses on intake and appetite ratings in human volunteers. Appetite. 1997;29(1):61-76.

32. Benelam B. Satiation, satiety and their effects on eating behaviour. Nutrition Bulletin. 2009;34(2):126-73.

33. Park S, Shin W-S. Differences in eating behaviors and masticatory performances by gender and obesity status. Physiology \& behavior. 2015;138:69-74.

34. Koh J, Pliner P. The effects of degree of acquaintance, plate size, and sharing on food intake. Appetite. 2009;52(3):595-602.

35. Hermans RC, Larsen JK, Herman CP, Engels RC. How much should I eat? Situational norms affect young women's food intake during meal time. British Journal of Nutrition. 2012;107(04):588-94.

36. Robinson E, Hardman CA, Halford JC, Jones A. Eating under observation: a systematic review and meta-analysis of the effect that heightened awareness of observation has on laboratory measured energy intake. The American journal of clinical nutrition. 2015;102(2):324-37. 
37. Brown KW, Ryan RM. The benefits of being present: mindfulness and its role in psychological well-being. Journal of personality and social psychology. 2003;84(4):822.

38. Daubenmier J, Lin J, Blackburn E, Hecht FM, Kristeller J, Maninger N, et al. Changes in stress, eating, and metabolic factors are related to changes in telomerase activity in a randomized mindfulness intervention pilot study. Psychoneuroendocrinology. 2012;37(7):917-28.

39. Monroe JT. Mindful Eating Principles and Practice. American Journal of Lifestyle Medicine. 2015:1559827615569682.

40. Kristeller JL, Wolever RQ. Mindfulness-based eating awareness training for treating binge eating disorder: the conceptual foundation. Eating Disorders. 2010;19(1):49-61.

41. Garland EL, Gaylord SA, Boettiger CA, Howard MO. Mindfulness training modifies cognitive, affective, and physiological mechanisms implicated in alcohol dependence: results of a randomized controlled pilot trial. Journal of psychoactive drugs. 2010;42(2):177-92.

42. Duclaux R, Feisthauer J, Cabanac M. Effets du repas sur l'agrément d'odeurs alimentaires et nonalimentaires chez l'homme. Physiology \& Behavior. 1973;10(6):1029-33.

43. Hepworth NS. A mindful eating group as an adjunct to individual treatment for eating disorders: A pilot study. Eating Disorders. 2010;19(1):6-16.

44. Kristeller JL, Hallett CB. An exploratory study of a meditation-based intervention for binge eating disorder. Journal of health psychology. 1999;4(3):357-63.

45. Timmerman GM, Brown A. The effect of a mindful restaurant eating intervention on weight management in women. Journal of nutrition education and behavior. 2012;44(1):22-8.

46. O'Reilly G, Cook L, Spruijt-Metz D, Black D. Mindfulness-based interventions for obesity-related eating behaviours: a literature review. Obesity Reviews. 2014;15(6):45361.

47. Cavanagh K, Vartanian LR, Herman CP, Polivy J. The effect of portion size on food intake is robust to brief education and mindfulness exercises. Journal of health psychology. 2014;19(6):730-9.

48. Dalen J, Smith BW, Shelley BM, Sloan AL, Leahigh L, Begay D. Pilot study: Mindful Eating and Living (MEAL): weight, eating behavior, and psychological outcomes associated with a mindfulness-based intervention for people with obesity. Complementary therapies in medicine. 2010;18(6):260-4.

49. Daubenmier J, Kristeller J, Hecht FM, Maninger N, Kuwata M, Jhaveri K, et al. Mindfulness intervention for stress eating to reduce cortisol and abdominal fat among 
overweight and obese women: an exploratory randomized controlled study. Journal of obesity. 2011;2011.

50. Creswell JD, Pacilio LE, Lindsay EK, Brown KW. Brief mindfulness meditation training alters psychological and neuroendocrine responses to social evaluative stress. Psychoneuroendocrinology. 2014;44:1-12.

51. Alberts H, Thewissen R, Raes L. Dealing with problematic eating behaviour. The effects of a mindfulness-based intervention on eating behaviour, food cravings, dichotomous thinking and body image concern. Appetite. 2012;58(3):847-51.

52. Katterman SN, Kleinman BM, Hood MM, Nackers LM, Corsica JA. Mindfulness meditation as an intervention for binge eating, emotional eating, and weight loss: A systematic review. Eating behaviors. 2014;15(2):197-204.

53. Kristeller J, Wolever RQ, Sheets V. Mindfulness-based eating awareness training (MBEAT) for binge eating: A randomized clinical trial. Mindfulness. 2014;5(3):282-97.

54. Jordan $\mathrm{CH}$, Wang W, Donatoni L, Meier BP. Mindful eating: Trait and state mindfulness predict healthier eating behavior. Personality and Individual Differences. 2014;68:107-11.

55. Marchiori D, Papies EK. A brief mindfulness intervention reduces unhealthy eating when hungry, but not the portion size effect. Appetite. 2014;75:40-5.

56. Alberts HJ, Mulkens S, Smeets M, Thewissen R. Coping with food cravings. Investigating the potential of a mindfulness-based intervention. Appetite. 2010;55(1):160-3.

57. Laitinen J, Ek E, Sovio U. Stress-related eating and drinking behavior and body mass index and predictors of this behavior. Preventive medicine. 2002;34(1):29-39.

58. Konttinen H, Männistö S, Sarlio-Lähteenkorva S, Silventoinen K, Haukkala A. Emotional eating, depressive symptoms and self-reported food consumption. A population-based study. Appetite. 2010;54(3):473-9.

59. Macht M, Simons G. Emotions and eating in everyday life. Appetite. 2000;35(1):65-71.

60. Williams RA, Roe LS, Rolls BJ. Assessment of satiety depends on the energy density and portion size of the test meal. Obesity. 2014;22(2):318-24.

61. Blatt AD, Williams RA, Roe LS, Rolls BJ. Effects of Energy Content and Energy Density of Pre-Portioned Entrées on Energy Intake. Obesity. 2012;20(10):2010-8.

62. Rolls BJ, Meengs JS, Roe LS. Variations in Cereal Volume Affect the Amount Selected and Eaten for Breakfast. Journal of the Academy of Nutrition and Dietetics. 2014;114(9):1411-6.

63. Williams RA, Roe LS, Rolls BJ. Comparison of three methods to reduce energy density. Effects on daily energy intake. Appetite. 2013;66:75-83. 
64. Meengs JS, Roe LS, Rolls BJ. Vegetable variety: an effective strategy to increase vegetable intake in adults. Journal of the Academy of Nutrition and Dietetics. 2012;112(8):1211-5.

65. De Graaf C, Blom WA, Smeets PA, Stafleu A, Hendriks HF. Biomarkers of satiation and satiety. The American journal of clinical nutrition. 2004;79(6):946-61.

66. Flint A, Raben A, Ersbøll A, Holst J, Astrup A. The effect of physiological levels of glucagon-like peptide-1 on appetite, gastric emptying, energy and substrate metabolism in obesity. International journal of obesity and related metabolic disorders: journal of the International Association for the Study of Obesity. 2001;25(6):781-92.

67. Hogenkamp PS, Schiöth HB. Effect of oral processing behaviour on food intake and satiety. Trends in Food Science \& Technology. 2013;34(1):67-75.

68. Ruijschop RM, Zijlstra N, Boelrijk AE, Dijkstra A, Burgering MJ, Graaf Cd, et al. Effects of bite size and duration of oral processing on retro-nasal aroma release-features contributing to meal termination. British Journal of Nutrition. 2011;105(02):307-15.

69. Rolls BJ. Sensory-specific satiety. Nutrition Reviews. 1986;44(3):93-101.

70. Liddle RA, Goldfine ID, Rosen MS, Taplitz R, Williams J. Cholecystokinin bioactivity in human plasma. Molecular forms, responses to feeding, and relationship to gallbladder contraction. Journal of Clinical Investigation. 1985;75(4):1144.

71. Moran TH, Kinzig KP. Gastrointestinal satiety signals II. Cholecystokinin. American Journal of Physiology-Gastrointestinal and Liver Physiology. 2004;286(2):G183-G8.

72. Cummings DE, Overduin J. Gastrointestinal regulation of food intake. Journal of Clinical Investigation. 2007;117(1):13.

73. Ng DM, Jeffery RW. Relationships between perceived stress and health behaviors in a sample of working adults. Health Psychology. 2003;22(6):638.

74. McCann BS, Warnick GR, Knopp RH. Changes in plasma lipids and dietary intake accompanying shifts in perceived workload and stress. Psychosomatic medicine. 1990;52(1):97-108.

75. Grunberg NE, Straub RO. The role of gender and taste class in the effects of stress on eating. Health Psychology. 1992;11(2):97.

76. Cartwright M, Wardle J, Steggles N, Simon AE, Croker H, Jarvis MJ. Stress and dietary practices in adolescents. Health Psychology. 2003;22(4):362.

77. Oliver G, Wardle J, Gibson EL. Stress and food choice: a laboratory study. Psychosomatic medicine. 2000;62(6):853-65. 
78. Leon GR, Fulkerson JA, Perry CL, Early-Zald MB. Prospective analysis of personality and behavioral vulnerabilities and gender influences in the later development of disordered eating. Journal of Abnormal Psychology. 1995;104(1):140.

79. van Strien T. Ice-cream consumption, tendency toward overeating, and personality. International Journal of Eating Disorders. 2000;28(4):460-4.

80. Van Strien T, Engels RC, Van Leeuwe J, Snoek HM. The Stice model of overeating: tests in clinical and non-clinical samples. Appetite. 2005;45(3):205-13.

81. Van Strien T, Ouwens MA. Counterregulation in female obese emotional eaters: Schachter, Goldman, and Gordon's (1968) test of psychosomatic theory revisited. Eating Behaviors. 2003;3(4):329-40.

82. Wadden TA, Stunkard AJ. Handbook of obesity treatment: Guilford Press; 2002.

83. Hubert HB, Feinleib M, McNamara PM, Castelli WP. Obesity as an independent risk factor for cardiovascular disease: a 26-year follow-up of participants in the Framingham Heart Study. Circulation. 1983;67(5):968-77.

84. Finkelstein EA, Khavjou OA, Thompson H, Trogdon JG, Pan L, Sherry B, et al. Obesity and severe obesity forecasts through 2030. American journal of preventive medicine. 2012;42(6):563-70.

85. Cawley J, Meyerhoefer C. The medical care costs of obesity: an instrumental variables approach. Journal of health economics. 2012;31(1):219-30.

86. Weinsier RL, Hunter GR, Heini AF, Goran MI, Sell SM. The etiology of obesity: relative contribution of metabolic factors, diet, and physical activity. The American journal of medicine. 1998;105(2):145-50.

87. Tappy L. Thermic effect of food and sympathetic nervous system activity in humans. Reproduction Nutrition Development. 1996;36(4):391-7.

88. Levine JA, Vander Weg MW, Hill JO, Klesges RC. Non-exercise activity thermogenesis the crouching tiger hidden dragon of societal weight gain. Arteriosclerosis, thrombosis, and vascular biology. 2006;26(4):729-36.

89. Kant AK, Graubard BI. 40-year trends in meal and snack eating behaviors of American adults. Journal of the Academy of Nutrition and Dietetics. 2015;115(1):50-63.

90. Medicine ACoS, editor. ACSM's guidelines for exercise testing and prescription. 9th ed. New York: Lippincott Williams \& Wilkins; 2013.

91. Alexander GL, McClure JB, Calvi JH, Divine GW, Stopponi MA, Rolnick SJ, et al. A randomized clinical trial evaluating online interventions to improve fruit and vegetable consumption. American journal of public health. 2010;100(2):319-26. 
92. Medicine ACoS. Appropriate intervention strategies for weight loss and prevention of weight regain for adults. Med Sci Sports Exerc. 2001;33(12):2145-56.

93. Kramer FM, Jeffery RW, Forster JL, Snell MK. Long-term follow-up of behavioral treatment for obesity: patterns of weight regain among men and women. International journal of obesity. 1988;13(2):123-36.

94. Whelton PK, Appel LJ, Espeland MA, Applegate WB, Ettinger Jr WH, Kostis JB, et al. Sodium reduction and weight loss in the treatment of hypertension in older persons: a randomized controlled trial of nonpharmacologic interventions in the elderly (TONE). Jama. 1998;279(11):839-46.

95. Group HPTR. The Hypertension Prevention Trial: three-year effects of dietary changes on blood pressure. Archives of Internal Medicine. 1990;150(1):153-62.

96. Gletsu-Miller N, McCrory MA. Modifying Eating Behavior: Novel Approaches for Reducing Body Weight, Preventing Weight Regain, and Reducing Chronic Disease Risk. Advances in Nutrition: An International Review Journal. 2014;5(6):789-91.

97. Koidis F, Brunger L, Gibbs M, Hampton S. The effect of eating rate on satiety in healthy and overweight people-A pilot study. e-SPEN Journal. 2014;9(2):e54-e8.

98. Shah M, Copeland J, Dart L, Adams-Huet B, James A, Rhea D. Slower eating speed lowers energy intake in normal-weight but not overweight/obese subjects. Journal of the Academy of Nutrition and Dietetics. 2014;114(3):393-402.

99. Sun L, Ranawana DV, Tan WJK, Quek YCR, Henry CJ. The impact of eating methods on eating rate and glycemic response in healthy adults. Physiology \& behavior. 2015;139:50510.

100. Rahula W. What the Buddha Taught. New York: Grove Weidenfeld; 1959.

101. Ostafin BD, Robinson MD, Meier BP. Handbook of Mindfulness and Self-regulation: Springer; 2015.

102. Dutton GR. The role of mindfulness in health behavior change. ACSM's Health \& Fitness Journal. 2008;12(4):7-12.

103. Kabat-Zinn J. Wherever You Go, There You Are: Mindfulness Meditation in Everyday Life. New York: Hyperion; 1994.

104. Fisher N, Lattimore P, Malinowski P. Attention with a mindful attitude attenuates subjective appetitive reactions and food intake following food-cue exposure. Appetite. 2016;99:10-6.

105. Miller CK, Kristeller JL, Headings A, Nagaraja H, Miser WF. Comparative effectiveness of a mindful eating intervention to a diabetes self-management intervention among adults 
with type 2 diabetes: a pilot study. Journal of the Academy of Nutrition and Dietetics. 2012;112(11):1835-42.

106. Jenkins KT, Tapper K. Resisting chocolate temptation using a brief mindfulness strategy. British journal of health psychology. 2014;19(3):509-22.

107. Papies EK, Barsalou LW, Custers R. Mindful attention prevents mindless impulses. Social Psychological and Personality Science. 2012;3(3):291-9.

108. Arch JJ, Brown KW, Goodman RJ, Della Porta MD, Kiken LG, Tillman S. Enjoying food without caloric cost: The impact of brief mindfulness on laboratory eating outcomes. Behaviour research and therapy. 2016;79:23-34.

109. Fulwiler C, Brewer JA, Sinnott S, Loucks EB. Mindfulness-Based Interventions for Weight Loss and CVD Risk Management. Current Cardiovascular Risk Reports. 2015;9(10):1-8.

110. Kissileff HR, Carretta JC, Geliebter A, Pi-Sunyer FX. Cholecystokinin and stomach distension combine to reduce food intake in humans. American Journal of PhysiologyRegulatory, Integrative and Comparative Physiology. 2003;285(5):R992-R8.

111. Degen L, Matzinger D, Drewe J, Beglinger C. The effect of cholecystokinin in controlling appetite and food intake in humans. Peptides. 2001;22(8):1265-9.

112. Melton PM, Kissileff HR, Pi-Sunyer FX. Cholecystokinin (CCK-8) affects gastric pressure and ratings of hunger and fullness in women. American Journal of Physiology-Regulatory, Integrative and Comparative Physiology. 1992;263(2):R452-R6.

113. Chida Y, Steptoe A. Cortisol awakening response and psychosocial factors: a systematic review and meta-analysis. Biological psychology. 2009;80(3):265-78.

114. Rosmond R. Stress induced disturbances of the HPA axis: a pathway to type 2 diabetes? Medical Science Monitor. 2003;9(2):RA35-RA9.

115. Smith SM, Vale WW. The role of the hypothalamic-pituitary-adrenal axis in neuroendocrine responses to stress. Dialogues in clinical neuroscience. 2006;8(4):383.

116. Peters A, Schweiger U, Pellerin L, Hubold C, Oltmanns K, Conrad M, et al. The selfish brain: competition for energy resources. Neuroscience \& Biobehavioral Reviews. 2004;28(2):143-80.

117. Kuo LE, Kitlinska JB, Tilan JU, Li L, Baker SB, Johnson MD, et al. Neuropeptide Y acts directly in the periphery on fat tissue and mediates stress-induced obesity and metabolic syndrome. Nature medicine. 2007;13(7):803-11.

118. Epel E, Jimenez S, Brownell K, Stroud L, Stoney C, Niaura R. Are stress eaters at risk for the metabolic syndrome? Annals of the New York Academy of Sciences. 2004;1032(1):208-10. 
119. Blackburn EH. Telomere states and cell fates. Nature. 2000;408(6808):53-6.

120. Westenhoefer J, Broeckmann P, Münch A-K, Pudel V. Cognitive control of eating behavior and the disinhibition effect. Appetite. 1994;23(1):27-41.

121. Westenhoefer J, Stunkard AJ, Pudel V. Validation of the flexible and rigid control dimensions of dietary restraint. International Journal of Eating Disorders. 1999;26(1):5364.

122. Elfhag K, Rössner S. Who succeeds in maintaining weight loss? A conceptual review of factors associated with weight loss maintenance and weight regain. Obesity reviews. 2005;6(1):67-85.

123. Wardle J. Cognitive control of eating. Journal of psychosomatic research. 1988;32(6):60712.

124. Geliebter A. Gastric distension and gastric capacity in relation to food intake in humans. Physiology \& behavior. 1988;44(4):665-8.

125. English P, Ghatei M, Malik I, Bloom S, Wilding J. Food fails to suppress ghrelin levels in obese humans. The Journal of Clinical Endocrinology \& metabolism. 2002;87(6):2984- .

126. Batterham RL, Cohen MA, Ellis SM, Le Roux CW, Withers DJ, Frost GS, et al. Inhibition of food intake in obese subjects by peptide YY3-36. New England Journal of Medicine. 2003;349(10):941-8.

127. Le Roux C, Batterham R, Aylwin S, Patterson M, Borg C, Wynne K, et al. Attenuated peptide YY release in obese subjects is associated with reduced satiety. Endocrinology. 2006;147(1):3-8.

128. Lissner L, Stevens J, Levitsky D, Rasmussen K, Strupp B. Variation in energy intake during the menstrual cycle: implications for food-intake research. The American journal of clinical nutrition. 1988;48(4):956-62.

129. Framson C, Kristal AR, Schenk JM, Littman AJ, Zeliadt S, Benitez D. Development and validation of the mindful eating questionnaire. Journal of the American Dietetic Association. 2009;109(8):1439-44.

130. McLean JA, Barr SI. Cognitive dietary restraint is associated with eating behaviors, lifestyle practices, personality characteristics and menstrual irregularity in college women. Appetite. 2003;40(2):185-92.

131. Rideout CA, McLean JA, Barr SI. Women with high scores for cognitive dietary restraint choose foods lower in fat and energy. Journal of the American Dietetic Association. 2004;104(7):1154-7. 
132. Ferriday D, Bosworth ML, Godinot N, Martin N, Forde CG, Van Den Heuvel E, et al. Variation in the Oral Processing of Everyday Meals Is Associated with Fullness and Meal Size; A Potential Nudge to Reduce Energy Intake? Nutrients. 2016;8(5):315.

133. Forman EM, Shaw JA, Goldstein SP, Butryn ML, Martin LM, Meiran N, et al. Mindful decision making and inhibitory control training as complementary means to decrease snack consumption. Appetite. 2016;103:176-83.

134. Vieaux LE. A Brief Appetite Awareness Intervention for Eating and Weight Regulation Among College Freshmen: A Randomized Clinical Trial: University of Minnesota; 2016.

135. Goldbacher E, La Grotte C, Komaroff E, Vander Veur S, Foster GD. An initial evaluation of a weight loss intervention for individuals who engage in emotional eating. Journal of behavioral medicine. 2016;39(1):139-50.

136. Daubenmier J, Moran PJ, Kristeller J, Acree M, Bacchetti P, Kemeny ME, et al. Effects of a mindfulness-based weight loss intervention in adults with obesity: A randomized clinical trial. Obesity. 2016;24(4):794-804.

137. Mason AE, Epel ES, Kristeller J, Moran PJ, Dallman M, Lustig RH, et al. Effects of a mindfulness-based intervention on mindful eating, sweets consumption, and fasting glucose levels in obese adults: data from the SHINE randomized controlled trial. Journal of behavioral medicine. 2016;39(2):201-13.

138. Lee JS, Mishra G, Hayashi K, Watanabe E, Mori K, Kawakubo K. Combined eating behaviors and overweight: Eating quickly, late evening meals, and skipping breakfast. Eating behaviors. 2016;21:84-8.

139. Hill JO, Peters JC, Wyatt HR. Using the energy gap to address obesity: a commentary. Journal of the American Dietetic Association. 2009;109(11):1848.

140. Ross R, Hill JO, Latimer A, Day AG. Evaluating a small change approach to preventing long term weight gain in overweight and obese adults-Study rationale, design, and methods. Contemporary clinical trials. 2016;47:275-81.

141. Hill JO. Can a small-changes approach help address the obesity epidemic? A report of the Joint Task Force of the American Society for Nutrition, Institute of Food Technologists, and International Food Information Council. The American journal of clinical nutrition. 2009;89(2):477-84. 